UNIVERSIDADE DE SÃO PAULO

ESCOLA DE ENFERMAGEM

VANESSA AUGUSTA SOUZA BRAGA

ATUAÇÃO DOS ENFERMEIROS NA PREVENÇÃO E NO CONTROLE DA OBESIDADE NA ATENÇÃO PRIMÁRIA À SAÚDE 
VANESSA AUGUSTA SOUZA BRAGA

\section{ATUAÇÃO DOS ENFERMEIROS NA PREVENÇÃO E NO CONTROLE DA OBESIDADE NA ATENÇÃO PRIMÁRIA À SAÚDE}

Dissertação apresentada ao Programa de PósGraduação em Enfermagem da Escola de Enfermagem da Universidade de São Paulo para obtenção do título de Mestre em Ciências.

Área de concentração: Cuidado em Saúde.

Orientadora: Prof. ${ }^{a}$ Dr. ${ }^{a}$ Maria Cristina Pinto de Jesus. 
AUTORIZO A REPRODUÇÃO TOTAL OU PARCIAL DESTE TRABALHO, POR QUALQUER MEIO CONVENCIONAL OU ELETRÔNICO, PARA FINS DE ESTUDO E PESQUISA, DESDE QUE CITADA A FONTE.

Assinatura:

Data

Catalogação na Publicação (CIP)

Biblioteca "Wanda de Aguiar Horta"

Escola de Enfermagem da Universidade de São Paulo

Braga, Vanessa Augusta Souza

Atuação dos enfermeiros na prevenção e no controle da obesidade na Atenção Primária à Saúde / Vanessa Augusta Souza Braga. São Paulo, 2018.

$99 \mathrm{p}$.

Dissertação (Mestrado) - Escola de Enfermagem da Universidade de São Paulo.

Orientadora: Prof. ${ }^{\text {a }}$ Dr. ${ }^{\text {a }}$ Maria Cristina Pinto de Jesus

Área de concentração: Cuidado em Saúde

1. Obesidade. 2. Atenção Primária à Saúde. 3. Enfermagem Prática. 4. Pesquisa Qualitativa. I. Título.

Ficha catalográfica elaborada por Fabiana Gulin Longhi Palacio (CRB-8: 7257) 
Nome: Vanessa Augusta Souza Braga

Título: Atuação dos enfermeiros na prevenção e no controle da obesidade na Atenção Primária à Saúde.

Dissertação apresentada ao Programa de Pós-Graduação em Enfermagem da Escola de Enfermagem da Universidade de São Paulo para obtenção do título de Mestre em Ciências.

Aprovado em:

\section{Banca Examinadora}

Orientador: Prof. Dr.

Instituição: Assinatura:

Prof. Dr.

Julgamento:

Instituição:

Assinatura:

Prof. Dr.

Instituição:

Julgamento:

Assinatura:

Prof. Dr.

Instituição:

Julgamento:

Assinatura: 


\section{DEDICATÓRIA}

Dedico este trabalho às pessoas com obesidade. Que este estudo possa trazer reflexões para os enfermeiros e para os gestores de saúde com vistas a melhorias no cuidado dessas pessoas. 


\section{AGRADECIMENTOS}

À minha orientadora, Professora Doutora Maria Cristina Pinto de Jesus, pela confiança e oportunidade em trabalhar ao seu lado.

À Professora Doutora Miriam Aparecida Barbosa Merighi pelo apoio no desenvolvimento deste estudo.

Ao Doutor Marcelo Henrique da Silva, que, por sua experiência na Atenção Primária à Saúde, contribuiu com reflexões que aprimoraram este manuscrito.

Aos membros da Comissão Examinadora por aceitarem o convite e contribuírem para o enriquecimento do trabalho.

Aos Integrantes do Grupo de Pesquisa em Enfermagem em Abordagens Fenomenológicas, pelas valiosas contribuições durante a pesquisa.

Em especial, à Renata Evangelista Tavares pelo companheirismo nas atividades desenvolvidas no grupo de pesquisa.

Ao Programa de Pós-Graduação da Escola de Enfermagem da Vniversidade de São Paulo por ter, durante esse período, oferecido apoio além de condições técnicas e logísticas para o desenvolvimento do curso de Mestrado.

Às enfermeiras que participaram do estudo pela disponibilidade em fornecerem seus depoimentos.

À minha querida família pelo apoio incondicional e estímulo em todas as minhas iniciativas. Ao meu marido, Rodolfo, pelo companheirismo e carinho ao longo do período de desenvolvimento deste trabalho. 
"A menos que modifiquemos a nossa maneira de pensar, não seremos capazes de resolver os problemas causados pela forma como nos acostumamos a ver o mundo". Albert Einstein 
Braga VAS. Atuação dos enfermeiros na prevenção e no controle da obesidade na Atenção Primária à Saúde [dissertação]. São Paulo: Escola de Enfermagem, Universidade de São Paulo; 2018.

\section{RESUMO}

Introdução: as ações dos enfermeiros na atenção primária à saúde podem auxiliar os usuários a controlar e perder peso, bem como a melhorar seus hábitos alimentares e de atividade física, impactando o cotidiano de toda a família. Objetivo: compreender a atuação dos enfermeiros na prevenção e no controle da obesidade na Atenção Primária à Saúde. Método: pesquisa de abordagem fenomenológica, realizada com 12 enfermeiros atuantes em Unidades Básicas de saúde em um município de Minas Gerais. Para obtenção dos depoimentos, foi utilizada a entrevista com as seguintes questões norteadoras: o que você tem feito em relação à prevenção e controle da obesidade na Unidade Básica de Saúde? Quais suas expectativas em relação a sua atuação frente à obesidade? A organização e a análise dos depoimentos foram realizadas em conformidade com o proposto por estudiosos da fenomenologia social de Alfred Schütz. Resultado: a fenomenologia social de Alfred Schütz permitiu identificar o típico da atuação do enfermeiro, a prevenção e controle da obesidade no contexto da Atenção Primária à Saúde, como sendo aquele que atua orientando sobre hábitos de vida saudáveis às mães de crianças, a gestantes e adultos com doenças crônicas e coletivamente na caminhada orientada e nos grupos operativos existentes na unidade de saúde, com gestantes e usuários com doenças crônicas. Tem como dificuldades para sua atuação questões relacionadas aos hábitos não saudáveis de vida dos usuários e resistência à mudança de comportamento, além das limitações impostas pelo serviço e equipe de saúde. Suas expectativas incluem conhecer o perfil alimentar e do peso da população, realizar grupos específicos para o controle de peso, melhorar a articulação da Unidade Básica de Saúde com outros equipamentos sociais, atuar com crianças e adolescentes fora do espaço da Unidade e receber capacitação para atuar frente à obesidade. Conclusão: acredita-se que essas características de atuação dos enfermeiros fornecem subsídios para a reflexão acerca do modo como as pessoas estão sendo cuidadas neste ponto de atenção da Rede de Atenção à Saúde. Nesse sentido, podem oferecer pistas para a gestão dos serviços de saúde promover o efetivo desenvolvimento das políticas de saúde, assegurando o atendimento de qualidade voltado aos usuários com obesidade.

Palavras-chave: Obesidade. Atenção Primária à Saúde. Enfermagem Prática. Pesquisa Qualitativa. 
Braga VAS. Nurses' performance in the prevention and control of obesity in Primary Health Care. [dissertation]. São Paulo: Escola de Enfermagem, Universidade de São Paulo; 2018.

\begin{abstract}
Introduction: the actions of nurses in Primary Health Care can help users to control and lose weight, as well as improving their eating habits and physical activity, impacting the daily routine of the whole family. Objective: to understand the role of nurses in prevention and in the control of obesity in Primary Health Care. Method: Phenomenological approach research performed with 12 nurses working in Basic Health Units in city of Minas Gerais. To obtain the testimonies, an interview was used with the following guiding questions: what have you done in relation to the prevention and control of the obesity in Basic Health Unit? What are your expectations regarding your performance against obesity? The organization and the analysis of the testimonies were carried out in accordance with the proposed by scholars of the social phenomenology of Alfred Schütz. Results: the Alfred Schütz social phenomenology made it possible to identify the typical of the nurse's action, the prevention and control of obesity in the context of Primary Health Care, as being the one that acts orienting healthy habits of life to the mothers of children, pregnant women and adults with chronic diseases and collectively in the oriented jogging and in the operative groups that exists in the health unit, with pregnant women and users with chronic diseases. Problems related to the unhealthy habits of the users' life and resistance to change of behavior, in addition to the limitations imposed by the service and the health team, are amenable to their actions. Their expectations include knowing the food profile and the weight of the population, performing specific groups for weight control, improving the articulation of the Basic Health Unit with other social facilities, acting with children and adolescents out of the Unit's space and receiving training to deal with obesity. Conclusion: it is believed that these nurses' performance characteristics provide support for the reflection about the way people are being cared for in this point of attention of the Health Care Network. In this sense, they can offer clues for the management of health services to promote the effective development of health policies, ensuring quality care for obese users.
\end{abstract}

Keywords: Obesity. Primary Health Care. Nursing, Practical. Qualitative Research. 


\section{LISTA DE SIGLAS}

ACS Agente Comunitário de Saúde

APS Atenção Primária à Saúde

DCNT Doença Crônica Não Transmissível

ESF Estratégia de Saúde da Família

IBGE Instituto Brasileiro de Geografia e Estatística

IMC Índice de Massa Corporal

NASF Núcleo de Apoio à Saúde da Família

OPAS Organização Pan-Americana de Saúde

RAS Rede de Atenção à Saúde

SISVAN Sistema de Vigilância Alimentar e Nutricional

SUS Sistema Único de Saúde

UBS Unidade Básica de Saúde

VIGITEL Vigilância de Fatores de Risco e Proteção para Doenças Crônicas por Inquérito Telefônico 


\section{SUMÁRIO}

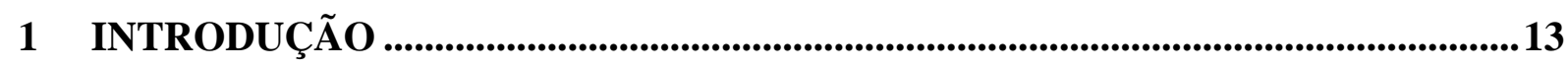

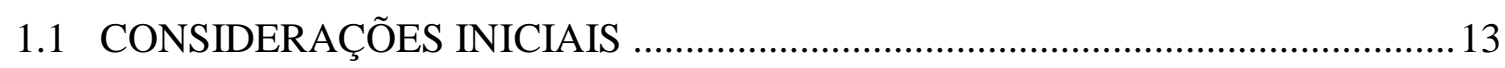

1.2 APROXIMAÇÃO COM A TEMÁTICA OBESIDADE .......................................... 14

1.3 QUESTÕES NORTEADORAS, OBJETIVO E JUSTIFICATIVA DO ESTUDO 15

2 CONTEXTUALIZAÇÃO DA TEMÁTICA …………………………………………….... 18

3 REFERENCIAL TEÓRICO-METODOLÓGICO .........................................................26

3.1 OPÇÃO PELA PESQUISA QUALITATIVA DE ABORDAGEM

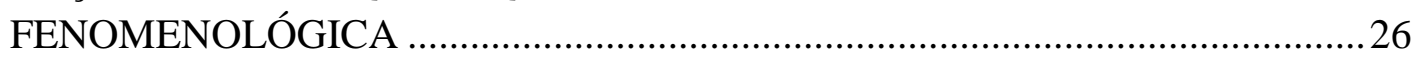

3.2 INTERFACE ENTRE O OBJETO DE ESTUDO E OS PRESSUPOSTOS TEÓRICO-METODOLÓGICOS DA FENOMENOLOGIA SOCIAL DE ALFRED

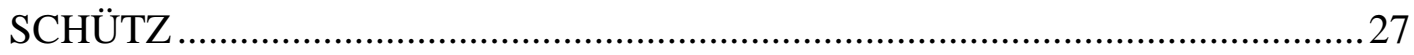

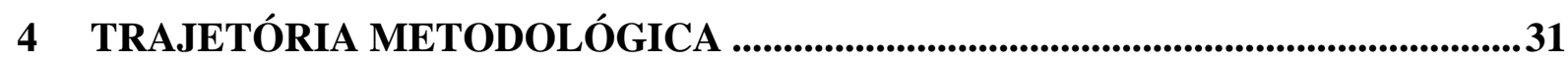

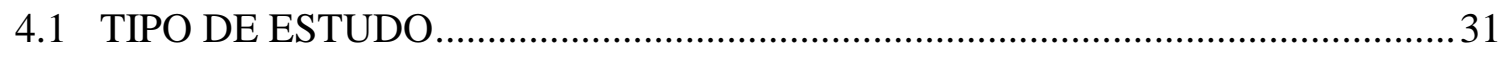

4.2 CENÁRIO E PARTICIPANTES DA PESQUISA ………………………………....... 31

4.3 DESCRIÇÃO ACERCA DA COLETA DOS DEPOIMENTOS ………………........

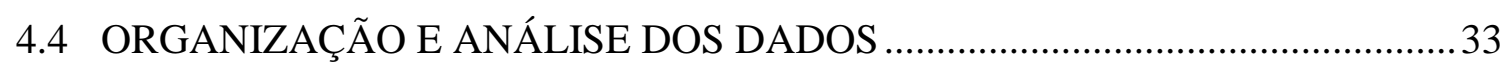

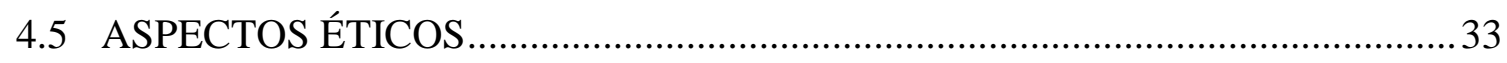

5 RESULTADOS..........................................................................................................................36

5.1 CARACTERÍSTICAS DOS PARTICIPANTES ……………………………........ 36

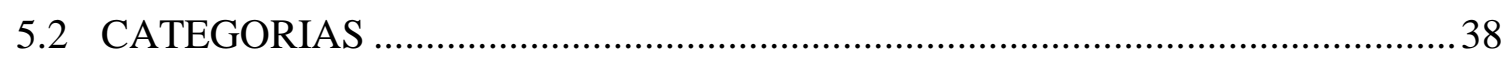

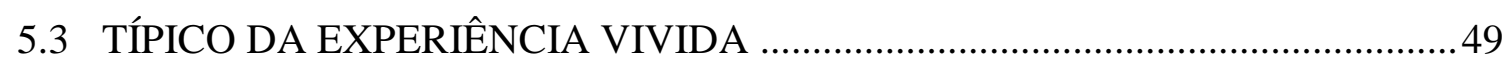

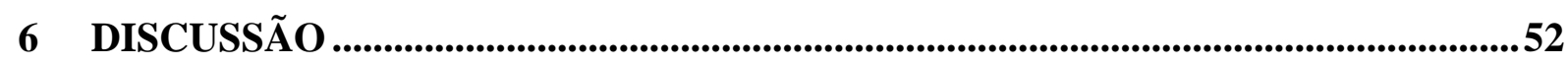

7 IMPLICAÇÕES DO ESTUDO PARA A PRÁTICA PROFISSIONAL .......................71

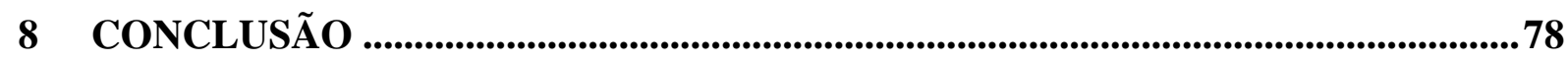

REFERÊNCIAS ...........................................................................................................

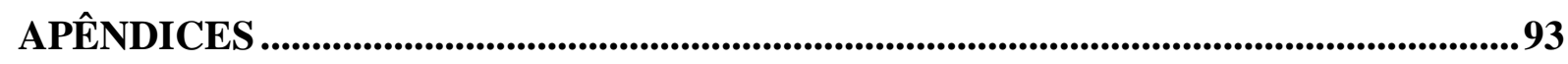

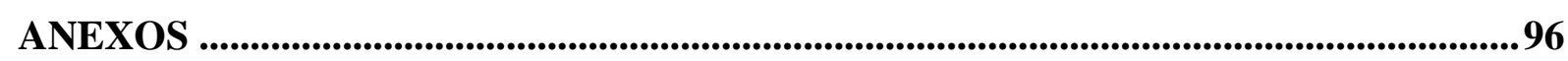


1 INTRODUCÃO 


\section{INTRODUÇÃO}

\subsection{CONSIDERAÇÕES INICIAIS}

A obesidade pode ser considerada um problema de saúde pública na atualidade tanto em países desenvolvidos como naqueles em desenvolvimento, apresentando-se como um desafio para os sistemas de saúde (Almeida L et al., 2017). Esse agravo de saúde está intimamente relacionado com o aumento da morbimortalidade das populações de todo o mundo, uma vez que a obesidade representa um importante fator de risco para o surgimento das Doenças Crônicas Não Transmissíveis (DCNTs) (WHO, 2017).

A Organização Mundial da Saúde (OMS) estimou que, em 2014, o índice de pessoas acima do peso atingiria mais de 1,9 bilhão de adultos, dos quais 600 milhões seriam obesos, correspondendo a $13 \%$ da população adulta do mundo. Em relação às crianças menores de 5 anos, a estimativa seria de 41 milhões (WHO, 2017).

Um estudo que considerou as tendências no Índice de Massa Corporal (IMC) de adultos em 200 países, entre os anos de 1975 a 2014, mostrou que, nas últimas quatro décadas, houve uma mudança global na qual o número de pessoas com obesidade superava o daquelas que estavam abaixo do peso em todas as regiões do mundo, com exceção de áreas da Ásia e da África Subsaariana. Esses números cresceram seis vezes, passando de 105 milhões de pessoas acima do peso (em 1975) para 641 milhões em 2014 (Di Cesare et al., 2016).

No Brasil, os dados da Vigilância de Fatores de Risco e Proteção para Doenças Crônicas por Inquérito Telefônico (Vigitel) 2016 mostraram uma frequência de excesso de peso na população adulta de 53,8\%. Salientou-se que esse aumento foi maior entre os homens do que entre as mulheres. Com relação à faixa etária, as taxas mais elevadas estavam entre os que tinham entre 35 e 64 anos. A obesidade atingiu 18,9\% da população, sendo que, em 2010, era de $15 \%$ (Brasil, 2017a).

A obesidade apresenta-se como um agravo de saúde complexo e de difícil enfrentamento devido a sua etiologia multifatorial composta por fatores genéticos, ambientais e socioculturais. O fator genético pode exercer papel expressivo no desequilíbrio energético determinante do excesso de peso. Os fatores relacionados ao ambiente são caracterizados na atualidade pelo aumento no consumo de alimentos de baixo custo, processados e de alta concentração energética. Além disso, somam-se a esses fatores, os hábitos culturais e sociais que influenciam o consumo de alimentos inadequados, bem como a inatividade física, 
resultando no excesso de peso (Dobbs et al., 2014). Nesse sentido, intervenções no campo da prevenção e controle da obesidade pressupõem uma abordagem, com articulações de dimensões biológicas, socioeconômicas e culturais vivenciadas pelas pessoas em seu cotidiano.

A complexidade da obesidade exige a atuação profissional em equipes multidisciplinares, buscando-se a resolubilidade das ações. As Unidades Básicas de Saúde (UBS) têm o potencial de viabilizar esta atuação, inclusive promovendo a articulação com outros equipamentos sociais e de saúde, que resultem em atividades que façam sentido para a população, o que facilita a adesão às atividades propostas (Costa et al., 2014). O desempenho em equipes multidisciplinares está baseado no cuidado compartilhado e na compressão do indivíduo em sua totalidade, garantindo integralidade da assistência e eficiência na prevenção e no controle da obesidade (Brasil, 2014a).

Na esfera das UBSs, o enfermeiro está presente em todas as equipes básicas dos serviços de saúde que compõem esse nível de atenção. É um profissional que está envolvido em muitas ações realizadas no âmbito da promoção da saúde, prevenção de agravos ou curativas. Dessa forma, está em contato direto com os indivíduos e suas famílias, sendo capaz de compreender o contex to existente indispensável para a superação dos problemas de saúde locais (Santos et al., 2014).

A compreensão do contexto social, econômico, cultural e de saúde em que se encontram as famílias moradoras no território de responsabilidade da UBS, somada às habilidades profissionais e interacionais do enfermeiro, faz deste um profissional importante para fortalecimento das ações relacionadas ao enfrentamento da obesidade. Estudos indicam que a atuação do enfermeiro é capaz de auxiliar os indivíduos a controlar/perder peso, bem como a melhorar seus hábitos alimentares e de atividade física, impactando o cotidiano de toda a família (Sargent, Forrest, Parker, 2012; Dillen et al., 2014).

\subsection{APROXIMAÇÃO COM A TEMÁTICA OBESIDADE}

Durante o Curso de Graduação em Enfermagem, iniciei minha aproximação com a temática da obesidade, por meio da participação em projetos de pesquisa, especialmente na área de cirurgia bariátrica, tema do meu Trabalho de Conclusão de Curso. Durante essa experiência da pesquisa, juntamente com as práticas das disciplinas curriculares, tive contato com pessoas com obesidade, suas famílias, a comunidade na qual estavam inseridas e os serviços de saúde frequentados por elas. 
Essa aproximação tornou-se mais vivenciada durante a realização da Residência Multiprofissional em Saúde do Adulto com Ênfase em Doenças Crônico-Degenerativas. Durante dois anos, atuei nos três níveis de atenção à saúde do Sistema Único de Saúde (SUS) e em todos observava o aumento das demandas apresentadas pelas pessoas com obesidade quer na necessidade de prevenção do agravo e de tratamento, quer nas agudizações dos quadros crônicos.

Em relação às práticas nas UBSs, observava que, apesar da grande demanda e da importância desse agravo, a pessoa com obesidade, principalmente aquela sem comorbidades, não tinha espaço bem definido na programação das ações de saúde. Isso dificultava a detecção precoce dos casos e culminava em agudizações que a faziam procurar por serviço de maior complexidade.

Em algumas UBSs, participei de atividades voltadas para a prevenção da obesidade, como a promoção da "Caminhada Orientada" em parceria com outros profissionais de saúde, além de realizar orientações a crianças e adolescentes sobre alimentação saudável e prática de atividades físicas em escolas. Experiências estas isoladas e que, muitas vezes, não tinham continuidade pela equipe de saúde local.

Percebo que, apesar de o enfermeiro ter certo preparo técnico para o controle da obesidade, nem sempre desenvolve ações específicas para essa clientela na área de abrangência das UBSs. Pouco se faz em relação à prevenção e ao controle da obesidade em cenários sociais frequentados pela população da área adstrita, como, por exemplo, escolas, igrejas, assim como no domicílio das famílias, o que deixa lacunas na assistência.

\subsection{QUESTÕES NORTEADORAS, OBJETIVO E JUSTIFICATIVA DO ESTUDO}

As seguintes perguntas nortearam a pesquisa: como é a atuação dos enfermeiros, no cotidiano do trabalho na UBS, frente à prevenção e controle da obesidade? Quais são as expectativas desses profissionais sobre a sua atuação?

Objetivou-se compreender a atuação dos enfermeiros na prevenção e no controle da obesidade na Atenção Primária à Saúde. O serviço de APS tem papel fundamental na gestão do cuidado das pessoas do território adstrito, com a atuação de suas equipes multidisciplinares e, em especial, do enfermeiro (Brasil, 2017b). Nesse contexto de cuidado, as ações de promoção da saúde, prevenção e controle de agravos resultantes da obesidade devem ser rotineiras, 
visando ao enfrentamento das dificuldades inscritas no manejo dessa doença crônica e garantindo o apoio necessário não somente às pessoas com obesidade, mas também àqueles em risco de desenvolvê-la (Dillen et al., 2015).

Um estudo de revisão sistemática da literatura destacou o trabalho do profissional enfermeiro que atua na UBS com a clientela portadora de doenças crônicas. Seus resultados apontaram a eficácia das intervenções realizadas por esses profissionais, com enfoque no estilo de vida, visando a mudanças positivas nos comportamentos associados à prevenção de doenças crônicas. Entre as ações mais realizadas pelos enfermeiros estava o controle de peso, da pressão arterial, do colesterol, além do incentivo a comportamentos alimentares saudáveis e à prática de atividade física (Sargent, Forrest, Parker, 2012).

Outro estudo de revisão sistemática mostrou que, no Reino Unido, Países Baixos e Países Escandinavos, o enfermeiro na UBS tem papel definido no aconselhamento sobre estilo de vida saudável com vistas ao controle do peso. Já nos Estados Unidos da América (EUA), as atividades dos enfermeiros na UBS ainda não se encontram bem definidas e este profissional atua nessas atividades, segundo sua motivação pessoal. Os enfermeiros, embora mencionassem como barreira a falta de tempo, mostraram-se com mais disponibilidade que o médico para fazer o aconselhamento às pessoas com obesidade (Dillen et al., 2014).

Revisão integrativa da literatura sobre as intervenções do enfermeiro às pessoas com obesidade na APS apontou que este profissional utiliza tecnologias baseadas em recursos digitais, técnicas motivacionais e consulta de enfermagem para realizar o aconselhamento em saúde de crianças e seus familiares, adolescentes e adultos com obesidade com ou sem comorbidades. O conteúdo das intervenções de enfermagem incluiu aspectos da alimentação preventiva da obesidade na infância, importância da atividade física e hábitos alimentares (Braga et al., 2017).

Considerando a importância dessa temática para atenção à saúde da população na APS, julgou-se relevante realizar este estudo, que busca compreender a atuação do enfermeiro na prevenção e no controle da obesidade neste contexto de atenção à saúde. Espera-se, com os resultados deste estudo, estimular a reflexão sobre a prática de enfermagem na APS, assim como promover discussões no âmbito da formação e educação permanente sobre a atuação dos enfermeiros na prevenção e no controle da obesidade. 
2 CONTEXTUALIZACÃO
DA TEMÁTICA 


\section{CONTEXTUALIZAÇÃO DA TEMÁTICA}

O rápido crescimento da obesidade no mundo permite afirmar que, caso esta doença crônica continue aumentando, cerca de um quinto da população mundial estará acima do peso considerado saudável em menos de dez anos. Em 2025, a prevalência da obesidade global poderá atingir $18 \%$ em homens e ultrapassar $21 \%$ em mulheres. A obesidade grave poderá superar 6\% no sexo masculino e 9\% no feminino (Di Cesare et al., 2016).

Países como EUA, Inglaterra, Austrália, México e Canadá mostram um rápido crescimento da prevalência da obesidade, liderando o ranking de nações com maior prevalência da obesidade. Suíça, Itália, Espanha, Coreia do Sul e França mostram crescimento mais lento, na maioria das vezes, com início tardio de obesidade (Frank, 2016).

Em relação à América Latina e ao Caribe, os resultados são semelhantes. Com exceção de Haiti (38,5\%), Paraguai (48,5\%) e Nicarágua (49,4\%), o sobrepeso atinge mais da metade da população de todos os países da região, sendo Chile (63\%), México (64\%) e Bahamas (69\%) os que registram as taxas mais altas. A obesidade afeta 140 milhões de pessoas $(23 \%$ da população regional) e as maiores prevalências são observadas em todos os países do Caribe: Bahamas (36,2\%), Barbados (31,3\%), Trinidad e Tobago (31,1\%) e Antígua e Barbuda (30,9\%) (PAHO, 2016).

No Brasil, os dados levantados pelo Instituto Brasileiro de Geografia e Estatística (IBGE) em 2016 registraram, além do excesso de peso, que o número de obesos vem aumentando com a idade, sendo mais prevalente entre 35 e 64 anos e apresenta maior incidência em indivíduos com menor escolaridade (IBGE, 2017).

Tendo em vista esse panorama mundial da obesidade, várias ações e acordos em nível internacional e nacional têm sido realizados com vistas à prevenção e ao tratamento desse agravo à saúde em todas as fases da vida. Um importante compromisso mundial acordado foi o Plano de Ação Global contra DCNTs 2013-2020 firmado na Assembleia Mundial de Saúde, que inclui um conjunto de ações a serem realizadas pelos Estados-Membros, parceiros e o secretariado da OMS visando à prevenção das DCNTs, promoção de dietas saudáveis e de atividade física, além do alcance de nove metas voluntárias globais até 2025. Entre essas nove metas, salienta-se "parar" o aumento do diabetes mellitus e da obesidade em adultos e adolescentes, bem como o aumento do sobrepeso e obesidade infantil até 2025 (WHO, 2013). Ainda em nível mundial, no ano de 2016, a Assembleia Geral das Nações Unidas proclamou o Decênio de Ação sobre a Nutrição 2016-2025 com o objetivo de colocar no centro dessas 
iniciativas a promoção da cooperação e respeito à segurança alimentar em todo o mundo (FAO, 2016).

No arcabouço das políticas brasileiras relacionadas à prevenção e ao controle da obesidade, cabe destacar que, desde 2006, quando foi publicada a primeira versão da Política Nacional de Promoção da Saúde, com reedição em 2015, ocorreu o estímulo para o desenvolvimento de diversas propostas de ação no que tange à promoção da saúde, prevenção de agravos, incluindo as políticas e ações no campo da obesidade (Brasil, 2015a).

Ressalta-se a criação de importantes iniciativas intersetoriais com vistas à promoção da saúde e prevenção da obesidade por meio do estimulo à alimentação saudável e à prática de atividade física regular como o "Programa Saúde na Escola" (Brasil, 2007), o "Programa Nacional de Alimentação Escolar" (Brasil, 2009) e o "Programa Academia da Saúde" (Brasil, 2011a).

Em 2011, o Plano de Ações Estratégicas para o Enfrentamento das DCNTs 2011-2022 foi publicado e visou preparar o país para enfrentar as doenças crônicas e seus fatores de risco como tabagismo, consumo nocivo de álcool, inatividade física, alimentação inadequada e obesidade (Brasil, 2011b). Considerando a obesidade um fator de risco e ao mesmo tempo uma doença crônica, salientam-se ações de estruturação e implementação de modelos de atenção integral à saúde à pessoa com excesso de peso/obesidade nas Redes de Atenção à Saúde (RASs), em especial na APS (Brasil, 2011b).

No ano de 2013, a publicação da Política Nacional de Alimentação e Nutrição apresentou linhas de ação para a promoção da saúde da população nas quais se encontra a diretriz "Promoção da Alimentação Adequada e Saudável" com vistas à prevenção da obesidade. Esta política objetiva a promoção de ações intersetoriais no âmbito individual e coletivo, contribuindo para a redução desse agravo à saúde (Brasil, 2013a).

Outra iniciativa que merece destaque foi a definição da obesidade como linha de cuidado prioritária da Rede de Atenção à Saúde de pessoas com doenças crônicas, por meio da Portaria n. 424, de 19 de março de 2013 (Brasil, 2013b). Esta Portaria apresenta como diretrizes: identificar indivíduos com sobrepeso e obesidade, detectar outros fatores de risco e comorbidades, articular ações intersetoriais, capacitar profissionais de saúde, oferecer apoio diagnóstico e terapêutico para esse público específico, ofertar práticas integrativas e complementares às pessoas com obesidade, entre outras (Brasil, 2013b).

Em 2014, o Caderno de Atenção Básica enfocou a obesidade como doença crônica. Esta publicação estabelece estratégias para abordagem das pessoas com obesidade, fornece subsídios aos profissionais da APS para avaliar o estado nutricional dos usuários, determina o papel dos 
profissionais nos tratamentos cirúrgicos relacionados à necessidade de perda de peso, bem como aponta possibilidades de tratamentos dietéticos, promoção da atividade física e tratamento medicamentoso (Brasil, 2014b).

Ainda em 2014, o Ministério da Saúde, em parceria com a Organização Pan-Americana da Saúde (OPAS), divulgou o documento intitulado "Perspectivas e Desafios no Cuidado às Pessoas com Obesidade no SUS". Este apresenta a necessidade de superação do modelo biomédico, propondo um novo olhar sobre as pessoas contextualizadas em suas realidades. Neste contexto, a RAS destaca-se como ponto-chave para o atendimento integral às pessoas com obesidade, sendo a UBS responsável pelo primeiro acolhimento dessas pessoas, bem como por seu acompanhamento longitudinal (Brasil, 2014a).

A Estratégia Intersetorial de Prevenção e Controle da Obesidade, também datada do ano de 2014, possui seis eixos estratégicos de ação. Entre eles, destaca-se a atenção integral à saúde da pessoa com sobrepeso/obesidade nas RASs como responsabilidade da APS. Além disso, incentiva a criação de comitês locais de enfrentamento da obesidade, bem como a participação da sociedade civil no controle das ações relacionadas à temática (Brasil, 2014c).

Também no ano de 2014, foi reeditado o Guia Alimentar para a População Brasileira que traz informações para os usuários e profissionais de saúde acerca da alimentação saudável e da importância desta na promoção da saúde (Brasil, 2014d). O Guia Alimentar defende o consumo de alimentos com nenhum ou reduzido grau de processamento, estimula o consumo de alimentos in natura e minimamente processados. Alerta que os alimentos ultraprocessados são, normalmente, produtos com alta concentração de aditivos e de conservantes, alto valor calórico e quantidades elevadas de sódio, gordura, açúcar e pobres em fibras. Ao abordar princípios para uma alimentação saudável, caracteriza-se como um apoio às ações de educação alimentar e nutricional no SUS e em outros setores (Brasil, 2014d).

Com a finalidade de auxiliar os profissionais da UBS no enfretamento da obesidade, em 2015, foi lançada a publicação Orientações para Avaliação de Marcadores de Consumo Alimentar na Atenção Básica, que oferece subsídios para avaliação nutricional, introdução de alimentos de qualidade em tempo oportuno, identificação de marcadores de risco ou proteção para as carências de micronutrientes e a ocorrência de excesso de peso (Brasil, 2015b).

Salienta-se que tanto as diretrizes nacionais quanto as internacionais fornecem orientações semelhantes em relação ao enfrentamento da obesidade. Um dos consensos observados é a necessidade da atuação em equipe multiprofissional, com o propósito de ajudar o usuário a adotar hábitos permanentes relacionados ao seu estilo de vida. De acordo com o Ministério da Saúde e com base nas linhas de cuidado da RAS, a "porta de entrada" para acesso 
às ações de prevenção e controle da obesidade deve ser as UBSs, com acolhimento da equipe multidisciplinar (IESS, 2015).

Nesse sentido, a Atenção Primária à Saúde (APS) é considerada o nível de atenção fundamental para o enfrentamento de agravos, como a obesidade, uma vez que atende a populações residentes em territórios sanitários singulares onde os moradores se organizam socialmente em famílias e comunidades. O conhecimento aprofundado acerca dessa população é imprescindível para o atendimento das demandas típicas dessas pessoas com vistas à implementação de uma gestão com base nas necessidades de saúde específicas e reais (Brasil, 2015c).

O levantamento do estado da arte frente à atuação do enfermeiro na obesidade no contexto da APS apontou que esse profissional tem a oportunidade de desempenhar um papelchave na abordagem dessa doença crônica rotineiramente, aconselhando sobre nutrição, atividade física e esclarecendo dúvidas (Smith et al., 2015).

A importância do aconselhamento em saúde às pessoas e seus familiares, visando à promoção de hábitos saudáveis de vida é apontada na Política Nacional de Promoção da Saúde (Brasil, 2015a). Também um ensaio clínico randomizado realizado na Suécia mostrou que as famílias devem ser o foco das ações com vistas às melhorias atuais e futuras, especialmente de crianças e comunidade, considerando que, quando os pais e/ou responsáveis são abordados, as mudanças de comportamento tendem a ser possíveis (Doring et al., 2014).

Especialmente no primeiro ano de vida, o estado nutricional é considerado um fator determinante na saúde da criança. As etapas iniciais do desenvolvimento humano serão fundamentais para definir suas condições de saúde em longo prazo, impactando diretamente a vida adulta (Cota et al., 2016). Os estudos revisados apontaram que o aconselhamento em saúde voltado à infância foi realizado pelo enfermeiro predominantemente durante as consultas de puericultura e também direcionado aos pais das crianças. O conteúdo desses conselhos envolvia aspectos da alimentação infantil relevantes para a prevenção da obesidade, tempo de prática de atividade física e hábitos familiares (Laws et al., 2015; Tucker et al., 2013).

As intervenções realizadas por enfermeiros com pais de crianças no primeiro ano de vida podem ser capazes de melhorar índices físicos e de hábitos de vida tanto das crianças como de suas mães (Doring et al., 2014). Famílias orientadas por enfermeiros aumentaram o consumo de frutas e legumes, diminuíram horas assistidas de televisão e aumentaram as horas de atividades físicas (Tucker et al., 2013). Por outro lado, um estudo realizado na Austrália mostrou que menos da metade dos enfermeiros participantes promovia rotineiramente atividade 
física e discutia com pais ou responsáveis as limitações do comportamento sedentário (Laws et al., 2015).

Salienta-se que os resultados das intervenções dos enfermeiros eram mais expressivos à medida que estas fossem mais prolongadas, mostrando que os impactos podem demorar a emergir, mas são efetivos, especialmente se as intervenções ocorrerem em longo prazo (Barte et al., 2012; Tucker al., 2013; Doring et al., 2014).

Quando o público-alvo das ações foram os adolescentes com obesidade, um elemento considerado dificultador é a quase inexistência de contatos face a face desses usuários com os enfermeiros no contexto da UBS. Estudo mostrou que a aplicação de tecnologias, por meio de intervenções baseadas em técnicas motivacionais via Web, configurou-se como uma importante ferramenta para que adolescentes fossem sensibilizados quanto à adoção de hábitos saudáveis de vida. Obtiveram-se resultados positivos em relação à melhoria na aptidão cardiorrespiratória, ao controle do peso e à qualidade de vida desses adolescentes (Riiser et al., 2014).

Outra estratégia de atendimento às pessoas com obesidade utilizada pelo enfermeiro nos serviços de APS é a Consulta de Enfermagem. Salienta-se que, no contexto do cuidado convencional, a Consulta de Enfermagem apresenta-se como um momento propício para realização do aconselhamento em saúde aos usuários com sobrepeso e obesidade e, por meio dessa estratégia de cuidado, o enfermeiro adquire subsídios para tomada de decisão, planejamento e avaliação das ações voltadas ao indivíduo, às famílias e à comunidade (Dantas, Santos, Tourinho, 2016).

Nessa perspectiva, dois estudos realizados na Holanda observaram cem consultas de enfermagem, objetivando avaliar o conteúdo fornecido por enfermeiros às pessoas com obesidade e o tipo de comunicação utilizado por eles. As pesquisas apontaram que os conselhos se direcionavam a perda de peso, orientação nutricional e atividade física. Porém, os profissionais não abordaram as dificuldades envolvidas no processo de perda de peso e não mantiveram o apoio com avaliações subsequentes. A maioria dos enfermeiros utilizou a comunicação motivacional para abordar as questões de peso e atividade física e a comunicação informacional para discussões sobre nutrição (Dillen et al., 2014; Dillen et al., 2015).

A literatura mostrou que as intervenções feitas por enfermeiros frente à obesidade foram mais presentes no contexto das UBSs quando na presença de comorbidades, principalmente em relação aos grupos de hipertensos e diabéticos (Phillips, Wood, Kinnersley, 2014). Nos EUA, pessoas com obesidade que apresentavam Hipertensão Arterial Sistêmica (HAS) tiveram melhorias estatisticamente significativas na dieta e nos escores de estilo de vida, bem como houve significativa perda de peso (média $1,6 \mathrm{~kg}$ perdido) durante a intervenção de dois meses. 
Estas foram abordadas com base no aconselhamento dietético, atividade física e avaliação da prontidão para mudança de comportamento (Jarl et al., 2014). No Brasil, a presença de condições crônicas associadas a obesidade, como HAS e dislipidemia, foi apresentada em um estudo como condições que influenciavam os profissionais de saúde a realizarem orientações sobre o peso em relação aos demais usuários (Toledo et al., 2017).

Revisão sistemática com metanálise, publicada na Itália, salientou que, em contextos comunitários, enfermeiros especialmente treinados eram capazes de gerar redução da pressão arterial e da glicemia em pacientes com doenças crônicas, bem como incentivá-los para a realização do autocuidado por meio de aconselhamento para a melhoria de hábitos de vida (Massimi et al., 2017).

Ressalta-se a necessidade de o enfermeiro atentar para suas atribuições frente ao cuidado às pessoas com obesidade na UBS, independentemente de elas apresentarem ou não comorbidades. Nesse sentido, além de abordar o obeso como aquelas pessoas com comorbidades instaladas, deve direcionar ações para a estratificação do risco para obesidade e atividades de promoção da saúde e prevenção de agravos (Brasil, 2014b). Contudo, para as pessoas com obesidade que possuem comorbidades, a atenção do enfermeiro em relação aos hábitos alimentares e de atividade física deve ser redobrada, havendo necessidade imprescindível de avaliação cardiovascular - ferramenta importante para compreensão do risco de ocorrência de um evento agudo (Brasil, 2014b).

Além dos estudos de intervenção do enfermeiro voltada às ações de prevenção e controle da obesidade na APS, a busca na literatura revelou investigações que traziam a importância que estes profissionais atribuem à sua atuação, assim como as dificuldades enfrentadas para a realização das atividades.

Apesar de considerarem importante sua atuação, enfermeiros na Suécia avaliaram o trabalho realizado com pessoas com obesidade como difícil, devido à falta de uniformização das orientações para a prevenção e o controle dessa doença crônica, bem como à gestão deficiente dos serviços. Esses profissionais ressaltaram que trabalhar com questões relativas à obesidade dependia das prioridades pessoais dos enfermeiros, do conhecimento, da responsabilidade e da cooperação entre os membros da equipe de saúde (Isma et al., 2013).

Uma pesquisa que envolveu a equipe multiprofissional da APS em Portugal mostrou que os nutricionistas e enfermeiros se percebiam mais motivados para abordar essa clientela, apesar das dificuldades imbricadas no controle da obesidade (Teixeira, Pais-Ribeiro, Maia, 2015). Por outro lado, na Austrália, estudo mostrou que os enfermeiros relataram que a falta de 
confiança no trabalho desenvolvido com as pessoas com obesidade foi considerada um fator dificultador (Robinson et al., 2013).

Em relação aos problemas gerenciais, estudo brasileiro constatou a falta de prioridade na gestão da obesidade, falta de tempo no dia a dia, carga de trabalho elevada e falta de clareza sobre protocolos e papéis que norteiam a atuação clínica do enfermeiro (Vasconcelos, Magalhães, 2016). Também na Inglaterra, uma investigação descreveu experiências de enfermeiros na discussão sobre controle do peso na APS e identificou que esses profissionais possuíam preocupação com as consequências negativas do excesso de peso, porém consideravam que seu tempo e recursos eram limitados para trabalhar a temática (Blackburn et al., 2015).

As fragilidades estruturais nos serviços de saúde que dificultavam as ações no campo da prevenção e do controle da obesidade, como inexistência de materiais e equipamentos compatíveis com a estrutura corporal das pessoas com excesso de peso e falta de material para o desenvolvimento de grupos educativos, foram destacadas por enfermeiros em uma investigação brasileira (Matos et al., 2015). Para que a APS seja resolutiva na prevenção e no controle da obesidade, é fundamental que as UBSs sejam dotadas de infraestrutura adequada, como rampas de acesso, portas largas, cadeiras, macas e balanças com capacidade para mais de 200kg, esfigmomanômetro, entre outros (Brasil, 2014b).

Possuir conhecimentos limitados sobre obesidade foi um tema destacado pelos enfermeiros nas pesquisas encontradas sobre a percepção desse profissional acerca de sua atuação frente à obesidade na APS (Isma et al., 2013; Blackburn et al., 2015). Ressalta-se que a falta de capacitação da equipe pode ser um dificultador no acolhimento às pessoas com obesidade, uma vez que é imprescindível que os profissionais de saúde da UBS estejam aptos e sensibilizados para captação e acolhimento eficientes dessa demanda (Brasil, 2014b).

Apesar da publicação do Plano de Ação Global para Prevenção e Controle das DCNTs 2013-2020, que visa cumprir os compromissos da Declaração Política das Nações Unidas sobre DCNT, aprovada pelos Chefes de Estado e de Governo, em setembro de 2011 (WHO, 2013), constata-se que são escassas as publicações no Brasil sobre a atuação do enfermeiro na prevenção e no controle da obesidade no contexto das APS (Braga et al., 2017), o que estimulou a realização desta investigação. 


\section{REFERENCIAL TEÓRICO-METODOLÓGICO}




\section{REFERENCIAL TEÓRICO-METODOLÓGICO}

\subsection{OPÇÃO PELA PESQUISA QUALITATIVA DE ABORDAGEM FENOMENOLÓGICA}

Para investigar a "atuação do enfermeiro na prevenção e no controle da obesidade na APS", na perspectiva do próprio profissional, foi adotada uma fundamentação baseada em princípios da pesquisa qualitativa. Esta abordagem permite ao pesquisador ter acesso ao universo das emoções, perspectivas, crenças, valores, ações, comportamentos e significados que as pessoas constroem sobre suas experiências, o que possibilita investigar a essência das situações, aprofundando o conhecimento acerca do fenômeno investigado (Minayo, 2015).

A investigação qualitativa, no decorrer do tempo, ganhou espaço no universo da pesquisa social ao reconhecer a influência das relações intersubjetivas e dos valores pessoais envolvidos (Falsarella, 2015). Entre as diversas abordagens qualitativas, no presente estudo, a fenomenologia se mostrou como melhor opção por possibilitar a compreensão do mundo tal como ele se apresenta à consciência humana (Brum, Bertineti, Souza, 2013).

A fenomenologia parte da suposição de que o conhecimento se fundamenta no conhecimento originário, é de natureza intuitiva e direcionado pela consciência subjetiva onde a realidade se constitui pela intencionalidade da consciência. Acredita que o mundo é criado pela consciência, sendo, portanto, um conjunto de significações de sentidos produzidos por esta consciência (Brum, Bertineti, Souza, 2013).

Para buscar coerência e consistência na investigação fenomenológica, é preciso atentar para a construção do objeto de estudo e para as questões de pesquisa, bem como para a postura do pesquisador e para a escolha da técnica de produção de dados. O primeiro momento da pesquisa fenomenológica se refere à busca de algo que se pretende conhecer, porém o objeto não está explicitado (pré-reflexivo). A trajetória da pesquisa fenomenológica inicia-se com a pergunta norteadora. Ela é que serve de abertura e de guia para o que se pretende investigar (Gil, Yamauchi, 2012).

A entrevista fenomenológica é o instrumento utilizado para apreender os aspectos da subjetividade dos participantes da pesquisa. Ao conduzi-la, o pesquisador precisa exercitar a atitude fenomenológica, mediada pela empatia e intersubjetividade, e se mobilizar com aquilo que foi dito e com o que foi silenciado. Esse movimento permite escutar, calar, sentir, falar e refletir, para acessar a compreensão do fenômeno (Paula et al., 2014). 
Neste estudo, a abordagem fenomenológica foi escolhida por permitir ao pesquisador ir à consciência do enfermeiro que atua na prevenção e no controle da obesidade no contexto da APS, buscando sua intencionalidade voltada para essas ações.

Considerando-se que a experiência dos enfermeiros, além de individual, está contextualizada em uma estrutura social na qual se estabelece uma relação intersubjetiva, elegeu-se a fenomenologia social de Alfred Schütz para fundamentar este estudo.

\subsection{INTERFACE ENTRE O OBJETO DE ESTUDO E OS PRESSUPOSTOS TEÓRICO-METODOLÓGICOS DA FENOMENOLOGIA SOCIAL DE ALFRED SCHÜTZ}

Alfred Schütz, sociólogo, nasceu na Áustria, em 1899, e faleceu nos EUA, em 1959. Lecionou Sociologia em Viena, Áustria, e, antes da invasão de seu país pelos nazistas, migrou para a França e depois para os EUA. Atuou como professor na University in Exile, posteriormente chamada de Graduate Faculty of the New School for Social Research, local onde se manteve exilado até a morte (Schütz, 2012).

Sua formação sociológica sob a influência de Max Weber o inspirou a pensar a realidade social a partir do significado das ações do ser humano. Buscou em Edmund Husserl a compreensão dos fenômenos sociais fundamentada no significado que é atribuído à ação pelas pessoas envolvidas na cena social. Para isso, utilizava especialmente os conceitos de mundo social, intencionalidade e intersubjetividade (Schütz, 2012).

Cabe destacar que a intencionalidade na perspectiva da fenomenologia social é voltarse para o outro ser humano, não somente no nível individual, mas no social, uma vez que o homem vivencia um mundo de interações. Assim, embora a experiência seja individual e única, ela é vivida no contexto das relações sociais, por isso apresenta um sentido social (Schütz, 2009).

Para fundamentação desta pesquisa, serão utilizados os seguintes pressupostos, aplicados ao mundo social, descrito na fenomenologia social de Alfred Schütz: mundo da vida, intersubjetividade, acervo de conhecimentos, situação biográfica, ação social, "motivos porque" e "motivos para", além de tipologia da ação social.

O mundo da vida, também denominado de mundo social, é permeado pelas relações sociais. Nessas, os seres humanos compartilham o tempo e o espaço. Um está consciente da presença do outro, ou seja, um volta-se para o outro, conferindo significado a este encontro. $\mathrm{O}$ 
fluxo similar da consciência que se dá nesse mundo propicia a construção social das pessoas e influencia suas relações, em um contexto de "intersubjetividade" (Schütz, 2009).

A partir do momento em que a pessoa é parte desse mundo social, a ela é apresentada a realidade socialmente construída, que pode ser modificada em função da posição que ela ocupa nesse mundo. A pessoa reage de modo espontâneo às questões do dia a dia, sem questionar esta realidade, sendo capaz de influenciar e sofrer influências do meio em que vive (Schütz, 2012).

No mundo social, o homem possui um acúmulo de experiências vividas presentes em sua consciência, as quais são utilizadas para fundamentar os seus projetos de vida. Soma-se às experiências vividas o conhecimento transmitido inicialmente pela família e, posteriormente, por mestres e pessoas que com ele convive. Desse modo, o conjunto dos elementos transmitidos por pessoas significativas e advindos da experiência vivida denomina-se "acervo de conhecimentos" (Schütz, 2009).

Este acervo de conhecimentos sofre influências de elementos da cultura como crenças, questões ideológicas, religiosas, técnicas e científicas. Desse modo, o conhecimento social encontra-se disponível e acessível para as pessoas, segundo a posição que estas ocupam no mundo da vida. Esta posição é denominada "situação biográfica" (Schütz, 2012). As múltiplas interpretações singulares desse mundo social, de certo modo, combinam entre si, em determinadas facetas que acabam por formar uma visão de mundo comum, caracterizando os grupos sociais (Schütz, 2012).

$\mathrm{Na}$ presente pesquisa, o grupo social estudado diz respeito aos enfermeiros que atuam na prevenção e no controle da obesidade no contexto da APS. Nesta realidade social, estes profissionais experienciam diariamente relações sociais com o público obeso ou em risco de obesidade e mantêm com ele a relação denominada por Schütz de face a face. Esta relação permite uma experiência direta entre pessoas com interações capazes de apoiá-las/educá-las, promovendo mudanças nos seus hábitos de vida de modo a promover a adoção de comportamentos de prevenção e controle da obesidade.

Quando o enfermeiro volta sua intencionalidade em direção às ações de prevenção e controle da obesidade no serviço de APS, atribui um conjunto de motivos em vista dos quais deseja agir (motivos para). Para tal, recorre à sua bagagem de conhecimentos disponíveis (conhecimento técnico e experiência profissional) e retrospectivamente reflete acerca dos motivos em razão dos quais age (motivos porque).

Desse modo, a ação humana é dotada de intencionalidade e está relacionada a um projeto no qual o homem encontra significado. Os motivos porque se prendem ao passado sedimentado na consciência (bagagem de conhecimentos adquiridos e experienciados no 
mundo da vida) e fundamentam a elaboração de projetos (motivos porque). Os "motivos para" e "motivos porque" referem-se ao comportamento motivado que desencadeia a ação humana (Schütz, 2012).

A ação humana tem o seu cerne no mundo das relações sociais e sua compreensão ocorre primeiramente no mundo social, por meio da tipificação. Na esfera científica, o típico da ação elaborada pelo pesquisador constitui-se em uma organização teórica que representa a ação das pessoas no mundo social. Esta retrata o significado atribuído pelo próprio homem à vida social. Portanto, a identificação da estrutura comum dos significados conferidos a uma determinada ação social pode ocorrer quando estes são reduzidos aos seus motivos típicos (Schütz, 2012).

Destarte, o típico da ação social em pauta (atuação do enfermeiro na prevenção e no controle da obesidade na APS) poderá ser representado por uma construção teórica elaborada a partir da experiência vivida pelos enfermeiros envolvidos nessa ação. A tipificação deve satisfazer às exigências primeiramente do mundo social e depois da ciência.

A construção do típico da ação pressupõe obedecer aos postulados fundamentais do método científico: postulado da racionalidade, consistência lógica e adequação entre as construções do pesquisador e as experiências do sentido comum. O postulado da interpretação subjetiva usado para a apreensão do mundo da vida, ao ser conjugado aos demais, fundamenta o método da sociologia fenomenológica de Alfred Schütz (Schütz, 2009). Desse modo, a presente investigação - atuação dos enfermeiros na prevenção e no controle da obesidade na APS - fundamentou-se a partir dos pressupostos teóricos acima mencionados. 


\section{TRAJETÓRIA METODOLÓGICA}

\subsection{TIPO DE ESTUDO}

Estudo qualitativo, fundamentado na fenomenologia social de Alfred Schütz.

\subsection{CENÁRIO E PARTICIPANTES DA PESQUISA}

A pesquisa foi realizada com enfermeiros que atuam em UBSs localizadas em um município de Minas Gerais. Esse município possui uma população estimada de 563.769 habitantes segundo informações do IBGE de 2017 (IBGE, 2017).

A rede de serviços de APS da cidade é composta por 63 UBSs distribuídas em sete regiões administrativas e 12 sanitárias. Em 39 UBSs, existem 89 equipes que compõem a Estratégia de Saúde da Família (ESF), 24 equipes que atuam segundo o modelo Tradicional de Assistência. Em duas das UBSs, convivem o Modelo Tradicional e a ESF (Juiz de Fora, 2014).

No contexto do município estudado, os hábitos de vida da população, incluindo a obesidade, apresentam-se como importantes causas do agravamento de doenças, internações de urgência e mortes prematuras (Juiz de Fora, 2014).

Participaram do estudo 12 enfermeiros, efetivos no serviço público, que atuavam nas UBSs há pelo menos três anos, pressupondo-se que o tempo de experiência no serviço poderia ser um fator facilitador em relação à realização de atividades de prevenção e controle da obesidade.

Foram excluídos aqueles enfermeiros com contrato de trabalho temporário, os que ocupavam cargos de gestão e/ou estavam afastados do serviço para tratamento de saúde ou licença-maternidade. Considerou-se que a fragilidade do contrato de trabalho temporário podia interferir na motivação do profissional quanto ao planejamento e execução de ações voltadas para a prevenção e o controle da obesidade.

\subsection{DESCRIÇÃO ACERCA DA COLETA DOS DEPOIMENTOS}

A entrevista fenomenológica foi utilizada para a obtenção dos depoimentos. Nesta modalidade de entrevista, busca-se a aproximação com os participantes, o desenvolvimento da empatia e a descrição da experiência. Assim, o pesquisador pergunta ao participante e este 
responde, descrevendo sua ação social frente ao fenômeno estudado (Jesus et al., 2013). Neste estudo, a experiência do participante foi traduzida pela fala do enfermeiro quando este descreveu o significado da sua atuação na prevenção e no controle da obesidade no contexto da APS.

O acesso aos participantes foi realizado após autorização do Departamento de Programas e Ações da Atenção Primária à Saúde (DPAAPS) da Subsecretaria de Atenção Primária à Saúde do município do estudo (Anexo 1).

Para selecionar as UBSs que participaram do estudo, foi solicitada ao chefe do DPAAPD a listagem de unidades com os respectivos enfermeiros que compõem as equipes de saúde. De posse da listagem, efetuou-se o sorteio dos participantes. Após o sorteio, realizou-se o contato telefônico com os possíveis participantes que atenderam aos critérios de inclusão da pesquisa para agendamento de data, horário e local de realização da entrevista.

A maioria dos depoimentos foi cedida nas UBSs, durante o expediente, utilizando-se de uma sala privativa a fim de que os participantes se sentissem à vontade e seguros para verbalizarem suas experiências. Uma das entrevistas foi realizada na residência da participante, em um local da casa adequado à obtenção do depoimento.

Antes de iniciar a entrevista, a pesquisadora esclareceu para os enfermeiros os objetivos da pesquisa, a duração da entrevista (aproximadamente 40 minutos), os aspectos éticos envolvidos e a necessidade de assinatura do Termo de Consentimento Livre e Esclarecido (Apêndice A).

Foi solicitada a permissão dos participantes para o uso do gravador de áudio durante as entrevistas, a fim de possibilitar o registro na íntegra de seus depoimentos e sua posterior análise. O áudio gravado será arquivado durante cinco anos, em local de acesso apenas dos pesquisadores, e depois será destruído.

Para nortear a entrevista, foi utilizado um roteiro com as seguintes questões abertas: o que você tem feito em relação à prevenção e ao controle da obesidade na UBS? Quais suas expectativas em relação a sua atuação frente à obesidade? Além dessas questões, foram acrescentadas no roteiro de coleta de dados informações pessoais, socioeconômicas e profissionais (Apêndice B).

Para garantir o anonimato, os depoimentos foram identificados pela abreviatura da palavra "Enf." e a numeração arábica correspondente à ordem das mesmas: Enf. 1 a Enf.12. Em conformidade com os princípios da pesquisa qualitativa, o total de participantes não foi estabelecido a priori. As entrevistas foram encerradas quando o conteúdo dos depoimentos dos enfermeiros foi suficiente para o alcance dos objetivos da pesquisa, permitindo o 
aprofundamento, a abrangência e a diversidade do conteúdo estudado, segundo a pesquisa qualitativa (Minayo, 2017). Salienta-se que foram incluídos na pesquisa os 12 enfermeiros entrevistados, não havendo perdas amostrais.

\subsection{ORGANIZAÇÃO E ANÁLISE DOS DADOS}

A organização e a análise dos resultados foram fundamentadas em pressupostos descritos em estudos embasados na fenomenologia social, por meio das seguintes etapas: obtenção dos depoimentos, leitura e releitura minuciosa dos relatos, distanciando-se da teoria para valorizar os sentidos explicitados pelos participantes; análise compreensiva e organização dos depoimentos em categorias que expressam o vivido pelos enfermeiros na prevenção e no controle da obesidade na APS; interpretação dos resultados a partir da fenomenologia e referencial teórico relacionado ao tema estudado (Jesus et al., 2013).

\subsection{ASPECTOS ÉTICOS}

Foram atendidos todos os requisitos éticos e legais da pesquisa envolvendo seres humanos em consonância com o previsto na Resolução n. 466/2012 (Brasil, 2012). As entrevistas foram iniciadas após a aprovação do projeto de pesquisa pelo Comitê de Ética em Pesquisa com seres Humanos da Escola de Enfermagem da Universidade de São Paulo, sob o Parecer $n^{\circ}$ 2.340.033, CAAE 77967117.7.0000.5392 aprovado em 20 de outubro de 2017 (Anexo 2).

A Figura 1 apresenta a síntese da trajetória metodológica do estudo. 
Figura 1 - Trajetória Metodológica do Estudo. São Paulo, 2018

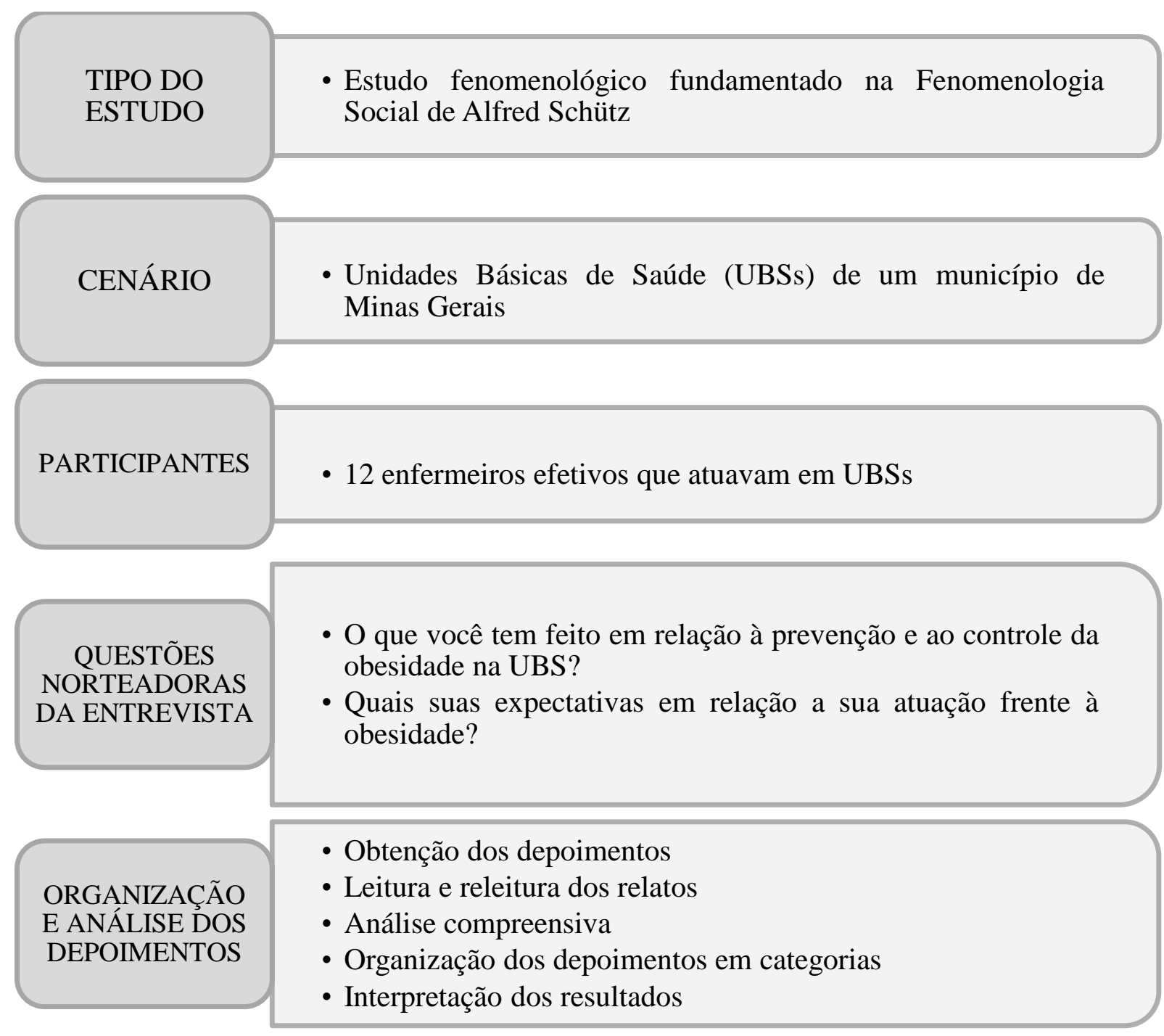

Fonte: Os autores 


\section{RESULTADOS}

\subsection{CARACTERÍSTICAS DOS PARTICIPANTES}

A seguir, são apresentadas as principais características dos 12 enfermeiros que compuseram o grupo social estudado:

Entrevista 01 - Sexo feminino, 57 anos, 28 anos de formada, está na UBS de atuação há 14 anos. Especialista em Terapia Intensiva, Saúde da Família e Enfermagem do Trabalho. Não recebeu capacitação voltada para obesidade. Modelo da UBS de atuação: ESF.

Entrevista 02 - Sexo feminino, 48 anos, 21 anos de formada, está na UBS de atuação há nove anos. Especialista em Saúde da Família, Obstetrícia, Terapia Floral, Gestão de Redes de Saúde, Preceptoria do SUS e é mestre. Não recebeu capacitação voltada para obesidade. Modelo da UBS de atuação: misto.

Entrevista 03 - Sexo feminino, 39 anos, 15 anos de formada, está na UBS de atuação há sete anos. Especialista em Saúde da Família e Gestão em Saúde. Não recebeu capacitação voltada para obesidade. Modelo da UBS de atuação: ESF.

Entrevista 04 - Sexo feminino, 32 anos, dez anos de formada, está na UBS de atuação há quatro anos. Especialista em Saúde da Família, Gestão em Saúde e Enfermagem do Trabalho. Não recebeu capacitação voltada para obesidade. Modelo da UBS de atuação: ESF.

Entrevista 05 - Sexo feminino, 44 anos, 22 anos de formada, está na UBS de atuação há 15 anos. Especialista em Saúde da Família, Obstetrícia e Gestão da Clínica. Recebeu capacitação voltada para obesidade em 2017. Modelo da UBS de atuação: ESF.

Entrevista 06 - Sexo masculino, 40 anos, 17 anos de formado, está na UBS de atuação há oito anos. Especialista em Saúde da Família, Estomaterapia, com Mestrado 
e Doutorado em Ciências. Não recebeu capacitação voltada para obesidade. Modelo da UBS de atuação: ESF.

Entrevista 07 - Sexo feminino, 50 anos, 29 anos de formada, está na UBS de atuação há 15 anos. Especialista em Saúde da Família e Obstetrícia. Não recebeu capacitação voltada para obesidade. Modelo da UBS de atuação: ESF.

Entrevista 08 - Sexo masculino, 41 anos, 17 anos de formado, está na UBS de atuação há 15 anos. Especialista em Saúde da Família. Não recebeu capacitação voltada para obesidade. Modelo da UBS de atuação: tradicional.

Entrevista 09 - Sexo feminino, 35 anos, 12 anos de formada, está na UBS de atuação há cinco anos. Especialista em Saúde da Família, Gestão em Saúde e é mestre. Recebeu capacitação voltada para obesidade em 2010 e 2014. Modelo da UBS de atuação: tradicional.

Entrevista 10 - Sexo feminino, 38 anos, 12 anos de formada, está na UBS de atuação há cinco anos. Especialista em Terapia Intensiva e Preceptoria do SUS. Não recebeu capacitação voltada para obesidade. Modelo da UBS de atuação: ESF.

Entrevista 11 - Sexo feminino, 36 anos, 12 anos de formada, está na UBS de atuação há cinco anos. Especialista em Saúde da Família, Residência em Saúde da Família e Gestão de Políticas Públicas. Não recebeu capacitação voltada para obesidade. Modelo da UBS de atuação: ESF.

Entrevista 12 - Sexo feminino, 40 anos, 15 anos de formada, está na UBS de atuação há cinco anos. Especialista em Saúde da Família, Terapia Intensiva e Residência em Saúde do Adulto. Recebeu capacitação voltada para obesidade em 2005. Modelo da UBS de atuação: ESF. 


\subsection{CATEgORIAS}

Da análise dos depoimentos resultou o conjunto de categorias que emergiram da experiência de enfermeiros em relação à prevenção e ao controle da obesidade na APS. As três primeiras categorias referem-se ao contexto da experiência (motivos porque): "Orientação sobre hábitos saudáveis de vida", "Ações coletivas de promoção da saúde e controle de agravos" e "Dificuldades que impactam a atuação do enfermeiro". A última categoria revela os projetos dos enfermeiros frente a sua atuação (motivos para): "Expectativas de atuação frente à obesidade".

\section{Categoria 1: Orientação sobre hábitos saudáveis de vida}

Os enfermeiros referiram fazer orientações sobre alimentação e atividades físicas ao atender crianças na puericultura, gestantes e adultos com doenças crônicas. Os participantes relataram ainda que a pessoa com obesidade em situação de risco é encaminhada para o nível secundário de atenção à saúde.

A Consulta de Enfermagem foi citada como estratégia utilizada para os atendimentos às mães de recém-nascidos e crianças de até 2 anos de idade, conforme preconizado pelo Ministério da Saúde:

Eu atuo com a criança [...] orientando a dieta para a mãe, investigando como ela vivencia a alimentação. (Enf. 2)

[...] oriento a mãe em relação à amamentação e faço questão de marcar uma consulta antes da criança fazer seis meses para orientar a alimentação após a amamentação exclusiva. Eu faço um cardápio do que a mãe tem que oferecer como alimentação para a criança. O mais saudável possível. [...] introduzo sulfato ferroso até dois anos. Eu escrevo para a mãe quais são as opções dentro da realidade dela. (Enf. 3)

[...] faço orientações sobre qual alimentação é adequada para aquela faixa etária, qual o crescimento e desenvolvimento esperado, mais ou menos assim. Inclusive ensino a mãe a entender o perfil e o biotipo da família. A mãe vem com a uma inquietação de que a criança ou é muito miúda ou é muito grande, então ensino considerar o perfil da família. (Enf. 5)

No ambulatório, geralmente acompanho as crianças desde o nascimento até dois anos como é preconizado. Na puericultura, faz parte o acompanhamento do peso e altura para se ter noção do IMC e classificar a criança. Tento conhecer a realidade da mãe primeiro para saber quais são os recursos que ela tem para então orientar. [...] a condição social e econômica da família dificulta o acesso a uma alimentação mais variada para prevenir a obesidade. [...] faço as orientações para as mães a respeito da nutrição, sobre qual alimentação é mais adequada para cada fase da criança. Com isso eu tento prevenir a obesidade [...]. (Enf. 6) 
[...] na puericultura, atendo crianças de 0 a 2 anos de idade. Se é uma criança pequena que está com mamadeira e ela já está em sobrepeso, corto a farinha e ensino para oferecer só o leite. [...] faço a avaliação dietética e oriento a mãe. (Enf. 7)

$\mathrm{O}$ acesso à alimentação saudável para algumas pessoas às vezes é mais difícil porque elas consomem a batata chips, é mais barata. É mais fácil de consumir, além de ser barato. Então eu oriento tentando tirar esse hábito a longo prazo. (Enf. 9)

[...] oriento aleitamento materno até os seis meses e depois oriento dar preferência as comidas como verduras, carnes, legumes. Faço orientações para uma alimentação mais saudável, tirando biscoitos que as mães têm costume de dar. Eu oriento dar a comida da família, tirando refrigerantes. [...] quando você vai orientar que uma criança de um ano não pode comer "miojo", os pais ficam horrorizados porque eles já estão dando, é mais barato e mais fácil. (Enf. 10)

[...] tem o calendário do Ministério da Saúde e sigo ele, mas, quando identifico qualquer alteração, seja em relação à obesidade ou ao baixo peso, faço um cronograma diferenciado. [...] marco retorno em um tempo menor. (Enf. 11)

[...] estimulo o aleitamento materno. Quando não tem como amamentar, oriento a mãe a questão do cuidado ao preparar a mamadeira, dosagem, leitura do rótulo, oferta a cada três horas com volume certo. [...] quando tem obesidade, oriento evitar refrigerante, flocos de Fandangos [...] converso, procuro orientar. (Enf 12)

\section{A Consulta de Enfermagem à gestante foi referida pelo enfermeiro como oportunidade} para orientar quanto à alimentação durante a gestação:

$\mathrm{Na}$ consulta com a gestante, eu faço a pesagem da mulher e oriento em relação à alimentação dentro do universo e do ritmo de vida dela. Sempre tentando adaptar aos hábitos dela, pois existem várias dietas, vários padrões de alimentação. (Enf. 2)

Na verdade, independentemente de ela ser obesa ou não, eu trabalho com ela a questão da alimentação mais natural possível e ingestão de água. (Enf. 3)

[...] faço o exame físico e oriento muito em relação alimentação e ingesta hídrica da gestante. Percebo que elas não bebem água. Tem gente que fala que bebe só com remédio. E outra coisa que eu faço é orientar sobre a alimentação mais natural, evitando doces, refrigerantes, frituras, lanches. (Enf. 3)

Pergunto a gestante sobre alimentação, necessidades fisiológicas, ingesta hídrica. Eu oriento a comer mais frutas, legumes, evitar salgadinhos, refrigerante principalmente no início em que elas queixam muito enjoo. (Enf. 4)

Eu explico para a gestante que não é o momento de ela usar adoçante, fazer dieta, mas que ela precisa fazer melhores escolhas alimentares. Que ela pode ficar satisfeita, mas ela tem que ficar nutrida. (Enf. 5)

$\mathrm{Na}$ minha abordagem com a gestante, eu tento modificar a ideia de que ela tem que comer para dois. Desde o início da gestação, preocupo com o ganho de peso excessivo, com o perigo do diabetes gestacional, com as hipertensões, principalmente aquelas com características familiares. (Enf. 7)

Eu falo para ter maior cuidado com a alimentação, principalmente com os desejos próprios da gravidez e estão relacionados a alimentos que engordam muito como é a questão do carboidrato, do açúcar. [...] oriento a comer fracionado, em menor volume [...]. (Enf. 8)

[...] na primeira consulta do pré-natal, olho a questão do peso da gestante e faço as orientações pertinentes. Eu oriento a gestante adotar uma alimentação mais saudável 
possível. Ter uma alimentação regular, não ficar muitas horas sem se alimentar e verificar o que está comendo. Então trabalho isso com ela. (Enf. 9)

Oriento sobre a alimentação de três em três horas. Muitas gestantes já chegam obesas. Não estão ganhando peso só na gestação! (Enf. 10)

Eu incentivo desde o pré-natal o aleitamento materno e o preparo da mama. Oriento essa mãe a ter uma alimentação mais balanceada de modo que ela possa alimentar bem sem ficar preocupada com balança, com o ganho de peso excessivo. Então, durante o pré-natal, converso com ela para comer mais frutas, optar pelo alimento feito em casa, evitar fazer lanches pela rua, saber a procedência da água antes de tomar. Então trabalho no pré-natal a alimentação dessa mãe. (Enf. 12)

De acordo com os depoimentos, o enfermeiro faz orientações às pessoas com doenças crônicas sobre alimentação e estimula a realização de atividades físicas no acolhimento e atendimentos individuais:

[...] atendo no acolhimento pessoas hipertensas e diabéticas e faço as orientações sobre alimentação, necessidade de atividade física e controle do peso. (Enf.1)

[...] eu atendo no acolhimento hipertensos e diabéticos e, nesses atendimentos, principalmente no caso de diabetes, eu percebo que as pessoas necessitam de orientação para dieta [...]. (Enf. 3)

Eu oriento individualmente que as pessoas aproveitem o próprio trajeto de casa até o trabalho e outros para fazer exercício. [...] também o espaço que tem em casa desde que pegue uma orientação e faça a atividade dentro do que pode. [...] geralmente nos adultos, o sobrepeso e a obesidade já vêm com alguma doença crônica. [...] tento estimular para as atividades físicas que o serviço oferece. (Enf. 5)

[...] existem aqueles casos de hipertensão e diabetes mais leves que acompanho na consulta de enfermagem. E aí fica na orientação nutricional mesmo, no incentivo à atividade física, na mudança de estilo de vida [...]. Eu acho que a prevenção da obesidade na população de hipertensos e diabéticos é mais complicada de trabalhar porque muitas vezes eles já chegam obesos, alguns com sobrepeso. (Enf. 6)

[...] trabalho adultos em consultas de acompanhamento a questão da orientação. [...] oriento dieta e a prática da atividade física. (Enf.9)

[...] os hipertensos e diabéticos oriento uma atividade física que dê para fazer como uma caminhada ou uma natação ou hidroginástica. [...] Estimulo dentro do possível, do que dá para fazer. (Enf. 10)

Eu tenho pacientes obesos que são diabéticos e hipertensos, que são de difícil controle. Eu bato muito na tecla das orientações alimentares. Tento acompanhar os adultos em relação à dieta, controle do colesterol, açúcar, triglicerídeos, o que pode e o que não pode comer. (Enf. 11)

[...] eu tento colocar para eles a questão da alimentação. Peço para que faça uma refeição a cada três horas. A importância de pelo menos o café da manhã, almoço e jantar. (Enf. 12)

Os enfermeiros ressaltaram que, nos casos de obesidade grave em crianças, gestantes e adultos, estes são encaminhados para o nível secundário de atenção à saúde:

Se eu percebo que a gestante está obesa, muito acima do peso, eu encaminho para o acompanhamento de alto risco. Lá tem o acompanhamento com nutricionista e com o 
endocrinologista. Quando as pessoas voltam para a UBS, vem com o cardápio. Apesar do encaminhamento, eu sempre oriento. (Enf. 3)

Encaminho a pessoa com obesidade para o próprio médico da UBS acompanhar quando não tem muitas comorbidades associadas. Quando têm comorbidades, encaminho para o endocrinologista. Até para pensar em uma cirurgia bariátrica se for o caso. (Enf. 6)

[...] quando a criança está muito obesa, encaminho ao endocrinologista. [...] quando a gestante já é obesa, não acompanho aqui na unidade. Faço a referência para o alto risco e depois este setor faz a contrarreferência para a UBS. [...] antes de encaminhar, a gente faz a primeira consulta e faz toda essa abordagem com ela também. (Enf. 7)

Às vezes, preciso referenciar a gestante para o setor de alto risco. Direciono também alguns casos de sobrepeso ou obesidade para um atendimento especializado da rede assistencial de saúde. (Enf. 9)

Quando eu pego a gestante com IMC acima de 40, eu encaminho para o pré-natal de alto risco. São pedidos exames e faz-se encaminhamento para o endocrinologista. Às vezes, ela ainda não está em situação de alto risco, mas, para o enfermeiro, é difícil acompanhar essa gestante. Não temos um nutricionista na rede. As gestantes já engravidam obesas. Aí é mais complicado porque a gente não consegue acompanhar ela bem aqui. (Enf. 10)

[...] tenho alguns casos de obesidade infantil. Então, quando vejo que o gráfico está muito acima, que o índice de massa corpórea está acima do esperado, eu encaminho para o médico da UBS [...] e o médico, se achar necessário, encaminha para o endocrinologista infantil. [...] as gestantes obesas são encaminhadas para o setor de atendimento de alto risco. Depois que a criança nasceu, eu faço a visita puerperal, mas a abordagem dela é feita quase toda no setor de alto risco. (Enf. 11)

\section{Categoria 2: Ações coletivas de promoção da saúde e controle de agravos}

Os enfermeiros relataram que realizam ações coletivas de promoção da saúde e controle de agravos no contexto da APS, por meio de orientação sobre hábitos saudáveis de vida. Para tal, utilizam os grupos de caminhada orientada e grupos operativos voltados para as pessoas com doenças crônicas, gestantes e cessação do tabagismo. O trabalho com adolescentes na escola foi referido como uma atividade esporádica ou ausente no âmbito da UBS.

De acordo com os participantes, o grupo de caminhada orientada é uma ação realizada na UBS, sob a responsabilidade do profissional de educação física:

Temos na UBS o grupo de caminhada [...]. Eu peso os usuários e incentivo para a participação na caminhada de acordo com o que a pessoa pode fazer. Às vezes, a pessoa trabalha e não pode participar. [...] então, oriento a fazer uma caminhada de meia hora, três vezes na semana, que já ajuda no controle do peso. (Enf. 2)

O que nós temos de legal aqui na UBS é o grupo de caminhada, onde algumas pessoas participam ativamente [...]. Alguns participantes estão até com sobrepeso, mas são bem ativos. Quem coordena é um professor de ginástica. [...] eu não participo porque a demanda para o enfermeiro aqui na UBS é muito grande. [...] o professor de educação física orienta sobre o sobrepeso e o resultado positivo no peso das pessoas que fazem atividade física [...]. (Enf. 3) 
Para o adulto, temos o grupo de caminhada às segundas e quartas-feiras. Nós temos uma educadora física que faz essa atividade. Inclusive ela faz um trabalho com a enfermagem e com o médico de melhorar os índices laboratoriais dos participantes da caminhada. Ela faz avaliação de IMC, peso e de bioimpedância. Ela faz essa avaliação anual com eles. (Enf. 5)

Temos um grupo de atividade física aqui na UBS [...]. Um profissional de educação física vem três vezes na semana e ele trabalha com ginástica laboral e alongamento. As aulas são na quadra do bairro, onde eles fazem ginástica e caminhada. Eu não atuo diretamente nessas atividades, mas, quando o professor vai fazer uma atividade mais vigorosa, os participantes vêm na UBS, eu faço aferição da pressão arterial, peso e, depois que termina o exercício, eles retornam na unidade e repito as aferições. (Enf. 11)

Para o grupo de gestantes e de pessoas com doenças crônicas como HAS e diabetes mellitus, segundo os participantes, realiza-se a avaliação antropométrica e são feitas orientações relacionadas ao incentivo à alimentação saudável:

[...] eu abordo a questão da alimentação para gestantes hipertensos e diabéticos para prevenção da obesidade. [...] existe o controle individual e de grupo para esses usuários. (Enf. 2)

No grupo de hipertensos e diabéticos, eu sempre peso, faço o cálculo do IMC e aferição da circunferência abdominal. [...] eu incentivo a alimentação saudável, diminuir o sal na alimentação, usar corretamente a medicação. Caso seja necessário, eu marco uma consulta para a pessoa. (Enf. 4)

Os grupos de hipertensos e diabéticos acontecem semanalmente. Cada equipe faz o seu. É um grupo-consulta. Nesse dia, eu faço a sala de espera com os usuários, a antropometria, aproveito para fazer os registros, para atualizar algum dado cadastral. Naquele mesmo dia, a pessoa vai para o atendimento médico [...] nos grupos de gestantes, a questão do peso é um dos temas que eu abordo. Falo da importância de frequentar o pré-natal, do perfil de peso necessário para evitar complicações na gestação. (Enf. 5)

Tanto no grupo de gestantes como no de hipertensos e diabéticos, faço a avaliação antropométrica e a classificação do IMC. A partir daí, eu vou trabalhando a questão do peso. (Enf. 6)

Aqui na UBS, o grupo com hipertensos e diabéticos é realizado mensalmente. Eu procuro conversar com eles sobre alimentação. A maioria dos obesos tem comorbidades associadas [...]. [...] no grupo de gestantes, eu verifico o perfil alimentar e faço as orientações em relação ao peso. (Enf. 9)

[...] nos grupos de hipertensos, eu coloco para os usuários a parte de alimentação. Falo com eles sobre o consumo de refrigerantes, das calorias, do consumo de açúcar. Englobo todas essas orientações alimentares que influenciam no peso. (Enf. 10)

Quanto ao trabalho com o grupo operativo voltado para a cessação do tabagismo, os enfermeiros consideraram este um momento propício para realização de orientações em relação à mudança de hábitos alimentares, uma vez que o abandono do uso do tabaco pode gerar ganho de peso: 
[...] no grupo de tabagismo [...], tem uma parte específica voltada para orientação nutricional. Por conta de deixar o tabaco, a pessoa muitas vezes vai ganhando peso. Falo dicas de como a pessoa deixa de fumar sem ganhar peso. (Enf. 6)

[...] para o tabagista, fica sempre aquela questão que gera muita dúvida que, se ele parar de fumar, ele vai engordar. Eu oriento a mudança de hábitos e o cuidado com a balança. (Enf. 8)

Os participantes salientaram que, na UBS onde atuam, o trabalho na escola acontece de forma esporádica ou não acontece:

[...] os acadêmicos de enfermagem é que trabalham a questão da alimentação saudável na escola. [...] não temos nenhuma ação em curso para esse público, mas eu precisava ter porque percebo que os adolescentes estão engordando, eles estão alimentando mal. (Enf.1)

Não temos nenhuma ação fora da UBS. (Enf. 3)

Atividades em escolas já tem um tempo que estão paradas. Não faz parte da rotina da Unidade. (Enf. 4)

Às vezes, nós fazemos pesagem na escola, mas é muito esporádico, não é rotineiro. (Enf. 6)

[...] eu faço atividades na escola de acordo com a demanda que ela traz. (Enf. 8)

\section{Categoria 3: Dificuldades que impactam a atuação do enfermeiro}

Ao descrever as ações individuais e coletivas especialmente em relação à adoção de uma alimentação saudável, os enfermeiros apontam dificuldades relacionadas ao próprio usuário, como resistência à mudança de comportamento, o que impacta a sua adesão às recomendações profissionais:

Eu acho que a dificuldade é a adesão para mudança de hábitos. [...] o hábito da pessoa com obesidade que vem de muitos anos e você não consegue mudar. Você conversa com o diabético e fala com ele que ele tem que fazer dieta. Ele diz que está fazendo, mas você vê que não está porque a glicemia está altíssima, que ele está com sobrepeso, que o peso está muito acima do ideal. Você vê que ele não adere às orientações. (Enf. 3)

Eu vejo que o que dificulta é a resistência da própria pessoa em mudar os hábitos. [...] resistência em aderir à dieta, alimentação saudável [...]. (Enf. 4)

[...] os hábitos de vida da avó da criança com obesidade podem ser prejudiciais ao tratamento. A avó tem mais dificuldade de seguir as orientações e sai da dieta. Então eu tento buscar esse compromisso também com a avó nessa educação para a saúde da criança. (Enf. 7)

[...] eu vejo muita resistência à mudança de hábitos. Então é um trabalho de formiguinha. Paulatinamente você vai conseguindo adesão dos usuários. (Enf. 9)

Eu acho que a dificuldade está na mudança da alimentação da família. Eles já estão acostumados a usar um tipo de alimentação e precisa uma mudança brusca. [...] as vezes, é a mãe que faz a comida e ela está obesa, então é preciso cozinhar diferente para todos da casa e nem sempre eles aceitam a mudança. Eu acho que fica muito 
nessa questão cultural. Eles consomem muito fast food. [...] eu oriento, mas não vejo mudança. (Enf. 10)

$\mathrm{Eu}$ oriento as pessoas e parece que entra em um ouvido e sair no outro. Eles não aderem ao tratamento. Eles falam que entenderam as orientações, mas não fazem nada do que eu falo. Abusam na alimentação, não tomam a medicação corretamente. [...] eu vejo pouco resultado e pouca adesão dos usuários com obesidade [...]. Eu acho que é mais a questão de hábito alimentar que ele traz. (Enf. 11)

Os enfermeiros salientaram a falta de comparecimento aos grupos educativos ofertados pela UBS:

Não temos nenhuma ação coletiva com as gestantes na UBS [...]. Temos muita dificuldade de adesão. Costuma vir uma ou duas. Assim, acaba que não forma um grupo. (Enf. 4)

[...] eu estou tendo muita dificuldade de programação dos grupos educativos por conta da falta de comparecimento dos usuários. Eles não valorizam esse tipo de atividade [...]. Antes eu fazia grupos de diabetes, grupos de hipertensão, gestantes, mas não faço no momento. (Enf. 7)

O que a gente ainda não conseguiu efetivar na prática aqui na UBS é a questão dos grupos educativos devido à falta de adesão porque os usuários não veem isso como importante. (Enf. 12)

No que tange às dificuldades relacionadas ao serviço de saúde, os enfermeiros ressaltaram que o desequilíbrio entre o número reduzido de profissionais de saúde atuantes nas UBSs e a grande demanda para esse serviço impacta negativamente sua atuação frente à obesidade:

[...] nós somos uma equipe pequena, então nós não damos conta da demanda da UBS. Algumas atividades eu tive que suspender, mas é temporário. Nós precisamos voltar com o grupo de controle de obesidade porque as pessoas que frequentavam estão sem assistência. [...] existem as demandas prioritárias que eu preciso cumprir e isso vai limitando em relação às outras ações que deveriam ser feitas como, por exemplo, na questão da obesidade. (Enf.1)

A quantidade de profissional é reduzida na UBS. Eu sou a única enfermeira da unidade e tenho uma série de atividades para resolver. O que eu posso fazer é priorizar e colocar como meta o grupo de controle de peso com os hipertensos e os diabéticos, mas nem sempre consigo. (Enf. 2)

A quantidade de demandas me dificulta fazer uma nova ação, como na obesidade. Às vezes o que eu planejo eu não consigo cumprir porque, de repente, chega uma outra demanda que me tira do foco. Se eu quiser fazer uma nova ação, eu preciso sair da UBS e deixar toda a demanda para trás [...]. (Enf. 3)

[...] ultimamente eu estou envolvida em diversas demandas como a vacinação de febre amarela, ações sobre a dengue, avaliação do Pmaq, visitas do Ministério da Saúde. Eu não consegui planejar mais nada. (Enf. 5)

[...] seria interessante eu voltar a olhar mais para a obesidade, mas fico muito sobrecarregado de tanta burocracia, demanda espontânea que sufoca o enfermeiro. Então às vezes planejar um grupo e os atendimentos voltados apenas para a questão da obesidade é difícil. [...] vou inserindo ações em relação à obesidade nos diversos 
grupos, mas ter uma ação só para isso fica inviável, considerando todo o volume de trabalho na UBS. (Enf. 6)

[...] às vezes a situação dentro da UBS não me permite sair para outro espaço e fazer um grupo educativo voltado para a temática da obesidade. Tem sempre uma coisa mais urgente na demanda. A UBS fica muito cheia, com situações especiais que demandam a minha presença. Eu sobrecarrego a minha agenda de atendimentos, às vezes preciso ajustar a agenda para tentar ir equilibrando as outras demandas que requerem a minha presença. (Enf. 7)

[...] na UBS em que atuo, eu sou o único enfermeiro. Eu sou o supervisor da UBS e faço várias outras coisas. [...] faço coleta de sangue no domicílio, atuo na vacinação de febre amarela, faço grupos educativos fora da unidade, faço atendimentos individuais [...]. Às vezes, uma pessoa com obesidade vem até a unidade e eu nem fico sabendo porque estou em outra atividade. (Enf. 8)

Os participantes apontaram que a falta de profissionais de outras categorias na equipe de saúde da UBS e na RAS do município, como no Núcleo de Apoio à Saúde da Família (Nasf), limita a efetividade da atuação do enfermeiro na prevenção e controle da obesidade:

[...] eu sinto falta de ter uma pessoa mais especializada para estar junto nos grupos educativos [...]. Minhas orientações às pessoas com obesidade são diminuir o peso e fazer reeducação alimentar [...]. Se a gente tivesse uma equipe com outros profissionais, como o psicólogo, o nutricionista, o educador físico, eu acho que fecharia um grupo que poderia dar um excelente resultado. (Enf.1)

Eu acho que a equipe da UBS deveria expandir, ter outros profissionais como um nutricionista porque nós não temos, precisamos encaminhar os usuários para esse atendimento. (Enf. 3)

Nós não temos Nasf no município. Se houvesse, nós teríamos o nutricionista mais próximo. Então acaba que eu mesmo faço as orientações. (Enf. 5)

Eu tentei implementar um grupo de atividade física na UBS. [...] tinha até um educador físico para fazer a atividade com a população. [...] depois a gente ficou sem esse profissional e acabamos não conseguindo continuar com a atividade. (Enf. 8)

[...] eu sinto falta de uma equipe multiprofissional para conseguir abordar a obesidade. [...] mais profissionais para ajudarem no acompanhamento dos usuários, no desenvolvimento das crianças ou para ações de controle do IMC, do controle dos resultados laboratoriais dos pacientes [...]. Nós não temos o Nasf. Se houvesse, haveria uma retaguarda com o apoio da nutrição que faz muita falta. [...] nós não temos aqui na UBS um profissional de educação física. Em uma equipe muito pequena eu não consigo atuar como deveria. Então a equipe da Atenção Básica fica com fragilidade ao lidar com a obesidade. (Enf. 9)

[...] eu sinto falta de um profissional de educação física porque eu acho que faz diferença no atendimento da pessoa com obesidade [...]. Muitos hipertensos que vêm aqui na UBS já chegam com um problema ortopédico e não podem fazer qualquer atividade física, então fica difícil eu orientar um exercício. [...] também precisaria de um nutricionista na equipe para orientar uma dieta de acordo com o grau que a obesidade do usuário. (Enf. 10)

Os enfermeiros referiram que as instalações precárias da UBS, bem como a falta de equipamentos necessários à assistência e material educativo, dificultam a realização das atividades de prevenção e controle da obesidade: 
Eu não tenho nada, só a balança. Não tem nada visual que eu possa mostrar para os usuários com obesidade que vêm às consultas. (Enf. 3)

Nós tínhamos aqui na UBS um folheto que falava sobre alimentação saudável, mas ele desapareceu [...]. Eu acho que faltam recursos para fazer um trabalho específico como o grupo para obesos, como ter material para trabalhar só com essa área. Eu não vejo esse incentivo. (Enf. 4)

[...] a equipe da UBS não recebe apoio da gestão com insumos e treinamentos para lidar com as demandas. A gestão acaba priorizando outras coisas. Nos atendimentos em grupo, se eu preciso de material educativo, eu tenho que criar com minhas próprias mãos. [...] falta o básico mesmo, como a balança. [...] se a balança estraga, leva cerca de seis meses para consertar. Aí eu tenho que fazer o atendimento sem balança. (Enf. 6)

[...] o espaço físico da UBS não permite a realização de um grupo educativo. Eu preciso lançar mão de outros espaços na comunidade para fazer. [...] tenho dificuldade de planejar os grupos por essa questão de espaço que a unidade não tem. (Enf. 7)

Os entrevistados destacaram também que o agendamento da pessoa com obesidade para o atendimento especializado é demorado, o que impacta negativamente a continuidade do cuidado na UBS:

[...] no nível secundário, tem nutricionista, mas, às vezes, eu não consigo encaminhar pessoas que necessitam assistência especializada (Enf. 3)

Eu mesmo faço a orientação porque só agora chegou o nutricionista na Rede Assistencial do município, mas nós não temos facilidade de marcar. (Enf. 5)

O que falta muitas vezes às pessoas com obesidade é o acesso ao sistema de referência. Quando encaminhamos, demora muito para sair uma vaga para o endocrinologista [...] a pessoa espera quatro ou cinco meses. É bem lento. Tem esse gargalo de acesso no sistema. (Enf. 6)

Tem hora que eu fico vendo os usuários desestimulados porque recebem um encaminhamento para um atendimento especializado e a consulta não sai. Ele precisa disso para o seguimento do tratamento dele. Então isso desestimula os usuários. (Enf. 9)

A única coisa que a gente tem na rede assistencial do município é o endocrinologista e ele não é uma consulta fácil de conseguir. (Enf. 10)

Infelizmente a endocrinologia é uma especialidade muito difícil de ser marcada no SUS. Então os adultos com obesidade eu tento acompanhar aqui mesmo na UBS. (Enf. 11)

Outro fator dificultador apontado pelos enfermeiros diz respeito à limitação de conhecimentos e de educação permanente na temática obesidade:

[...] eu não sou a profissional mais indicada para fazer um grupo de controle de peso, mas, diante da nossa dificuldade de ter outros profissionais, eu abracei a causa. Eu busquei conhecimento para dar informações mais coerentes às pessoas. (Enf.1)

Às vezes, eu trabalho a questão da alimentação, mas me sinto limitada em termos de conhecimentos específicos. Como fazer um cardápio para um diabético, eu acho que necessita o profissional especializado. (Enf. 3) 
[...] falta capacitação dos profissionais porque, na Atenção Básica, tudo está sendo descentralizado, mas nunca tem capacitação dos profissionais para atender às demandas. (Enf. 6)

Eu não tenho capacitação suficiente para orientar as pessoas com obesidade. Eu falo para a pessoa não comer macarrão, não comer arroz, mas fica muito vago para eu passar algum tipo de dieta para ela. (Enf. 10)

\section{Categoria 4: Expectativas de atuação frente à obesidade}

Ao serem questionados sobre seus projetos em relação à prevenção e ao controle da obesidade no contexto da APS, os enfermeiros desejaram conhecer o diagnóstico situacional do peso da população sob sua responsabilidade, realizar grupos específicos para o controle de peso, melhorar a articulação entre a UBS e outros serviços da comunidade que oferecem atividade física para a população, atuar com crianças e adolescentes fora do espaço da UBS e receber capacitação para atuar na obesidade.

Os participantes da pesquisa esperam conhecer o perfil alimentar e de peso da população, por meio de instrumentos do Sistema de Vigilância Alimentar e Nutricional (Sisvan), para então estabelecer estratégias de prevenção e controle da obesidade:

[...] eu acho que uma das metas é alimentar os Marcadores Alimentares para fazer um diagnóstico populacional mais claro de quem está com o peso normal, quem está com sobrepeso e obesidade e depois sentar com a equipe e propor estratégias. [...] essa é uma das minhas expectativas. (Enf. 6)

Existe uma recomendação de preenchimento da ficha de vigilância alimentar e nutricional do Sisvan, mas, aqui na unidade de saúde, ainda não comecei a preencher. [...] a prioridade é de cadastrar crianças, gestantes e idosos. Aqui nós ainda não conseguimos implementar esse preenchimento do impresso, mas esperamos conseguir. (Enf. 8)

Começou esse ano a exigência de conhecer os marcadores alimentares que é um programa do Ministério da Saúde (Sisvan) e a Secretaria de Saúde pactuou com a UBS a necessidade de traçar o perfil de gestantes e crianças menores de 2 anos. Agora eu estou fazendo, entrou na minha rotina. [...] todo atendimento de enfermagem eu preencho a folha de marcadores alimentares. É uma expectativa minha fazer o preenchimento para conhecer o perfil da população em relação ao peso. (Enf. 11)

Agora eu tenho o formulário de marcadores alimentares para preencher parecido com o Sisvan que ainda não terminei, mas pretendo terminar. (Enf. 12)

Realizar grupos específicos para o controle do peso na UBS apresenta-se como outra expectativa de atuação do enfermeiro:

[...] eu convidei as pessoas com obesidade para estarem voltando para o grupo de controle do peso. Eu acho que é muito importante, nós tivemos bastante sucesso na época que nós tivemos o grupo. (Enf.1)

Eu quero criar um grupo de controle de peso para crianças e adultos porque hoje o atendimento é mais individual. [...] eu tenho a perspectiva, de realizar o grupo específico para perda de peso porque dá muito resultado [...]. (Enf.2) 
[...] eu acho que nós temos a obrigação de fazer alguma coisa porque nós somos uma UBS. Quero ter o grupo de controle de peso como existe em outras unidades [...]. Mas

é algo que ainda não concretizamos. (Enf. 5)

\section{O enfermeiro espera melhorar a articulação entre a UBS e os serviços da comunidade} que oferecem atividade física para a população:

Eu tenho a perspectiva de integrar os grupos educativos e melhorar o vínculo com os serviços da comunidade. Quero poder direcionar os usuários para projetos de atividade física e outras realizadas na comunidade, mesmo que eu não consiga estar presente em todos os momentos em que os projetos ocorrem [...]. Eu converso muito com o conselho local de saúde sobre essa questão e esse ano eles estão buscando o estreitar os laços com a unidade e vice-versa. (Enf. 9)

Se eu pudesse encaminhar o usuário para um lugar onde tem atividade física, eu acho que faria muita diferença no controle do peso [...]. Eu acho que falta esses serviços na rede para a UBS encaminhar. Nem sei se todos iriam, mas aqueles que quisessem fazer uma hidroginástica pelo menos já teria um local para ela procurar. (Enf. 10)

Os participantes expressaram o desejo de promover ações preventivas para crianças e adolescentes fora do espaço da UBS:

O adolescente quase não vem na unidade, quando vem, nosso contato é no acolhimento [...]. Eu tenho desejo de trabalhar a questão da obesidade com eles na Casa do Pequeno Jardineiro (escola profissionalizante) [...]. (Enf. 3)

[...] o adolescente é uma população que fica um pouco solta no sistema. Então é importante ir às escolas para trabalhar com eles a prevenção de doenças [...]. [...] faço um trabalho todo segundo semestre. (Enf.5)

Tenho vontade de fazer atividades, segundo o Programa Saúde na Escola, levando informações para os alunos [...]. [...] porque, se conseguimos fazer a sensibilização desde cedo, eles já vão crescendo sabendo o que podem e o que não podem comer. (Enf. 7)

Receber capacitação para atuar na prevenção e no controle da obesidade foi também expectativa dos enfermeiros:

[...] a outra expectativa seria de ser melhor capacitado para atuar com as pessoas que apresentam obesidade porque, apesar de termos certo conhecimento, certas habilidades clínicas e até mesmo habilidades para o trabalho em grupo, com a pessoa obesa, é difícil lidar com essa questão. [...] por ser uma doença crônica de difícil controle vejo necessidade de desenvolver habilidades para lidar com esse público para que ocorra de certa forma uma mudança de comportamento do indivíduo, o que não é tarefa fácil. (Enf. 6)

Eu não tenho uma capacitação para trabalhar com pessoas com obesidade. A Secretaria Municipal de Saúde forneceu para a UBS um manual sobre saúde da população brasileira que fala sobre obesidade, mas precisamos ser capacitados. (Enf. 10) 
As categorias emergentes dos depoimentos podem ser visualizadas no Quadro 1.

Quadro 1 - Categorias que emergiram dos depoimentos. São Paulo, 2018

CATEGORIAS CONCRETAS QUE EMERGIRAM DOS DEPOIMENTOS

\begin{tabular}{|l|}
\hline \multicolumn{2}{|c|}{ "Motivos Porque" } \\
\hline Categoria 1: Orientação sobre hábitos \\
saudáveis de vida \\
$\checkmark$ Crianças na puericultura \\
$\checkmark$ Gestantes \\
$\checkmark$ Adultos com doenças crônicas \\
$\checkmark$ Encaminhamento para o nível secundário \\
\multicolumn{2}{|c|}{ de atenção à saúde, quando necessário }
\end{tabular}

Categoria 2: Ações coletivas de promoção à saúde e controle de agravos

$\checkmark$ Caminhada orientada

$\checkmark$ Grupo com pessoas com doenças crônicas

$\checkmark$ Grupo com gestantes

\section{Categoria 3: Dificuldades que impactam a} atuação do enfermeiro

$\checkmark$ Dificuldades relacionadas ao usuário:

-Resistência à mudança de hábitos de vida;

-Falta de comparecimento nos grupos educativos;

$\checkmark$ Dificuldades relacionadas ao serviço:

-Equipe reduzida e grande demanda de trabalho

-Falta de insumos, recursos e organização do serviço

-Ineficiência do encaminhamento para o nível secundário de atenção à saúde

-Formação e capacitação limitada para atuar

frente à obesidade

Fonte: Os autores

\subsection{TÍPICO DA EXPERIÊNCIA VIVIDA}

A fenomenologia social de Alfred Schütz permitiu identificar o típico da atuação do enfermeiro na prevenção e no controle da obesidade no contexto da APS como sendo aquele que atua orientando sobre hábitos de vida saudáveis as mães de crianças, as gestantes e os adultos com doenças crônicas e coletivamente na caminhada orientada e nos grupos operativos 
existentes na unidade de saúde, com gestantes e usuários com doenças crônicas. Tem como dificuldades para sua atuação questões relacionadas aos hábitos não saudáveis de vida dos usuários e resistência à mudança de comportamento, além das limitações impostas pelo serviço e equipe de saúde. Suas expectativas incluem conhecer o perfil alimentar e do peso da população, realizar grupos específicos para o controle de peso, melhorar a articulação da Unidade Básica de Saúde com outros equipamentos sociais, atuar com crianças e adolescentes fora do espaço da Unidade e receber capacitação para atuar frente à obesidade. 
6 DISCUSSÃO 


\section{DISCUSSÃO}

Ao refletirem sobre sua atuação em relação à prevenção e ao controle da obesidade no âmbito da APS, os enfermeiros colocaram em evidência a realização de ações de educação em saúde no âmbito individual e coletivo.

A educação em saúde realizada por meio do aconselhamento para a mudança de hábitos de vida, especialmente para adoção da alimentação saudável apresenta-se como uma estratégia importante para o atendimento dos pressupostos da APS, com vistas ao enfrentamento da obesidade. Um ensaio teórico que objetivou desenvolver uma reflexão sobre a adesão ao tratamento de usuário do SUS ressaltou que a educação em saúde deve ser um processo contínuo, sistemático e permanente inerente a todas as práticas desenvolvidas no âmbito do SUS, visando à promoção do autocuidado à saúde e à melhoria da qualidade de vida das pessoas (Borges, Porto, 2014).

No campo da alimentação, a educação em saúde tem sido considerada importante meio para a prevenção e controle de DCNTs, como a obesidade. A literatura mostrou que esse objetivo pode ser atendido por meio do incentivo à adoção de um estilo de vida saudável, valorização dos hábitos alimentares regionais e expressão da cultura alimentar pelas comunidades (Dillen et al., 2014; Ritten, Waldrop, Kitson, 2016).

Estudo realizado na Holanda analisou o conteúdo de orientações feitas por enfermeiros às pessoas com obesidade no contexto da APS e identificou que esses profissionais aconselhavam para a perda de peso a partir da ênfase na melhoria dos hábitos alimentares e da prática de atividade física (Dillen et al., 2014). Nos EUA, as pessoas que receberam esse tipo de aconselhamento melhoraram a responsabilidade sobre a saúde, a prática de atividade física, a nutrição, sendo que a pressão arterial e o IMC diminuíram significativamente (Ritten, Waldrop, Kitson, 2016).

No que tange ao atendimento individual, os participantes ressaltaram a consulta de enfermagem como momento oportuno para a realização de orientações para mudança de hábitos de vida. Em relação à assistência infantil, os enfermeiros do presente estudo enfatizaram orientar a mãe sobre dieta saudável e incentivo à amamentação, visando à prevenção da obesidade. Corroborando com os resultados da presente investigação, outra pesquisa realizada no sul do Brasil indicou que o incentivo ao aleitamento materno realizado por enfermeiros no contexto da APS é uma das ações que esse profissional realiza focando a prevenção e combate à obesidade infantil (Santos et al., 2014). 
Na Austrália, investigação sobre o conteúdo de orientações acerca da obesidade, durante as consultas de enfermagem de rotina a crianças de 0 a 5 anos, apontou que a maioria dos enfermeiros aconselhava os pais sobre aspectos da alimentação infantil. Por outro lado, esses profissionais raramente usavam gráficos de crescimento para identificar bebês ou crianças em risco de sobrepeso/obesidade (Laws et al., 2015).

Na Suécia, estudo avaliou um programa de intervenções de enfermeiros baseado em entrevistas motivacionais sociocognitivas com pais de bebês entre 9-10 meses a 4 anos, visando à prevenção da obesidade infantil. Demonstrou que o IMC e a cintura das crianças aos 4 anos foram significativamente reduzidos. Os resultados secundários mostraram a melhoria dos hábitos alimentares e de atividade física não somente das crianças como também das mães (Doring et al., 2014).

Os participantes do presente estudo demonstraram preocupação com o consumo infantil de alimentos industrializados. Em pesquisa realizada em São Paulo, Brasil, com 366 crianças entre 0 e 36 meses, demonstrou-se que alimentos como o petit suisse e o macarrão instantâneo eram consumidos por $89,6 \%$ e $65,3 \%$, respectivamente, pelos lactentes ainda no primeiro ano de vida. Os percentuais de adequação para carboidrato foram superiores a duas vezes o recomendado e os percentuais de sódio, 20 vezes superiores aos encontrados nos alimentos recomendados (Toloni et al., 2014).

Considerando a realidade socioeconômica da maioria das famílias das UBSs cenários do presente estudo, os enfermeiros referiram preocupação em orientar a alimentação infantil considerando o baixo poder aquisitivo dessas famílias. No que tange à questão econômica, pesquisa realizada em Teresina, Piauí, Brasil, mostrou que, de acordo com enfermeiros da APS, as condições de vida e pobreza da comunidade impactavam o avanço da consolidação das iniciativas de orientação em relação à alimentação e nutrição de crianças. Alertou-se para a facilidade do acesso pela família a alimentos processados de baixo valor nutritivo, de fácil preparo e valorizados pela mídia (Moura et al., 2015).

Além das orientações, os enfermeiros ressaltaram a realização de medidas antropométricas durante as consultas de puericultura para avaliação do peso da criança. Também um estudo de revisão sistemática da literatura apontou que o IMC é uma medida confiável no acompanhamento do peso da criança e sua utilização é fundamental para avaliação da eficácia das intervenções profissionais baseadas em orientação para mudança de hábitos de vida, possibilitando comparações entre uma consulta e outra (Brayant et al., 2014).

Os participantes também referiram fazer a avaliação antropométrica e a classificação do IMC em gestantes e em pessoas com doenças crônicas. Valores acima da referência como o 
sobrepeso, obesidade e circunferência abdominal aumentada apontam um risco maior de ocorrência de agravos à saúde e devem alertar o enfermeiro para a necessidade de atuação no controle dessa doença crônica (Brasil, 2014b).

A importância da avaliação antropométrica na APS foi corroborada por outros estudos brasileiros (Ferreira et al., 2017; Vieira et al., 2016). Investigação realizada no Estado de São Paulo, Brasil, em 14 UBSs de quatro municípios desse estado, com profissionais de saúde da APS, mostrou a atuação expressiva da equipe de enfermagem na aferição das medidas antropométricas dos usuários, especialmente em adolescentes, gestantes, adultos e idosos. Este estudo ressaltou que a subestimação ou negligência dos dados antropométricos da população podem gerar privação de atendimento àquelas pessoas com necessidade de acompanhamento do peso (Ferreira et al., 2017).

No município de Ouro Preto, Minas Gerais, Brasil, estudo realizado com 68 adultos entre 20 e 57 anos, por meio da avaliação antropométrica e consumo alimentar dos participantes, demonstrou que pessoas com excesso de peso possuem risco aumentado para o desenvolvimento de morbidades. Nesse sentido, a orientação nutricional é fundamental para que essas pessoas possam ser conscientizadas a adotar uma alimentação mais saudável e tenham melhor controle de sua condição crônica (Vieira et al., 2016).

Os enfermeiros participantes deste estudo realizam a Consulta de Enfermagem à gestante durante o pré-natal na UBS e vislumbram esse momento como oportuno para a realização de orientações sobre alimentação saudável na gestação.

O acompanhamento das gestantes do território sob a responsabilidade da UBS é uma das ações preconizadas para o enfermeiro na APS. Durante o pré-natal de baixo risco, as mulheres devem receber orientação nutricional com vistas à manutenção do peso. A recomendação das Diretrizes Brasileiras de Obesidade é de que gestantes que já apresentam sobrepeso ou obesidade devem comparecer à UBS em um intervalo menor do que o fixado no calendário habitual, uma vez que elas apresentam risco aumentado para o desenvolvimento de intercorrências gestacionais (ABESO, 2016).

Uma revisão integrativa da literatura salientou que o excesso de peso gestacional tem grande influência no desenvolvimento do diabetes mellitus gestacional e da doença hipertensiva específica da gestação. Salientou ainda que o IMC pré-gestacional foi o mais importante fator de risco modificável para desenvolvimento dessas doenças, o que mostra a necessidade de intervenções nutricionais e acompanhamento durante o pré-natal, evitando possíveis complicações tanto para mãe quanto para o feto (Oliveira A et al., 2016). Estudo realizado em um município da região oeste de Santa Catarina, Brasil, mostrou que os enfermeiros orientavam 
as gestantes sobre a adoção de hábitos alimentares saudáveis e importância do aleitamento materno com vistas à prevenção da obesidade infantil (Sousa et al., 2015).

Em relação aos usuários com doenças crônicas, os participantes referiram atuar aconselhando a mudança de estilo de vida com adoção de dieta saudável e atividade física. Uma revisão integrativa da literatura mostrou que o enfermeiro é reconhecido como líder na equipe de saúde para a realização de intervenções voltadas para o gerenciamento de DCNTs no âmbito da UBS (Stephen, McInnes, Halcomb, 2018). Pesquisa realizada na Finlândia identificou que o aconselhamento para mudança no estilo vida realizado pelo enfermeiro, durante três anos, resultou na redução de, pelo menos, $5 \%$ do peso inicial em $18 \%$ de pessoas com excesso de peso e comorbidades, sendo que estas conseguiram manter o resultado por três anos. Além disso, a maioria conseguiu estabilizar o peso após as intervenções (Korhonen, Järvenpää, Kautiainen, 2014).

Estudos mostraram uma tendência dos profissionais da APS em realizarem orientações voltadas para a obesidade apenas quando associada a comorbidades. Isso pode impactar negativamente a identificação e o acompanhamento precoce da obesidade entre as pessoas na comunidade (Toledo et al., 2017; Lindemann, Mendoza-Sassi, 2016; Phillips, Wood, Kinnersley, 2014).

Investigação realizada com usuários de UBS em Belo Horizonte, Minas Gerais, Brasil, mostrou que pessoas com HAS e hipercolesterolemia foram mais aconselhadas pelos profissionais da APS para adoção de hábitos saudáveis em comparação com os demais usuários (Toledo et al., 2017). Outro estudo desenvolvido em Pelotas, Rio Grande do Sul, Brasil, com 1.246 usuários da APS, identificou que orientações para uma alimentação saudável eram fornecidas pelos profissionais da APS, especialmente àqueles usuários com maior número de doenças crônicas (Lindemann, Mendoza-Sassi, 2016).

No País de Gales, uma pesquisa mostrou que os profissionais forneciam cuidados regulares para a obesidade apenas aos pacientes que possuíam comorbidades associadas. Além disso, os enfermeiros possuíam opiniões divididas sobre abordar a obesidade com pacientes considerados saudáveis não identificando o que o serviço de APS poderia oferecer a eles (Phillips, Wood, Kinnersley, 2014).

Cabe destacar que, no bojo das intervenções individuais, os enfermeiros da presente pesquisa focalizaram a importância da promoção de hábitos saudáveis de vida. Para efetivar essas intervenções, é estabelecida a relação social do tipo face a face que acontece quando as pessoas envolvidas têm consciência um do outro e compartilham o mesmo tempo e espaço. Ocorre assim, uma interação em que um está ao alcance da experiência direta do outro com o 
qual mantém intercâmbio em um ambiente comunicativo e mútuo (Schütz, 2012). A eficácia dessa intervenção está diretamente relacionada com a qualidade do tipo de relação social estabelecida. Esta relação precisa, por meio da intersubjetividade, aproximar o profissional de saúde e os usuários com obesidade ou com risco de desenvolver essa condição crônica.

Algumas condições clínicas da pessoa com obesidade indicam a necessidade de encaminhamento para o atendimento especializado, nos casos, por exemplo, de pacientes com suspeita de obesidade secundária e indicação para a realização de cirurgia bariátrica. De acordo com as Diretrizes Brasileiras de Obesidade, cabe à APS a responsabilidade pela coordenação do cuidado na RAS, atuando na referência e na contrarreferência aos serviços especializados. Contudo, o encaminhamento da pessoa com obesidade ao nível secundário de saúde não isenta a responsabilidade do profissional da APS de atuar para mudanças no estilo de vida com vistas à perda de peso, que, mesmo modesta, produz benefícios clinicamente significativos para essas pessoas (ABESO, 2016).

Considerando a APS como porta de entrada preferencial do usuário na RAS, esse nível de atenção à saúde apresenta-se como imprescindível para implementar a linha de cuidados das pessoas com obesidade. Nesse sentido, a APS ao buscar prevenir e controlar a obesidade, deve ser ordenadora da assistência para os demais pontos da RAS com manutenção do vínculo com o usuário e garantia da integralidade e longitudinalidade do cuidado (Brasil, 2014b).

Em relação ao encaminhamento de gestantes com obesidade ao nível secundário, um estudo que buscou identificar a prevalência e os fatores de risco associados à gestação de alto risco no município de Paranavaí, Paraná, Brasil, mostrou que tais fatores estavam vinculados às condições clínicas preexistentes, estando a obesidade mórbida evidenciada como um dos fatores mais frequentes entre as gestantes. Esses dados mostram a importância do acompanhamento longitudinal do enfermeiro da APS durante o pré-natal, atentando-se para a necessidade de acompanhamento especializado da gestante em relação ao controle do peso (Melo W et al., 2016).

No caso da obesidade na infância, a Associação Brasileira para Estudo da Obesidade e da Síndrome Metabólica recomenda que os profissionais da APS devem ser capazes de identificar crianças e adolescentes com sobrepeso associado a fatores de risco e com obesidade no território sob a responsabilidade da UBS e encaminhá-los para o serviço especializado. Tal ação terá impacto positivo na redução da mortalidade e no aumento da expectativa de vida, já que o tratamento da obesidade poderá ser iniciado na infância e adolescência (ABESO, 2016). 
O ponto de partida para as atividades grupais realizadas pelos participantes do presente estudo frente à prevenção e ao controle da obesidade é a orientação para uma alimentação saudável e a prática de atividade física.

Em relação à alimentação saudável, pesquisa realizada em João Pessoa, Paraíba, Brasil ressaltou que a APS potencializa o desenvolvimento de práticas educativas em segurança alimentar e nutricional, por meio de grupos educativos, promovendo a aproximação com as famílias, o uso de equipamentos sociais e a disponibilização de profissionais capacitados para esse tipo de atividade (Vasconcelos, Magalhães, 2016).

A orientação alimentar é importante ferramenta para a prevenção de doenças relacionadas ao controle de peso junto ao público em geral e não apenas aos que apresentam obesidade. Como encontrado no presente estudo, investigação realizada na cidade de São Paulo, Brasil, constatou que a grande demanda para grupos educativos que abordavam alimentação e nutrição era de pessoas que já possuíam HAS e diabetes mellitus associados ao quadro de sobrepeso e obesidade (Vincha et al., 2017).

A realização da atividade física, por exemplo, pode trazer benefícios para o controle do peso, especialmente quando combinada a orientação nutricional. Em conformidade com os resultados do presente estudo, em que os enfermeiros incentivam a participação em grupos de caminhada orientada, outro estudo realizado em Amargosa, Bahia, Brasil, analisou os efeitos de um programa de 12 semanas de prática de caminhada orientada e orientação nutricional para mulheres com obesidade e constatou diminuição do valor médio de todos os indicadores de gordura analisados. Além disso, a dobra cutânea subescapular apresentou diferença estatística significativamente menor (Oliveira et al., 2015).

Salienta-se que os enfermeiros participantes do presente estudo não eram responsáveis pelos grupos de caminhada orientada, contudo colaboravam em atividades relacionadas. A participação do enfermeiro em atividades físicas foi discutida em uma pesquisa realizada em Florianópolis, Santa Catarina, Brasil, com dez profissionais que trabalhavam em grupos educativos na APS. Destacou-se que esses profissionais aproveitavam a presença dos usuários nas atividades de caminhada orientada para realizarem atividades de educação em saúde na perspectiva da promoção da saúde, visando à melhoria na qualidade de vida, troca de experiências e construção de vínculo com a comunidade (Maceno, Heidmann, 2016).

Nos grupos de gestantes, a orientação alimentar também é realizada pelos enfermeiros do presente estudo, momento estratégico para o estímulo à adoção de hábitos saudáveis. Estudo de Rio Grande, Rio Grande do Sul, Brasil, que relatou a vivência de acadêmicas de enfermagem 
em grupo de gestantes, mostrou que a estratégia grupal para educação em saúde se apresenta como um instrumento que potencializa o cuidado na APS (Nunes et al., 2017).

Alguns participantes referiram fazer orientação para o controle do peso no grupo operativo voltado para a cessação do uso do tabaco. Este grupo educativo oportuniza ao enfermeiro informar ao usuário que deseja cessar o tabagismo sobre a possibilidade de ganho ponderal após a interrupção do hábito de fumar. Investigação realizada no Brasil acompanhou 135 pacientes em um programa de controle de tabagismo em UBSs do município do Rio de Janeiro e mostrou que pessoas que cessaram o hábito de fumar ganharam peso após três e seis meses. Engordar após a cessação do tabagismo é considerado um dos fatores responsáveis por recaídas ao uso do tabaco (Nascimento, Silva, Nascimento, 2016).

Outra investigação realizada com 62 ex-fumantes brasileiros mostrou que o ganho de peso (48\%) figurou como uma das situações mais referidas pelos participantes (Peuker, Bizarro, 2015). Também um estudo fenomenológico realizado em Juiz de Fora, Minas Gerais, Brasil, apontou que o ganho ponderal de usuários que cessaram o tabagismo foi uma dificuldade relatada por eles para manter a abstinência do tabaco. Identificou-se que o cigarro foi substituído por alimentos, o que gerou ganho de peso (Zampier et al., 2017). Nesse sentido, é preciso orientar que o abandono do cigarro sempre é benéfico e que a adoção de uma dieta saudável pode auxiliar nesse momento.

Em relação à atuação do enfermeiro com crianças e adolescentes na escola e outros equipamentos sociais, os participantes verbalizaram a inexistência de atividades. Salienta-se que a escola representa um espaço estratégico para atuação do enfermeiro junto aos adolescentes no contexto da APS, especialmente na realização de atividades de promoção à saúde (Brasil, 2017c). Por isso, estas atividades devem fazer parte da rotina de enfermeiros atuantes na UBS. Corrobora esses achados a revisão sistemática da literatura que apontou como inexpressiva a participação do enfermeiro nas ações junto às escolas, apesar das políticas indutoras do SUS (Barbiani, Nora, Schaefer, 2016).

Ações de educação em saúde com crianças e adolescentes são relevantes, uma vez que a obesidade instalada na infância e adolescência tende a se perpetuar na vida adulta. Estudo realizado com 212 adolescentes entre 11 e 19 anos de três escolas do município de Picos, Piauí, Brasil, mostrou que $26 \%$ das meninas apresentavam obesidade abdominal (21,5\% estavam na faixa etária de 15 a 19 anos), contra 9,4\% dos meninos. Esses dados reforçam a pertinência de se realizarem ações precoces de avaliação e controle do peso (Alencar et al., 2015).

Parcerias em projetos de educação em saúde podem facilitar a implementação de ações junto a escolares. Investigação no leste da Carolina do Norte (EUA) apresentou um projeto 
realizado por enfermeiros em conjunto com a universidade local com 690 adolescentes do quinto e sexto ano. Os resultados mostraram que a parceria entre o serviço de saúde e a instituição de ensino melhorou o programa de saúde escolar. A temática da obesidade e doenças crônicas foi trabalhada por docentes, estudantes da graduação e enfermeiros, além da realização de exames físicos, testes rotineiros de laboratório, diagnóstico e tratamento de condições comuns da idade, imunizações, serviços de saúde mental, educação em saúde e aconselhamento nutricional (Larson et al., 2015).

A intervenção do enfermeiro com crianças na escola pode influenciar na melhoria da escolha alimentar por esse grupo, resultando em melhores hábitos de saúde no futuro. Estudo desenvolvido na cidade de Floriano, Piauí, Brasil, avaliou uma intervenção educativa do enfermeiro baseada no incentivo aos hábitos alimentares saudáveis com 35 crianças entre 5 a 7 anos em uma pré-escola. Em relação às preferências alimentares antes da intervenção, 56,5\% das crianças afirmaram que gostavam de alimentos saudáveis e 71,3\% gostavam de alimentos que deveriam ser consumidos raramente. Após a intervenção, 76,8\% conseguiram classificar os alimentos considerados saudáveis e $75,5 \%$ os alimentos não saudáveis (Nascimento et al., 2016).

Para a abordagem dos adolescentes, é imprescindível que o enfermeiro utilize recursos adequados à faixa etária e ao seu desenvolvimento. Um estudo realizado em Campo Grande, Mato Grosso do Sul, Brasil, que avaliou o uso de recursos lúdicos e didáticos em grupos educativos com estudantes do Ensino Médio, sobre questões associadas ao diabetes mellitus, obesidade e nutrição mostrou o uso de modelos em "etil vinil acetato" (EVA) para simulação de células, realizou teatro participativo, montou uma cozinha-cenário, usou maquete sobre hipertrofia e hiperplasia adiposa, banner ilustrativo sobre o controle da saciedade, vídeo demonstrando a circulação de lipídeos no organismo, permitiu de modo participativo a observação do quanto eles careciam de informações biológicas sobre as doenças abordadas (Faccioni, Soler, 2018).

O uso da web também pode ser uma importante estratégia na abordagem junto aos adolescentes, visando à mudança de hábitos de saúde. Uma pesquisa realizada na Noruega com adolescentes entre 13 e 15 anos comparou um grupo intervenção que recebeu 12 semanas de acesso a um programa on-line com aconselhamento personalizado de atividade física e outro grupo que recebeu o acompanhamento padrão dos enfermeiros. O grupo de intervenção teve um aumento significativamente menor do IMC em relação ao grupo controle (Riiser et al., 2014). 
É importante salientar que, geralmente, os adolescentes mostram-se como um grupo populacional de difícil acompanhamento devido ao baixo comparecimento às UBSs. Assim, o trabalho na escola torna-se relevante especialmente no que diz respeito às ações de prevenção da obesidade.

A atenção aos adolescentes voltada para o controle do peso faz parte do cuidado integral na RAS e na APS. Para a efetivação dessa frente de cuidado, torna-se fundamental a realização de articulações intersetoriais, entre o serviço, as escolas e outros equipamentos sociais que possam contribuir com a promoção da saúde e a prevenção de agravos (Brasil, 2017c).

Salienta-se que a situação biográfica do enfermeiro, na condição de conhecedor de medidas de prevenção e controle da obesidade e de técnicas grupais, auxilia a sensibilização dos usuários das UBSs para adoção de hábitos saudáveis de vida. A situação biográfica inclui o ambiente físico e sociocultural definido pelo homem, assim como suas crenças e valores morais e ideológicos que compõem o mundo social (Schütz, 2012).

O mundo social caracteriza-se pelas relações de uns com os outros, essenciais para a compreensão entre os seres humanos. Trata-se do mundo da vida cotidiana, onde ao mesmo tempo influenciamos e sofremos influências (Schütz, 2012). Nesse sentido, as dificuldades exteriorizadas pelos enfermeiros em relação às ações voltadas para as questões da obesidade, primeiramente, referem-se ao modo como os usuários vivenciam essas questões. Desse modo, o conjunto de crenças e valores dos usuários deve ser considerado pelo enfermeiro ao promover estratégias de enfrentamento da obesidade.

Os enfermeiros mencionaram a resistência dos usuários à mudança de comportamento, o que compromete a adoção de hábitos saudáveis de vida e o controle dos problemas crônicos de saúde. Esse resultado foi corroborado por uma pesquisa realizada em Portugal com enfermeiros, médicos e nutricionistas da APS. Em seus discursos sobre a obesidade, os profissionais de saúde apontaram crenças e atitudes negativas em relação às pessoas com excesso de peso. Essas pessoas eram descritas como desmotivadas e passivas face ao tratamento (Teixeira, Pais-Ribeiro, Maia, 2015).

A dificuldade de adesão das pessoas em grupos educativos propostos pela APS também foi ressaltada na literatura (Andrade et al., 2013; Soares et al., 2017). Pesquisa realizada em um município de Santa Catarina, Brasil, com oito enfermeiros, identificou que a baixa adesão da comunidade às atividades grupais foi mencionada pela maioria dos participantes como um dos principais dificultadores para a continuidade das ações, impactando a efetividade do grupo e o tratamento dos usuários (Andrade et al., 2013). 
Em Campinas, São Paulo, Brasil, estudo desenvolvido com 150 pessoas que apresentavam obesidade, com idade entre 21 e 60 anos, concluiu que, entre os principais motivos de abandono do tratamento para perda de peso, estavam a falta de tempo dos usuários, dificuldade de transporte e autoconfiança (Soares et al., 2017).

Questões relativas à organização e ao planejamento das atividades no serviço também podem interferir na adesão do usuário aos grupos educativos. Estudo que avaliou os grupos de gestantes na APS no município de Niterói, Rio de Janeiro, Brasil, mostrou que, entre os principais motivos para a não adesão das mulheres às atividades, estavam a falta de planejamento participativo da comunidade, os meios de divulgação ineficientes, escolha aleatória das datas, cancelamentos e remarcações das reuniões (Pereira et al., 2017).

Para a realização de ações coletivas efetivas em relação ao peso, é essencial que o profissional da APS contextualize as atividades de acordo com a realidade das pessoas da comunidade de modo a favorecer o vínculo no serviço de saúde e compreenda o contexto das DCNTs na atualidade e seu impacto na vida das pessoas (Brasil, 2016).

Na APS, o vínculo entre os usuários e os profissionais de saúde é uma importante estratégia que se concretiza por meio da construção de relações estabelecidas no acolhimento, na responsabilização entre as partes e na confiança mútua entre profissional e usuário. Um estudo realizado em Natal, Rio Grande do Norte, Brasil, que investigou a percepção da equipe multiprofissional sobre a importância do vínculo na APS, identificou que este é uma ferramenta de consolidação da ESF no SUS e está articulado com o processo de trabalho nesse nível de atenção. Além de possibilitar o conhecimento acerca das subjetividades, individualidades e condições de vida das famílias, o vínculo pode ser utilizado como um recurso capaz de organizar o relacionamento entre equipes de saúde e a população usuária (Santos, Miranda, 2016).

Considerando a obesidade, o vínculo entre o profissional de saúde e o usuário é de grande valia na medida em que aumenta a confiança nas orientações profissionais, influenciando positivamente a adesão ao tratamento. Para tal, é importante o desenvolvimento de um plano de cuidado que considere os desejos, realidades e limitações dos usuários, fortalecendo-os para serem corresponsáveis pelo controle do peso (Brasil, 2014b).

A existência de limitações no serviço onde atuam, dificultando a realização de ações de prevenção e controle da obesidade, foi mencionada pelos participantes. Estes resultados são corroborados por outro estudo brasileiro realizado no nordeste do Brasil. O estudo objetivou avaliar as ações educativas em segurança alimentar e nutricional realizadas por profissionais de uma UBS e constatou que essas ações ocorriam de forma fragmentada e descontinuada. Isso 
devido a fatores como excesso de demanda dos profissionais, falta de fornecimento de insumos pela gestão e condições de vida desfavoráveis dos usuários, bem como formação profissional limitada na temática (Vasconcelos, Magalhães, 2016).

Em outra pesquisa realizada no Brasil, constatou-se que recursos humanos, físicos, materiais e financeiros foram considerados indispensáveis para a realização da vigilância alimentar e nutricional no âmbito da APS, bem como para o aumento da cobertura da população monitorada, diagnóstico precoce dos agravos nutricionais e melhoria na qualidade dos dados fornecidos ao Sisvan (Vitorino, Cruz, Barros, 2017).

A equipe de saúde da UBS reduzida frente à grande demanda da população foi uma dificuldade relatada. Para o atendimento dos objetivos propostos pela APS, é fundamental que as equipes de saúde estejam dimensionadas de acordo com o número de habitantes do território de abrangência da UBS, o que favorece o conhecimento das necessidades da população, bem como o planejamento e execução das ações (Brasil, 2017b). Estudo realizado no município de São Paulo, Brasil, com profissionais de saúde, dos quais 14 eram enfermeiros, mostrou que a indisponibilidade de recursos humanos na UBS impactava negativamente as ações multidisciplinares. Nesse sentido, a escolha de estratégias para o desenvolvimento dos grupos educativos sobre alimentação e nutrição, por exemplo, estava diretamente relacionada com o quantitativo de pessoal disponível, demandando do enfermeiro habilidades de adequação das ações de acordo com os recursos acessíveis no serviço de APS (Botelho et al., 2016).

Cabe ressaltar que, no presente estudo, algumas UBSs onde os enfermeiros participantes atuam funcionam a partir do modelo tradicional ou misto de atenção à saúde. Por não funcionarem de acordo os princípios da ESF, não há exigência de formação das equipes de saúde, segundo o dimensionamento da população, o que pode prejudicar o desenvolvimento das atividades profissionais.

Além do número reduzido de profissionais na equipe, a rotina do enfermeiro apresentase repleta de demandas preconizadas pela gestão, em detrimento de atividades condizentes com as necessidades da população do território adstrito. Corroborando com esse achado, investigação realizada com equipes de saúde de 20 UBSs em Campina Grande, Paraíba, Brasil, mostrou que a falta de tempo, o excesso de trabalho e a alta demanda foram relatados pelos profissionais de saúde como as principais dificuldades para efetivação das ações no campo da alimentação e nutrição na APS (Pedraza, Menezes, Costa, 2016).

A obesidade é uma doença multifatorial tornando seu enfrentamento uma tarefa complexa e demandando, portanto, de um trabalho multiprofissional. A equipe de saúde, desenvolvendo ações interdisciplinares, pode ser considerada um fator decisivo para a melhora 
da qualidade de vida e diminuição das enfermidades destes pacientes. Estudos nacionais e internacionais apontaram impactos positivos acerca das atividades de prevenção e controle da obesidade realizadas por equipes multiprofissionais na APS (Almeida A et al., 2017; Gorin et al., 2014; Costa et al., 2014).

Estudo que relatou a experiência de uma equipe multiprofissional em atividade de educação alimentar e nutricional em uma UBS de Maceió, Alagoas, Brasil, apontou impactos positivos na condição de saúde dos usuários participantes. Constatam-se redução do peso e da pressão arterial, mudança de práticas alimentares na família (redução do consumo do sal, açúcar, alimentos industrializados e aumento no consumo de saladas e frutas), maior cuidado na preparação dos alimentos e maior dedicação à realização da caminhada (Almeida A et al., 2017).

Nos EUA, um ensaio clínico realizado durante 12 meses, com médicos e enfermeiros da APS que atuavam com famílias de crianças entre 2 e 4 anos, identificou que as intervenções de aconselhamento visando à mudança de hábitos saudáveis por meio de consultas individuais na UBS e visitas domiciliares foram capazes de gerar redução no percentil do peso de crianças (Gorin et al., 2014).

Estudo desenvolvido em Maracanaú e Fortaleza, Ceará, Brasil, de abordagem qualitativa, realizado com enfermeiros, dentistas, médicos, fisioterapeutas e fonoaudiólogos vinculados a quatro UBSs e ao Nasf de referência, evidenciou que a atuação em equipe pode ser capaz de impactar a resolubilidade das ações na APS por meio de práticas que valorizem a discussão dos casos, o compartilhamento e a responsabilização do cuidado (Costa et al., 2014).

Ressalta-se que, no município cenário deste estudo, as equipes mínimas atuantes nas UBSs são compostas por enfermeiro, médico, técnico de enfermagem e Agentes Comunitários de Saúde (ACSs), não existindo Nasf. No âmbito da alimentação e nutrição, o Nasf pode atuar no sentido de ampliar e qualificar a análise da APS sobre a situação alimentar e nutricional da população, apoiando a implementação de ações no campo da atenção nutricional (Brasil, 2017d).

A literatura mostrou resultados positivos quando os serviços de APS contam com a parceria do Nasf (Melo A et al., 2016; Rosa, Sales, Andrade, 2017). Estudo realizado em Guarabira, Paraíba, Brasil, relatou a implementação e desenvolvimento de um grupo terapêutico com pessoas com sobrepeso e obesidade baseado em oficinas educativas e práticas corporais em uma UBS em parceria com profissionais do Nasf e mostrou que a intervenção levou a perda de peso, melhora nos níveis pressóricos, mudanças nos hábitos alimentares e melhor qualidade de vida (Melo A et al., 2016). 
Em um município da região sudeste do Brasil, uma investigação que utilizou a antropometria na APS para o diagnóstico e acompanhamento do crescimento de crianças e adolescentes em parceria com o Nasf apontou que a ação realizada com 200 participantes, proporcionou a sensibilização dos pais ou responsáveis quanto à prevenção de agravos à saúde, levando-os a refletir sobre seus hábitos alimentares (Rosa, Sales, Andrade, 2017).

Na presente pesquisa, os enfermeiros participantes atuavam em UBSs com equipes de saúde cujos componentes variam, prevalecendo a equipe mínima. Algumas equipes possuíam profissionais em conformidade com o modelo tradicional ou misto. Já nas equipes de ESF, algumas UBSs possuíam, além da equipe mínima, um ou mais dos seguintes profissionais: cirurgião-dentista, assistente social, farmacêutico, técnico de saúde bucal ou profissional de educação física. A inexistência de uma uniformização nas equipes de saúde pode impactar negativamente a padronização de ações de prevenção e controle da obesidade no município.

O desenvolvimento de ações no campo da obesidade, especialmente no controle dessa doença crônica demanda uma estrutura do serviço de saúde que inclui a disponibilização de equipamentos compatíveis com peso dos indivíduos, além de materiais educativos e espaço físico para a realização de atividades educativas coletivas. A inexistência desses recursos pode interferir no poder de resolução da APS e é considerada uma limitação para a implementação da Linha de Cuidado do Sobrepeso e da Obesidade na Rede de Atenção à Saúde das Pessoas com Doenças Crônicas (Brasil, 2014a).

Corroborando as dificuldades relativas ao serviço encontradas no presente estudo, pesquisa realizada em seis UBSs de São Luís, Maranhão, Brasil, identificou obstáculos enfrentados pelo enfermeiro na prevenção da obesidade infantil, entre os quais se encontrava a falta de recursos materiais utilizados nos atendimentos e grupos educativos, além de limitações físicas da UBS que prejudicavam as ações profissionais (Matos et al., 2015). Também estudo realizado com 18 enfermeiros de APS na Suécia apontou que a deficiência de recursos físicos e a desorganização do serviço de saúde limitavam os participantes em sua atuação na prevenção do sobrepeso e obesidade infantil, resultando na concepção de que esta é uma tarefa difícil de ser desenvolvida pelos profissionais nesse nível de atenção à saúde (Isma et al., 2013).

Segundo os enfermeiros, o acesso aos serviços especializado no SUS é difícil e marcado por filas de espera para consulta, especialmente para o endocrinologista e nutricionista. Nesse sentido, outro estudo brasileiro realizado com 15 profissionais de saúde da APS do Estado do Rio de Janeiro, Brasil, identificou que, em relação às pessoas com obesidade, a falha no acesso ao especialista foi a principal dificuldade que implicou a evolução da doença para graus mais avançados (Marchon, Mendes Júnior, Pavão, 2015). No Estado do Paraná, Brasil, uma pesquisa 
com gestores de saúde mostrou que as especialidades de endocrinologia e nutrição estão entre as mais difíceis de encaminhamento (Silva et al., 2017). Observa-se, portanto, que, na atualidade o serviço de referência brasileiro ainda é uma limitação da RAS que impacta a continuidade do cuidado à pessoa com obesidade.

Ressalta-se que, mesmo encaminhando as pessoas com obesidade para o nível secundário de atenção, muitas necessidades dessas pessoas devem ser solucionadas na APS. Nesse sentido, os "Protocolos de Encaminhamento da Atenção Básica para Atenção Especializada" apontam que é fundamental uma ampliação do cuidado clínico e da resolubilidade na APS com vistas a esgotar as possibilidades de cuidado aos usuários nesse nível de atenção (Brasil, 2015d). Além disso, cabe à gestão municipal a definição de metas para resolução das demandas das pessoas com obesidade na APS, prevendo a redução dos encaminhamentos para atenção especializada, muitas vezes desnecessários.

O conhecimento limitado na temática da obesidade foi outra dificuldade mencionada pelos participantes. Este resultado também foi encontrado por outros estudos de abrangência nacional e internacional (Almeida L et al., 2017; Dietz et al., 2015; Blackburn et al., 2015). Uma revisão sistemática da literatura mostrou que os profissionais de saúde são mal preparados para atuar com obesidade. Suas condutas são fortemente influenciadas por concepções preconceituosas sobre as pessoas com obesidade. Têm dificuldades para utilizar estratégias de mudança de comportamento, pouca capacidade de trabalhar colaborativamente com equipes interprofissionais e de integrar abordagens clínicas e comunitárias para a perda do peso da população. Os resultados da pesquisa apontaram a necessidade de mudança na formação de modo a superar o modelo de cuidados de eventos agudos e de avançar na melhoria do atendimento das necessidades das pessoas com doenças crônicas, altamente prevalentes na atualidade (Dietz et al., 2015).

Também uma revisão integrativa da literatura que objetivou identificar estratégias e desafios da gestão da APS no controle e na prevenção da obesidade destacou como uma das dificuldades para o enfrentamento desse agravo a falta de capacitação dos profissionais de saúde, o que prejudica o aconselhamento da população para a mudança de hábitos de vida (Almeida L et al., 2017). Na Inglaterra, estudo identificou, entre outras percepções dos enfermeiros, que estes profissionais possuem compreensão limitada sobre cuidados com obesidade, o que se constitui em uma barreira para a prática na APS no que tange à prevenção e ao controle desse agravo de saúde (Blackburn et al., 2015). Tendo em vista a alta prevalência desse agravo à saúde na atualidade, a qualificação dos profissionais de saúde no nível da APS para as questões relacionadas às doenças crônicas, como a obesidade, torna-se imprescindível. 
Na vida cotidiana, a situação biográfica e o acervo de conhecimentos da pessoa/grupo social servem como esquema interpretativo das experiências passadas e presentes, embasando os projetos de vida (Jesus et al., 2013). Desse modo, a experiência do grupo de enfermeiros participantes do presente estudo que atua na prevenção e no controle da obesidade foi expressa pela realização de ações individuais e grupais, permeadas por dificuldades relativas às resistências do próprio usuário para aderir às mudanças de hábitos de vida e obstáculos relativos ao serviço (motivos porque). Expressa também as expectativas que emergem da reflexão de sua prática, revelando a possibilidade de mudanças frente à obesidade, com vistas ao cuidado qualificado de usuários sob sua responsabilidade no contexto da APS (motivos para).

Conhecer o perfil de consumo alimentar e do peso da população da área de abrangência da UBS foi uma expectativa de atuação dos enfermeiros frente à obesidade. Os profissionais reconhecem que a condição alimentar e de saúde dos usuários sob sua responsabilidade deve ser o ponto de partida para a realização de atividades de prevenção e controle da obesidade. Desse modo, o enfermeiro deve estar apto a fazer o diagnóstico situacional do peso da população em articulação com a equipe de saúde, identificando o perfil alimentar e as situações de risco das pessoas sob sua responsabilidade (Brasil, 2015b).

O Ministério da Saúde estabelece como prioridade na APS a avaliação de marcadores de consumo de alimentos, uma vez que conhecer o padrão alimentar da população é essencial para orientar as estratégias de atenção integral à saúde. A análise da situação de saúde da população deve ser feita de maneira abrangente e as ações decorrentes dos resultados encontrados no perfil de consumo alimentar devem ser implementadas no âmbito individual e coletivo, levando-se em consideração os fatores de risco para o desenvolvimento da obesidade presentes na comunidade (Brasil, 2015b).

Salienta-se que a Secretaria Municipal de Saúde do município onde o presente estudo foi realizado pactuou com as UBSs o preenchimento de instrumentos que tratam dos marcadores alimentares, porém observou-se, nos depoimentos, a baixa aderência das equipes de saúde a esta recomendação. Os depoimentos mostraram a inexistência de grupos específicos para o controle da obesidade. A expectativa de implantar esses grupos e obter adesão dos usuários nas atividades desenvolvidas foi expressa como intencionalidade dos enfermeiros frente à sua atuação na obesidade.

A literatura mostrou que o trabalho de grupo associado a intervenções individuais pode trazer impactos positivos para os usuários com obesidade (Jarl et al., 2014; Vannuchi et al., 2016). Estudo realizado nos EUA avaliou orientações dietéticas para mudanças de estilo de vida feitas por enfermeiros a pessoas com obesidade em atividades grupais intercaladas por contatos 
telefônicos. $\mathrm{O}$ aconselhamento resultou em melhorias estatisticamente significativas na dieta e nos escores de estilo de vida, bem como significativa perda de peso e manutenção do IMC (Jarl et al., 2014).

Pesquisa realizada em uma UBS do Norte do Paraná, Brasil, analisou o impacto da intervenção multiprofissional em grupo no tratamento de mulheres com excesso de peso e obesidade. A intervenção baseada no aconselhamento nutricional, na prática do exercício físico e ações da psicologia voltadas para a motivação e mudança comportamental, por um período de 12 semanas, levou à redução significativa do peso, da circunferência da cintura e do IMC. Foram observadas também mudanças importantes nos hábitos de vida como o aumento do nível de atividade física, aumento do consumo de fibras e redução do sal, alimentos industrializados, açúcares e frequência do consumo de carnes vermelhas (Vannuchi et al., 2016).

O Ministério da Saúde recomenda que, para as pessoas com obesidade, as equipes da APS devem realizar planos de cuidado que incluam a participação nos grupos operativos para o controle do peso, uma vez que estes otimizam a oferta do cuidado, levando em conta a crescente demanda nas UBSs, gerando melhores resultados (Brasil, 2014b).

Para potencializar a adesão do usuário às atividades grupais de prevenção e controle da obesidade, os enfermeiros referiram o desejo de ampliar a parceria da UBS com outros equipamentos sociais da sua área de atuação. A parceria com equipamentos sociais do território contribui para o fortalecimento e ampliação das atividades desenvolvidas na APS, alcance de resultados que atendam às necessidades de saúde da população por meio do comprometimento local nas necessidades de saúde da população, como a obesidade (Brasil, 2017b).

Corroborando a relevância da articulação entre os diferentes equipamentos sociais no enfrentamento da obesidade, os resultados de uma revisão sistemática da literatura que objetivou a reflexão sobre a importância das Políticas Públicas voltadas para a obesidade mostrou que as ações nessa temática devem possuir caráter intersetorial, envolvendo estratégias no âmbito da saúde, educação, cultura, entre outras. Essa interação se faz necessária devido ao caráter multifatorial do agravo, demandando práticas amplas e integradas, de modo permanente e que favoreçam a adesão dos usuários aos serviços de saúde (Rech et al., 2016).

Ao refletir sobre sua prática no que tange às ações de prevenção e controle da obesidade, os enfermeiros referiram que as atividades fora da UBS são esporádicas ou mesmo inexistentes. Nesse sentido, os participantes expressaram a expectativa de atuar em outros equipamentos sociais, especialmente em escolas.

A literatura salienta a importância das intervenções da equipe multiprofissional, particularmente do enfermeiro, voltadas à prevenção e ao tratamento da obesidade em crianças 
e adolescentes em escolas (Martin et al., 2014; Banfield, McGorm, Sargent, 2015; Pbert et al., 2016).

Uma revisão sistemática da literatura constatou que intervenções para a mudança do estilo de vida realizadas por profissionais de saúde no ambiente escolar podem melhorar o desempenho escolar e a função cognitiva em crianças e adolescentes com sobrepeso ou obesidade em comparação com o cuidado convencional realizado por profissionais que não realizam educação em saúde (Martin et al., 2014).

Pesquisa realizada na Austrália com enfermeiros da APS, diretores de escolas, estudantes e pais constatou que os enfermeiros são uma fonte respeitada de informações sobre saúde nas escolas e são capazes de contribuir com crianças e adolescentes por meio de ações de promoção da saúde e prevenção precoce de agravos (Banfield, McGorm, Sargent, 2015).

Estudo randomizado avaliou ações baseadas em aconselhamento de escolares sobre a redução do peso em oito escolas de Massachusetts, EUA. Os resultados demonstraram que os estudantes que participaram das 12 intervenções com enfermeiros melhoraram seus hábitos alimentares, como a adoção do hábito do consumo do café da manhã anteriormente não realizado pelos escolares (Pbert et al., 2016).

Para concretizar a expectativa dos enfermeiros participantes do presente estudo de realizar atividades com escolares, no que diz respeito à promoção de saúde e prevenção de doenças crônicas, como a obesidade, estas atividades devem ser colocadas em pauta na agenda de trabalho das equipes de saúde da UBS (Brasil, 2017c).

Alguns enfermeiros salientaram limitações no conhecimento e de participação em ações de educação permanente que dificultam sua atuação na APS em relação à obesidade. Desse modo, receber capacitação para atuar na prevenção e no controle da obesidade foi também uma expectativa dos enfermeiros deste estudo.

Pesquisa realizada na Austrália que visou compreender as práticas e atitudes de enfermeiros na APS em relação ao excesso de peso e à obesidade identificou que $85 \%$ dos profissionais mostraram interesse em se capacitar para fazer prevenção da obesidade infantil (Robinson et al., 2013). Nos EUA, estudo realizado com médicos e enfermeiros da APS demostrou, entre outros resultados, que os profissionais tinham interesse em capacitações para melhor lidarem com o tratamento da obesidade infantil na comunidade em que atuavam (Findhout, Davis, Michael, 2013).

Salienta-se que, para realizar ações articuladas e efetivas, os diferentes profissionais que constituem as equipes de saúde devem receber, desde a formação básica, conteúdos que os instrumentalizem para atuação na lógica da integralidade do cuidado. Uma pesquisa realizada 
em São Paulo, Brasil, com docentes, trabalhadores e estudantes de saúde, identificou a necessidade de os profissionais em formação aprenderem a trabalhar juntos para superação do modelo biomédico, voltando-se para um cuidado centrado no usuário e na população e não somente nos serviços de saúde e profissionais (Silva et al., 2015).

Para que isso ocorra, faz-se necessário extrapolar o trabalho em equipe multiprofissional tradicionalmente concebido, vislumbrando uma perspectiva de interprofissionalidade. Isso requer aprofundar os saberes e as práticas no campo da saúde, principalmente em função da crescente complexidade dos problemas de saúde demandados. Um estudo utilizando a abordagem da realidade social do trabalho de uma equipe de ESF, em Belo Horizonte, Minas Gerais, Brasil, identificou a adoção de práticas colaborativas pelos profissionais da APS que resultavam em cuidado integral e segurança do paciente, avançando para uma lógica do cuidado interprofissional (Escalda, Parreira, Cyrino, 2017).

Segundo os depoimentos, há carência de preparo para atuação na obesidade, desde a graduação. Além disso, a capacitação em serviço é insuficiente, o que gerou nos participantes a expectativa de ser capacitado para o trabalho na obesidade. Além da formação básica, a educação permanente em saúde é considerada uma importante ferramenta no cotidiano de trabalho do enfermeiro, assim como uma possibilidade de busca de novos conhecimentos com vistas à melhoria do cuidado em enfermagem, como mostrou um estudo realizado no Rio Grande do Sul, Brasil (Weykamp et al., 2016).

A fenomenologia social como referencial teórico-metodológico utilizado neste estudo permitiu a compreensão dos significados subjetivos imbricados na experiência do enfermeiro ao realizar ações de prevenção e controle da obesidade. Contudo, por este ser um estudo qualitativo, os resultados apresentados constituem evidências que traduzem características específicas do grupo estudado. Este grupo social pertencente a uma realidade que pode diferenciar-se de outra, o que impede a generalização dos resultados. Por isso, outras possibilidades investigativas precisam ser implementadas. 
7 IMPLICACÕES DO ESTUDO PARA A PRÁTICA PROFISSIONAL 


\section{IMPLICAÇÕES DO ESTUdO PARA A PRÁTICA PROFISSIONAL}

A compreensão da experiência dos enfermeiros em relação à prevenção e ao controle da obesidade no contexto da APS, no cenário estudado, possibilitou destacar aspectos importantes que devem ser considerados na prática por esses profissionais.

A educação em saúde foi identificada como uma das estratégias mais importantes, utilizada pelos profissionais para a prevenção da obesidade e o controle do peso na APS tanto em atividades individuais quanto coletivas. Nesse sentido, a atuação dos enfermeiros precisa voltar-se para o apoio ao autocuidado no que diz respeito à orientação, visando à escolha por hábitos saudáveis que levem à melhoria da qualidade de vida. Esse apoio precisa levar em consideração os conhecimentos prévios dos usuários e seu contexto socioeconômico e cultural.

Os participantes do presente estudo relataram a influência familiar e social nos hábitos de vida das pessoas, portanto as ações profissionais devem levar em conta o contexto familiar e o comunitário nos quais emergem os valores simbólicos relacionados à alimentação. Isso faz com que o enfermeiro supere a atuação meramente prescritiva dos cuidados para considerar aspectos subjetivos relacionados aos valores pessoais acerca do processo saúde-doença. Desse modo, ressalta-se a importância da elaboração de projetos terapêuticos singulares com base em uma abordagem integral do cuidado para prevenção e controle da obesidade baseada em equipes multiprofissionais com atuação transdisciplinar, incorporando metodologias de planejamento e gestão participativa, colegiada e avançada na gestão compartilhada dos cuidados aos usuários.

Conforme apontam os resultados da presente pesquisa, não existe uma rotina de atendimentos programados para a assistência profissional à pessoa com obesidade no contexto da UBS. As orientações para a adoção de hábitos saudáveis de vida eram realizadas pelos enfermeiros em ações individuais e coletivas voltadas aos diferentes públicos já assistidos na UBS, independentemente de possuírem ou não o excesso de peso. No caso da assistência às pessoas com obesidade, considera-se relevante a reformulação das práticas profissionais de modo a contemplar especificamente esses usuários no cotidiano do serviço.

Entre as ações possíveis de ser realizadas no âmbito da APS, ressalta-se o acolhimento da pessoa com obesidade, independentemente de possuir doenças associadas; grupo interdisciplinar para o controle do peso; visita domiciliar para pessoas com obesidade que possuem dificuldade de locomoção; o encaminhamento para serviços de referência quando necessário (terapias complementares e integrais, nutricionista, endocrinologista, psicólogo, terapia de grupo e cirurgia bariátrica), atividades físicas (caminhada orientada, hidroginástica) 
(Brasil, 2014b); além de incentivo aos hábitos saudáveis de vida, incluindo o estímulo à promoção de horta comunitária e participação em oficina culinária (Brasil, 2014d).

Observou-se que as DCNTs, especialmente o diabetes mellitus e a HAS, apresentam-se como importante foco nas ações individuais e grupais com adultos na APS. Porém, sabe-se que muitas pessoas com agravos crônicos possuem obesidade, que muitas vezes passa despercebida pelos profissionais de saúde, situação que precisa ser revista pelas equipes. Nesse sentido, atuar com foco na prevenção à saúde e não na doença pode ser uma maneira de reorganizar as ações na UBS, racionalizando o tempo e os recursos destinados às ações, de modo a assistir as pessoas de forma integral e não fragmentada (Cervato-Mancuso; Vincha; Santiago, 2016).

Ações coletivas de promoção da saúde e controle de agravos são realizadas majoritariamente nos grupos de caminhadas e aproveitando os grupos operativos já instalados na UBS, como grupo de gestantes e de tratamento do tabagismo. A caminhada orientada, embora não seja uma atividade prioritariamente coordenada por enfermeiros, pode constituirse em um espaço de trabalho efetivo multiprofissional com reflexos positivos para a redução do peso e prevenção de agravos à saúde. Observa-se um aumento na oferta dessas práticas nas UBSs, favorecendo o acesso do usuário à atividade física, porém ainda são necessários avanços para a compreensão dessas práticas como potentes ferramentas para a obtenção de benefícios biológicos como a melhoria das taxas de glicemia, pressão arterial, perda de peso, entre outras, assim como o fortalecimento da autonomia e protagonismo da pessoa em prol da sua saúde (Carvalho, Nogueira, 2016).

Os resultados mostraram que os enfermeiros não realizam grupo específico para o tratamento da obesidade, o que gerou nos entrevistados a expectativa de implantá-lo. As políticas nacionais sugerem que pessoas com sobrepeso e obesidade, independentemente de possuírem doença crônica associada, sejam incluídas em grupos operativos de estímulo à alimentação saudável e atividade física, contando com a participação efetiva dos usuários. Características em comum dos participantes dos grupos, como o mesmo estágio de interesse para mudanças em relação à perda de peso, mesmas necessidades e interesses podem favorecer a troca de experiências e o enfrentamento das dificuldades por pessoas que estão com excesso de peso (Brasil, 2014b). Salienta-se que as práticas educativas precisam ser organizadas tendo como eixos centrais a promoção da saúde e o incentivo à adoção de padrões alimentares sustentáveis que preservem a saúde, considerando os aspectos culturais, sociais, os recursos naturais e o prazer relacionado à alimentação (Brasil, 2014b).

Merece destaque a expectativa dos participantes de conhecer o diagnóstico situacional do peso da população sob sua responsabilidade. Essa prática deve ser incentivada na medida 
em que, ao conhecer o perfil do peso das pessoas, a equipe de saúde pode identificar indivíduos em risco que necessitam de intervenção imediata, além do acompanhamento daqueles que vêm tendo aumento de peso importante ao longo do tempo. Nessa perspectiva, conhecer o consumo alimentar da população fornece subsídios para a APS organizar o cuidado integral dos usuários sob sua responsabilidade, uma vez que a prática alimentar está diretamente relacionada ao estado nutricional das pessoas e consequentemente às suas condições de saúde. Assim, o reconhecimento dos alimentos e comportamentos relacionados aos hábitos alimentares é uma necessidade atual dos serviços de saúde na APS frente ao aumento no consumo de alimentos processados identificados nos últimos inquéritos populacionais no Brasil (Brasil, 2015b).

Segundo os enfermeiros, ações educativas na escola sobre hábitos saudáveis de vida, com ênfase na alimentação, não fazem parte da rotina do profissional que atua na UBS. Demonstrando conhecer a relevância de atuar em atividades de promoção da saúde e prevenção de agravos não somente no espaço das UBSs, mas também nos equipamentos sociais da comunidade, o enfermeiro traz como uma de suas expectativas a implantação de trabalhos educativos na escola.

Salienta-se a relevância do papel da equipe multiprofissional no âmbito da APS, na qual o enfermeiro ocupa lugar de articulador no desenvolvimento de ações de promoção da saúde e prevenção de agravos, especialmente com crianças e adolescentes (Oliveira D et al., 2016). O trabalho em equipe é capaz de criar uma relação de compartilhamento do cuidado e discussão dos casos. Considerando que o enfermeiro não atua sozinho, ressalta-se a importância da equipe multiprofissional como estratégia de trabalho na APS, com vistas a lidar com as questões que dificultam a prevenção e o controle da obesidade.

A articulação do setor saúde com outros equipamentos sociais foi referida pelos enfermeiros como uma necessidade e importante estratégia para o fortalecimento das ações da APS no campo da obesidade. Nesse sentido, a soma de esforços intersetoriais deve resultar em ações que incentivem as pessoas a adotarem um estilo de vida mais saudável, com vistas à prevenção do ganho de peso. No contexto da APS, no momento da territorialização, deve-se levar em conta a existência de locais existentes na comunidade para realização de atividades físicas e de comercialização de alimentos. Para potencialização das ações realizadas pela UBS, os profissionais de saúde devem identificar quais políticas públicas (projetos e programas) existem na comunidade para prevenção e controle da obesidade, como a presença de instituições religiosas, lideranças comunitárias, Organizações não governamentais, empresas da iniciativa privada, universidades e outros serviços que podem contribuir com as ações desenvolvidas pela UBS (Brasil, 2017b). Além dos equipamentos presentes no território, ressalta-se a necessidade 
da participação popular nas instâncias colegiadas como os Conselhos Locais e Municipais de Saúde e os Conselhos de Segurança Alimentar e Nutricional, buscando o fortalecimento das ações de prevenção e controle da obesidade realizadas no âmbito da UBS (Brasil, 2013a).

Entre as dificuldades que impactam a atuação do enfermeiro, merece destaque a resistência dos usuários às mudanças de comportamento, o que gera no enfermeiro um sentimento de frustração e o desmotiva para o trabalho com a prevenção e controle da obesidade. É preciso compreender que a obesidade é uma doença complexa, cujo enfrentamento não se dá de forma linear, havendo necessidade de uma abordagem multifatorial que contemple o conceito ampliado de saúde (Dias et al., 2017).

Para a superação das dificuldades relacionadas à mudança de hábitos de vida das pessoas, ressalta-se ser imprescindível que o enfermeiro se aproprie do cotidiano dos usuários sob sua responsabilidade, com vistas a adequar as orientações às reais possibilidades de as mesmas serem seguidas. Neste contexto, o conhecimento do universo dos aspectos influenciadores dos hábitos de vida poderá subsidiar a orientação que considere a realidade cultural dessas pessoas.

A postura do enfermeiro em relação à corresponsabilização do cuidado pode ajudar o usuário com obesidade a superar suas dificuldades em relação a perda e controle de peso. Por isso, enfatiza-se a relevância de o profissional apoiar os usuários para tornarem-se autocuidadores. Para tal, as pessoas precisam de informações sobre como lidar com sua condição crônica e ser motivadas para promover mudanças de comportamento com vistas à melhoria da qualidade de vida. Portanto, as intervenções realizadas pelos enfermeiros, mesmo que não resultem em mudanças consideráveis nos hábitos de vida, podem impactar positivamente a vida das pessoas.

O estabelecimento de ações conjuntas da equipe de saúde na APS, em que o enfermeiro geralmente é o coordenador, pode viabilizar a prática do trabalho voltada para questões alimentares e nutricionais da população. A atuação do ACS, por exemplo, pode ser fundamental na busca ativa por pessoas com alteração de peso na comunidade e colaboração no segmento do cuidado, favorecendo a adesão ao tratamento.

Os profissionais de saúde da APS devem estar comprometidos com o fortalecimento das ações de prevenção e controle da obesidade como linha de cuidado da RAS. Nesse sentido, devem atuar na vigilância alimentar e nutricional da população, realizar ações intersetoriais com participação popular, apoiar o autocuidado para manutenção e recuperação do peso saudável, prestar assistência terapêutica multiprofissional aos indivíduos adultos com sobrepeso e obesidade e fazer o encaminhamento para o serviço especializado quando 
necessário. Já a gestão deve atuar no sentido de organizar a linha de cuidado das pessoas com sobrepeso e obesidade nos pontos de atenção à saúde, fornecendo subsídios para seu funcionamento, assim como a regulação do acesso da população às ações e serviços especializados, hospitalares e de apoio (Brasil, 2013b).

Outra questão que merece destaque diz respeito às limitações do serviço, especialmente no que concerne à equipe reduzida e organização do serviço de saúde. Evidencia-se que as ações preconizadas pela gestão e a demanda espontânea representam grande parcela da assistência prestada pelos enfermeiros. A excessiva busca da população por atendimento, com foco no adoecimento, intensifica o trabalho do enfermeiro, o que pode limitar sua atuação profissional no que tange à prevenção de agravos e promoção da saúde (Lopes et al., 2015).

Acrescida a esse problema, a insuficiente estrutura física das UBSs, o desacordo entre o número de profissionais e a população atendida, a precariedade na rede de referência, bem como a falta de insumos para o desenvolvimento das atividades, podem resultar em práticas descontinuadas, impactando negativamente as ações preventivas e o cuidado das pessoas com obesidade. Tal situação indica a necessidade de reorganização das UBSs de modo a favorecer o desenvolvimento das ações profissionais baseadas nos pressupostos da APS a fim de fortalecer esse nível de atenção com ênfase na promoção da saúde e prevenção de agravos.

Salienta-se que, no município onde o estudo foi realizado, não há um protocolo/fluxograma a ser seguido pelos profissionais da UBS para o atendimento da pessoa com obesidade que procura o serviço para o controle do peso. Inexiste também um protocolo com diretrizes voltadas às orientações, visando a promoção da alimentação saudável, avaliação antropométrica dos usuários e prática da atividade física. Além disso, falta a definição das competências de cada ponto de atenção à saúde na RAS para o atendimento dos usuários com obesidade, assim como a eficiência de um fluxo de referência e contrarreferência que facilite o acompanhamento longitudinal dessas pessoas. Nesse sentido, faz-se necessário sistematizar as ações voltadas para a assistência às pessoas com obesidade na RAS.

Alguns enfermeiros esboçam a expectativa de receber capacitação para desenvolver ações em relação à obesidade nas UBSs. Este desejo é conveniente na medida em que a mudança no perfil demográfico e de morbimortalidade da população resultou no aumento da complexidade das necessidades das pessoas com doenças crônicas que demandam reformulações na formação dos profissionais de saúde, bem como de promoção da educação permanente daqueles já atuantes na APS (Mendes, 2012).

Cabe à gestão do município oportunizar a participação dos profissionais de saúde em eventos de capacitação, além de manter um programa de formação continuada que os torne 
capazes de atuar frente à obesidade, especialmente no fornecimento à população de orientações sobre alimentação saudável, prática de atividade física, realização de medidas antropométricas, além de identificar distúrbios psicológicos relacionados à obesidade. Além disso, é fundamental que as equipes de saúde tenham acesso e sejam instruídas a respeito das publicações de referência do Ministério da Saúde para prevenção e controle da obesidade no âmbito da APS, especialmente o Caderno 38 de Atenção Básica à Saúde - Estratégias para o cuidado da pessoa com doença crônica: obesidade, o Guia Alimentar para a População Brasileira e a Portaria GM/MS 424, de 19 de março de 2013, que redefine as diretrizes para a organização da prevenção e do tratamento do sobrepeso e obesidade como linha de cuidado prioritária da Rede de Atenção à Saúde das Pessoas com Doenças Crônicas.

Além de conhecer e aplicar as orientações normatizadas nos manuais do Ministério da Saúde, o enfermeiro precisa fazer adequação dessas recomendações ao contexto de vida da população com obesidade assistida pela UBS. Nesse sentido, os profissionais de saúde precisam ser capazes de atuar de modo a apoiar a capacidade de autocuidado dos usuários em vez de apenas fornecer informações relativas à adoção de hábitos saudáveis, muitas vezes não compatíveis com suas realidades (Robinson et al., 2013). Para tal, é fundamental a superação de uma atuação fragmentada pelos conhecimentos profissionais e o desenvolvimento da capacidade de trabalhar em equipe, vinculando recursos clínicos e comunitários (Dietz et al., 2015). 
8 CONCLUSÃO 


\section{CONCLUSÃO}

A compreensão da experiência vivida pelos enfermeiros na prevenção e no controle da obesidade na APS, a partir da fenomenologia social de Alfred Schütz, trouxe características típicas da atuação desse profissional que poderão subsidiar reflexões no âmbito da prática, do ensino e da pesquisa na temática.

Os resultados mostram que os enfermeiros orientam a população sobre hábitos saudáveis de vida no âmbito individual e coletivo, contudo referem dificuldades relacionadas aos próprios usuários e ao serviço de saúde que interferem em sua atuação. Esses profissionais expressam a expectativa de conhecer o diagnóstico situacional do peso da população sob sua responsabilidade, realizar grupos específicos para o controle de peso, melhorar a articulação da UBS com outros equipamentos sociais, atuar com crianças e adolescentes fora do espaço da Unidade e receber capacitação para atuar frente à obesidade.

Acredita-se que o típico da atuação dos enfermeiros na APS em relação à prevenção e ao controle da obesidade fornece subsídios para a reflexão acerca do modo como as pessoas estão sendo cuidadas neste ponto de atenção da RAS. Nesse sentido, pode fornecer pistas para a gestão dos serviços promover o efetivo desenvolvimento das políticas de saúde, assegurando o atendimento de qualidade voltado aos usuários com obesidade. A consolidação das ações da APS com disponibilização da capacidade estrutural e de recursos humanos qualificados poderá facilitar o enfrentamento desse agravo crônico.

Sugere-se a realização de novas pesquisas de abordagem qualitativa com vistas a desvelar outras facetas da atuação dos enfermeiros frente à obesidade. $\mathrm{O}$ estudo de novas questões relacionadas ao tema poderá acrescer a esta investigação aspectos que agregarão valor a essa área do conhecimento. 
REFERENCIAS 


\section{REFERÊNCIAS}

Alencar JKA, Moura IH, Nobre RS, Carvalho GCN, Lima LHO, Silva ARV. Prevalência de obesidade central em adolescentes de escolas públicas do interior piauiense. Revista de Enfermagem da UFPI [Internet]. 2015 [cited 2018 June 10];4(2):11-6. Available from: http://www.ojs.ufpi.br/index.php/reufpi/article/viewFile/3116/pdf

Almeida AAS, Silva SC, Araújo WTC, Vasconcelos SML, Mélo MTS. Alimentação saudável na perspectiva multiprofissional: A experiência do Projeto "Saúde no Prato" desenvolvido na Atenção Básica. Rev Bra Edu Saúde [Internet]. 2017 [cited 2018 June 10];7(4):109-116. Available from: https://www.researchgate.net/publication/324274828_Alimentacao_saudavel_na_perspectiva_mu ltiprofissional_A_experiencia_do_Projeto_Saude_no_Prato_desenvolvido_na_Atencao_Basica

Almeida LM, Campos KFC, Randow R, Guerra VA. Estratégias e desafios da gestão da atenção primária à saúde no controle e prevenção da obesidade. Rev Gestão \& Saúde [Internet]. 2017 [cited 2018 June 10];8(01):114-139. Available from: http://periodicos.unb.br/index.php/rgs/article/download/23924/pdf_1

Andrade ACV, Schwalm MT, Ceretta LB, Dagostin VS, Saratto MT. Planejamento das ações educativas pela equipe multiprofissional da Estratégia Saúde da Família. O Mundo da Saúde [Internet]. 2013 [cited 2018 June 10];37(4):439-449. Available from: http://bvsms.saude.gov.br/bvs/artigos/mundo_saude/planejamento_acoes_educativas_equipe_ multiprofissional.pdf

Associação Brasileira para o Estudo da Obesidade e da Síndrome Metabólica. Diretrizes brasileiras de obesidade [Internet]. São Paulo; 2016 [cited 2018 June 10]. Available from: http://www.abeso.org.br/uploads/downloads/92/57fccc403e5da.pdf

Banfield M, McGorm K, Sargent G. Health promotion in schools: a multi-method evaluation of an Australian School Youth Health Nurse Program. BMC Nursing [Internet]. 2015 [cited 2018 June 10];14:21. Available from: https://www.ncbi.nlm.nih.gov/pmc/articles/PMC4416321/pdf/12912_2015_Article_71.pdf

Barbiani R, Nora CRD, Schaefer R. Nursing practices in the primary health care context: a scoping review. Rev. Latino-Am. Enfermagem [Internet]. 2016 [cited 2018 June 10];24: e2721. Available from: http://www.scielo.br/pdf/rlae/v24/0104-1169-rlae-24-02721.pdf

Barte JCM, Bogt NCW, Beltman FW, Meer K, Bemelmans WJE. Process evaluation of a lifestyle intervention in primary care: implementation issues and the participants' satisfaction of the GOAL study. Health Educ Behav [Internet]. 2012 [cited 2018 June 10];39(5):564-73. Available from: http://journals.sagepub.com/doi/pdf/10.1177/1090198111422936

Blackburn M, Stathi A, Keogh E, Eccleston C. Raising the topic of weight in general practice: perspectives of GPs and primary care nurses. BMJ Open [Internet]. 2015 [cited 2018 June 10];5(8):1-10. Available from: http://bmjopen.bmj.com/content/bmjopen/5/8/e008546.full.pdf 
Borges SAC, Porto PN. Por que os pacientes não aderem ao tratamento? Dispositivos metodológicos para a educação em saúde. Saúde Debate [Internet]. 2014 [cited 2018 June 10]; 38(101):338-346. Available from: http://www.scielo.br/pdf/sdeb/v38n101/0103-1104-sdeb38-101-0338.pdf

Botelho FC, Guerra LDS, Pava-Cárdenas A, Cervato-Mancuso AM. Pedagogical techniques in food and nutrition groups: the backstage of choice process. Ciência \& Saúde Coletiva [Internet]. 2016 [cited 2018 June 10];21(6):1889-1898. Available from: http://www.scielo.br/pdf/csc/v21n6/en_1413-8123-csc-21-06-1889.pdf

Braga VAS, Jesus MCP, Conz CA, Tavares RE, Silva MH, Merighi MAB. Nursing interventions with people with obesity in Primary Health Care: an integrative review. Rev Esc Enferm USP [Internet]. 2017 [cited 2018 June 10];51e03293. Available from: http://www.scielo.br/pdf/reeusp/v51/1980-220X-reeusp-S1980-220X2017019203293.pdf

Brasil. Ministério da Saúde, Secretaria de Vigilância em Saúde, Departamento de Vigilância de Doenças e Agravos não Transmissíveis e Promoção da Saúde. Vigitel Brasil 2016: vigilância de fatores de risco e proteção para doenças crônicas por inquérito telefônico: estimativas sobre frequência e distribuição sociodemográfica de fatores de risco e proteção para doenças crônicas nas capitais dos 26 estados brasileiros e no Distrito Federal em 2016. Brasília; 2017a.

Brasil. Ministério da Saúde, Perspectivas e desafios no cuidado às pessoas com obesidade no SUS: resultados do Laboratório de Inovação no manejo da obesidade nas Redes de Atenção à Saúde. Brasília; 2014a.

Brasil. Ministério da Saúde, Departamento de Atenção Básica. Política Nacional de Atenção Básica. Brasília; 2017 b.

Brasil. Ministério da Saúde, Secretaria de Vigilância em Saúde. Política Nacional de Promoção da Saúde. Brasília; 2015a.

Brasil. Ministério da Saúde, Decreto n. 6.286, de 5 de dezembro de 2007. Institui o Programa Saúde na Escola e dá outras providências. Diário Oficial da União, Brasília, DF, 06 dez. 2007. Seção 1:2.

Brasil. Resolução n. 38, de 16 de julho de 2009. Dispõe sobre o atendimento da alimentação escolar aos alunos da educação básica no Programa Nacional de Alimentação Escolar (PNAE). Diário Oficial da União, Brasília, DF, 17 jul. 2009. Seção 1:10.

Brasil. Ministério da Saúde, Portaria $\mathrm{n}^{\circ}$ 719, de 07 de abril de 2011. Institui o Programa Academia da Saúde no âmbito do Sistema Único de Saúde. Diário Oficial da União, Brasília, DF, 08 abr. 2011a. Seção 1:52.

Brasil. Ministério da Saúde, Secretaria de Vigilância em Saúde, Departamento de Análise de Situação de Saúde. Plano de ações estratégicas para o enfrentamento das doenças crônicas não transmissíveis (DCNT) no Brasil 2011-2022. Brasília; 2011 b. 
Brasil. Ministério da Saúde, Secretaria de Atenção à Saúde. Política Nacional de Alimentação e Nutrição. Brasília; 2013a.

Brasil. Ministério da Saúde. Portaria n. 424 de 19 de março de 2013. Redefine as diretrizes para a organização da prevenção e do tratamento do sobrepeso e obesidade como linha de cuidado prioritária da Rede de Atenção à Saúde das Pessoas com Doenças Crônicas. Diário Oficial da União, Brasília, DF, 28 jun. 2013b. Seção 1:55-56.

Brasil. Ministério da Saúde. Caderno de Atenção Básica n. 38: Estratégias para o cuidado da pessoa com doença crônica: obesidade. Brasília; 2014b.

Brasil. Ministério da Saúde, Câmara Interministerial de Segurança Alimentar e Nutricional. Estratégia Intersetorial de Prevenção e Controle da Obesidade. Brasília; 2014c.

Brasil. Ministério da Saúde, Secretaria de Atenção à Saúde, Departamento de Atenção Básica. Guia alimentar para a população brasileira: relatório final da consulta pública. Brasília; 2014d.

Brasil. Ministério da Saúde, Departamento de Atenção Básica. Orientações para avaliação de marcadores de consumo alimentar na Atenção Básica. Brasília; 2015 b.

Brasil. Ministério da Saúde, Conselho Nacional de Secretários de Saúde. A Atenção Primária e as Redes de Atenção à Saúde. Brasília; 2015c.

Brasil. Ministério da Saúde, Resolução 466 de 12 de dezembro de 2012. Aprova diretrizes e normas regulamentadoras de pesquisas envolvendo seres humanos. Diário Oficial da União, Brasília, DF, 13 jun. 2013. Seção 1:59.

Brasil. Ministério da Saúde, Secretaria de Atenção à Saúde, Departamento de Ações Programáticas e Estratégicas. Proteger e cuidar da saúde de adolescentes na Atenção Básica. Brasilia; 2017c.

Brasil. Ministério da Saúde, Universidade Federal de Minas Gerais. Instrutivo: metodologia de trabalho em grupos para ações de alimentação e nutrição na Atenção Básica. Brasília; 2016. $168 \mathrm{p}$.

Brasil. Ministério da Saúde, Secretaria de Atenção à Saúde, Departamento de Atenção Básica. Contribuições dos Núcleos de Apoio à Saúde da Família para a Atenção. Brasília; 2017d.

Brasil. Ministério da Saúde, Universidade Federal do Rio Grande do Sul. Protocolos de encaminhamento da Atenção Básica para a atenção especializada. Brasília; 2015d.

Brum MLT, Bertineti EP, Souza LP. As contribuições da fenomenologia na pesquisa em pedagogia social. Interfaces Acadêmica [Internet]. 2013 [cited 2018 June 10];8(1):75-86. Available from: file:///C:/Users/hpg62/Downloads/5-1-25-1-10-20140221.pdf 
Bryant M, Ashton L, Brown J, Jebb S, Wright J, Roberts K, et al. Systematic review to identify and appraise outcome measures used to evaluate childhood obesity treatment interventions (CoOR): evidence of purpose, application, validity, reliability and sensitivity. Health Technol Assess [Internet]. 2014 [cited 2018 June 10];18(51):1-380. Available from: https://www.ncbi.nlm.nih.gov/pubmedhealth/PMH0081758/

Carvalho FFB, Nogueira JAD. Práticas corporais e atividades físicas na perspectiva da Promoção da Saúde na Atenção Básica. Ciênc Saúde Coletiva [Internet]. 2016 [cited 2018 June 10];21(6):1829-1838. Available from: http://www.scielo.br/pdf/csc/v21n6/1413-8123-csc-2106-1829.pdf

Cervato-Mancuso AM, Vincha KRR, Santiago DA. Educação Alimentar e Nutricional como prática de intervenção: reflexão e possibilidades de fortalecimento. Physis [Internet]. 2016 [cited 2018 June 10];26(1):225-249. Available from: http://www.scielo.br/pdf/physis/v26n1/0103-7331-physis-26-01-00225.pdf

Costa JP, Jorge MSB, Vasconcelos SMGF, Paula ML, Bezerra IC. Resolubilidade do cuidado na Atenção Primária: articulação multiprofissional e rede de serviços. Saúde debate [Internet]. 2014 [cited 2018 June 10];38(103):733-743. Available from: http://www.scielo.br/pdf/sdeb/v38n103/0103-1104-sdeb-38-103-0733.pdf

Cota BC, Oliveira FCS, Silva LSB, Almeida C, Batalha JS, Novaes JF. Atividade de educação alimentar e nutricional desenvolvida com crianças de 4 a 6 anos de idade no laboratório de desenvolvimento infantil da Universidade Federal de Viçosa-MG: um trabalho de extensão desenvolvido pelo Programa de Educação Tutorial em Nutrição. JMPHC [Internet]. 2016 [cited 2018 June 10];7(1):31-31. Available from: http://www.jmphc.com.br/saudepublica/index.php/jmphc/article/viewFile/357/Atividade\%20de\%20alimentacao.

Dantas CN, Santos VEP, Tourinho FSV. Nursing consultation as a technology for care in light of the thoughts of Bacon and Galimberti. Texto Contexto Enferm [Internet]. 2016 [cited 2018 June 10];25(1):1-8. Available from: http://www.scielo.br/pdf/tce/v25n1/en_0104-0707-tce-2501-2800014.pdf

Di Cesare M, Bentham J, Stevens G, Zhou B, Danaei G, Lu Y, et al. Trends in adult body-mass index in 200 countries from 1975 to 2014: a pooled analysis of 1698 population-based measurement studies with 19.2 million participants. The Lancet [Internet]. 2016 [cited 2018 June 10];387(10026):1377-96. Available from: https://www.thelancet.com/pdfs/journals/lancet/PIIS0140-6736(16)30054-X.pdf

Dias PC, Henriques P, Anjos LA, Burlandy L. Obesity and public policies: the Brazilian government's definitions and strategies. Cad. Saúde Pública [Internet]. 2017 [cited 2018 June 10];33(7):e00006016. Available from: http://www.scielo.br/pdf/csp/v33n7/en_1678-4464-csp33-07-e00006016.pdf

Dietz WH, Baur LA, Hall K, Puhl RM, Taveras EM, Uauy R, et al. Management of obesity: improvement of health-care training and systems for prevention and care. The Lancet [Internet]. 2015 [cited 2018 June 10];385(9986):2521-2533. Available from: https://www.thelancet.com/pdfs/journals/lancet/PIIS0140-6736(14)61748-7.pdf 
Dillen SM, Noordman J, Dulmen S, Hiddink GJ. Quality of weight-loss counseling by dutch practice nurses in primary care: an observational study. Eur J Clin Nutr [Internet]. 2015 [cited 2018 June 10];69(1):73-8. Available from: https://www.ncbi.nlm.nih.gov/pubmed/24986823

Dillen SME, Noordman J, Dulmen S, Hiddink GJ. Examining the content of weight, nutrition and physical activity advices provided by dutch practice nurses in primary care: analysis of videotaped consultations. Eur J Clin Nutr [Internet]. 2014 [cited 2018 June 10];68(1):50-6. Available from: https://www.ncbi.nlm.nih.gov/pubmed/24169459

Dobbs R, Sawers C, Thompson F, Manyika J, Woetzel J, Child P et al. Overcoming obesity: an initial economic analysis executive summary. McKinsey Global Institute [Internet] 2014 [cited 2018 June 10]. Available from: https://www.mckinsey.com/ /media/McKinsey/Business\%20Functions/Economic\%20Studies $\%$ 20TEMP/Our\%20Insights/How\%20the\%20world\%20could\%20better\%20fight\%20obesity/ MGI_Overcoming_obesity_Full_report.ashx

Döring N, Hansson LM, Andersson ES, Bohman B, Westin M, Magnusson M, et al. Primary prevention of childhood obesity through counselling sessions at Swedish child health centres: design, methods and baseline sample characteristics of the PRIMROSE cluster-randomised trial. BMC [Internet]. 2014 [cited 2018 June 10];14:335. Available from: https://bmcpublichealth.biomedcentral.com/track/pdf/10.1186/1471-2458-14-335

Escalda P, Parreira C, Cyrino A. Dimensões do trabalho interprofissional e das práticas colaborativas desenvolvidas em uma unidade básica de saúde, por uma equipe de saúde da família. In: Anais do $6^{\circ}$ Congresso Ibero Americano de Investigação Qualitativa; 2017 jul 1314; Salamanca. Salamanca: Investigação Qualitativa em Saúde; 2017.

Faccioni LC, Soler RR. Abordagem lúdica sobre os aspectos celulares do diabetes e da obesidade para alunos do ensino médio. Revista Brasileira de Extensão Universitária [Internet]. 2018 [cited 2018 June 10];9(1):27-37. Available from: https://periodicos.uffs.edu.br/index.php/RBEU/article/view/6810/pdf

Falsarella AM. O lugar da pesquisa qualitativa na avaliação de políticas e programas sociais. Rev Avaliação [Internet]. 2015 [cited 2018 June 10];20(3):703-15. Available from: http://www.scielo.br/pdf/aval/v20n3/1414-4077-aval-20-03-00703.pdf

Ferreira MCS, Negri F, Galesi LF, Detregiachi CRP, Oliveira MRM. Monitoramento nutricional em unidades de Atenção Primária à Saúde. Rasbran [Internet]. 2017 [cited 2018 June 10];8(1):7-45. Available from: https://www.rasbran.com.br/rasbran/article/download/227/156

Findholt NE, Davis MM, Michael YL. Perceived barriers, resources, and training needs of rural primary care providers relevant to the management of childhood obesity. J Rural Health [Internet]. 2013 [cited 2018 June 10];29(1):17-24. Available from: https://www.ncbi.nlm.nih.gov/pubmed/23944276 
Food and Agriculture Organization of the United Nations (FAO). UN general assembly proclaims decade of action on nutrition. Geneva; 2016.

Frank J. Origins of the obesity pandemic can be analysed. Rev Nature [Internet]. 2016 [cited 2018 June 10];532(7598):149. Available from: https://www.nature.com/polopoly_fs/1.19744!/menu/main/topColumns/topLeftColumn/pdf/5 32149a.pdf

Gil AC, Yamauchi NI. Elaboração do projeto na pesquisa fenomenológica em enfermagem. Rev Baiana Enferm [Internet]. 2012 [cited 2018 June 10];26(3):565-73. Available from: https://portalseer.ufba.br/index.php/enfermagem/article/download/6613/6693

Gorin AA, Wiley J, Ohannessian CM, Hernandez D, Grant A, Michelle, et al. Steps to Growing Up Healthy: a pediatric primary care based obesity prevention program for young children. BMC Public Health [Internet]. 2014 [cited 2018 June 10];14(72):90-97. Available from: https://bmcpublichealth.biomedcentral.com/track/pdf/10.1186/1471-2458-14-72

Instituto Brasileiro de Geografia e Estatística. Censo Demográfico de 2017: documentação dos microdados da amostra. Rio de Janeiro; 2017.

Instituto de Estudos de Saúde Suplementar. Cirurgia Bariátrica: pareceres técnico-científicos Departamento de clínica médica da Universidade do Estado do Rio de Janeiro [Internet]. Rio de Janeiro; 2015 [cited 2018 June 10]. Available from: https://www.tjrs.jus.br/export/poder_judiciario/tribunal_de_justica/centro_de_estudos/doutrin a/doc/PARECER_CIENTIFICO_SOBRE_CIRURGIA_BARIATRICA.pdf

Isma GE, Bramhagen AC, Alhtrom G, Ostman M, Dykes AK. Obstacles to the prevention of overweight and obesity in the context of child health care in Sweden. BMC [Internet]. 2013 [cited 2018 June 10];14(143):1-10. Available from: https://www.ncbi.nlm.nih.gov/pmc/articles/PMC3852529/pdf/1471-2296-14-143.pdf

Jarl J, Tolentino JC, James K, Clark MJ, Ryan M. Supporting cardiovascular risk reduction in overweight and obese hypertensive patients through DASH diet and lifestyle education by primary care nurse practitioners. J Am Assoc Nurse Pract [Internet]. 2014 [cited 2018 June 10];26(9):498-503. Available from: https://www.ncbi.nlm.nih.gov/pubmed/24824790

Jesus MCP, Capalbo C, Merighi MAB, et al. The social phenomenology of Alfred Schütz and its contribution for nursing. Rev Esc Enferm USP [Internet]. 2013 [cited 2018 June 10]; 47(3): 736-41. Available from: http://www.scielo.br/pdf/reeusp/v47n3/en_0080-6234-reeusp-47-300736.pdf

Juiz de Fora. Secretaria Municipal de Saúde, Plano Diretor da Atenção Primária em Saúde: Projeto de Implantação [Internet]. Juiz de Fora; 2014 [cited 2018 June 10]. Available from: https://www.pjf.mg.gov.br/secretarias/ss/plano_diretor/docs/implantacao.pdf

Korhonen PE, Järvenpää S, Kautiainen H. Primary care-based, targeted screening programme to promote sustained weight management. Scand J Prim Health Care [Internet]. 2014 [cited 
2018

June

10];32(1):30-6.

Available

from:

https://www.ncbi.nlm.nih.gov/pmc/articles/PMC4137900/pdf/pri-32-30.pdf

Larson K, Colborn B, Engelke MK. A School-Based Health Center-University Nursing Partnership: How We Filled in the GAPS. The Journal of School Nursing [Internet]. 2015 [cited 2018 June 10]; 27(6):404-410. Available from: http://journals.sagepub.com/doi/pdf/10.1177/1059840511419370

Laws R, Campbell KJ, van der Pligt P, Ball K, Lynch J, Russell G, et al. Obesity prevention in early life: an opportunity to better support the role of maternal and child health nurses in Australia. BMC [Internet]. 2015 [cited 2018 June 10];14:26. Available from: https://www.ncbi.nlm.nih.gov/pmc/articles/PMC4429503/pdf/12912_2015_Article_77.pdf

Lindemann IL, Mendoza-Sassi RA. Guidelines to healthy eating and associated factors among users of primary health care in southern Brazil. RBPS [Internet]. 2016 [cited 2018 June 10]; 29(1):34-42 Available from: https://search.proquest.com/openview/a86f042681fcfbcc534582d40c6e5065/1?pqorigsite $=$ gscholar $\& \mathrm{cbl}=2046042$

Lopes AS, Vilar RLA, Melo RHV, França RCS. O acolhimento na Atenção Básica em saúde: relações de reciprocidade entre trabalhadores e usuários. Saúde Debate [Internet]. 2015 [cited 2018 June 10];39(104):114-123. Available from: http://www.scielo.br/pdf/sdeb/v39n104/01031104-sdeb-39-104-00114.pdf

Maceno PR, Heidmann ITSB. Unveiling the actions of nurses in primary health care groups. Texto Contexto Enferm [Internet]. 2016 [cited 2018 June 10];25(4):e2140015. Available from: http://www.scielo.br/pdf/tce/v25n4/0104-0707-tce-25-04-2140015.pdf

Marchon SG, Mendes Júnior WV, Pavão ANB. Characteristics of adverse events in primary health care in Brazil. Cadernos de Saúde Pública [Internet]. 2015 [cited 2018 June 10];31(11):2313-2330. Available from: http://www.scielo.br/pdf/csp/v31n11/en_0102-311Xcsp-31-11-2313.pdf

Martin A, Saunders DH, Shenkin SD, Sproule J. Lifestyle intervention for improving school achievement in overweight or obese children and adolescents. Cochrane Database of Systematic Reviews [Internet]. 2014 [cited 2018 June 10];14(3):CD009728. Available from: http://cochranelibrary-wiley.com/doi/10.1002/14651858.CD009728.pub2/epdf

Massimi A, De Vito C, Brufola I, Corsaro A, Marzuillo C, Migliara G, et al. Are community-based nurse-led self-management support interventions effective in chronic patients? Results of a systematic review and meta-analysis. PLoS One [Internet]. 2017 [cited 2018 June 10];12(3):e0173617. Available from: http://journals.plos.org/plosone/article/file?id=10.1371/journal.pone.0173617\&type=printable

Matos JC, Costa KJS, Andrade FCB, Alvarenga EVA, Henriques MVM. Atuação do enfermeiro na prevenção da obesidade infantil em uma capital do Nordeste. Gestão \& Saúde [Internet]. 2015 [cited 2018 June 10];6(3):2608-2622. Available from: http://periodicos.unb.br/index.php/rgs/article/download/22404/16002 
Melo ANL, Luna FDT, Ferreira ISV, Negreiros RV, Filomena SAM. Abordagem interdisciplinar com obesos e sobrepesos na Atenção Primária: relato de experiência. Rev Univ Vale do Rio Verde [Internet]. 2016 [cited 2018 June 10];14(2):853-863. Available from: http://periodicos.unincor.br/index.php/revistaunincor/article/download/2786/pdf_578

Melo WA, Alves JI, Ferreira AAS, Souza VS, Maran E. Gestação de alto risco: fatores associados em município do noroeste paranaense. Espaço para saúde [Internet]. 2016 [cited 2018 June 10];17(1):89-91. Available from: http://www.uel.br/revistas/uel/index.php/espacoparasaude/article/download/24981/11

Mendes EV. O cuidado das condições crônicas na Atenção Primária à Saúde: o imperativo da consolidação da estratégia da saúde da família [Internet]. 2012 [cited 2018 June 10]. Available from: http://bvsms.saude.gov.br/bvs/publicacoes/cuidado_condicoes_atencao_primaria_saude.pdf

Minayo MCS. Amostragem e saturação em pesquisa qualitativa: consensos e controvérsias. RPQ [Internet]. 2017 [cited 2018 June 10];5(7):1-12. Available from: https://edisciplinas.usp.br/pluginfile.php/4111455/mod_resource/content/1/Minayosaturacao.pdf

Minayo MCS. O desafio do conhecimento: pesquisa qualitativa em saúde. $14^{\mathrm{a}}$ ed. São Paulo: Editora Hucitec; 2015.

Moura MAP, Rocha SS, Pinho DLM, Guilhem D. Facilidades e dificuldades dos enfermeiros no cuidar da alimentação infantil na Atenção Básica. O Mundo da Saúde [Internet]. 2015 [cited 2018 June 10];39(2):231-238. Available from: http://bvsms.saude.gov.br/bvs/periodicos/mundo_saude_artigos/Facilidades_dificuldades_enf ermeiros.pdf

Nascimento APS, Avelino DM, Maximo MMG, Moura WC. Atuação do enfermeiro na educação alimentar de crianças em um núcleo de educação infantil. Rev Enferm UFPI [Internet]. 2016 [cited 2018 June 10];5(1):40-45. Available from: http://www.ojs.ufpi.br/index.php/reufpi/article/download/4572/pdf

Nascimento CCS, Silva GA, Nascimento MI. Fatores associados à recaída do tabagismo em pacientes assistidos em unidades de saúde da zona oeste do município do Rio de Janeiro. Rev. APS [Internet]. 2016 [cited 2018 June 10];19(4):556-67. Available from: https://aps.ufjf.emnuvens.com.br/aps/article/download/2510/1034

Nunes GP, Negreira AS, Costa MG, Sena FG, Amorin CB, Kerber NPC. Grupo de gestantes como ferramenta de instrumentalização e potencialização do cuidado. Cidadania em Ação [Internet]. 2017 [cited 2018 June 10];1(1):1-16. Available from: http://www.revistas.udesc.br/index.php/cidadaniaemacao/article/download/10932/pdf

Oliveira AC, Almeida LB, Lucca A, Nascimento V. Estudo da relação entre ganho de peso excessivo e desenvolvimento de diabetes mellitus e doença hipertensiva específica na gestação. J Health Sci Inst [Internet]. 2016 [cited 2018 June 10];34(4):231-9. Available from: https://www.unip.br/presencial/comunicacao/publicacoes/ics/edicoes/2016/04_outdez/V34_n4_2016_p231a239.pdf 
Oliveira CS, Brito BJQ, Quadros TMB, Gordia AP, Coelho FT. Avaliação de um projeto de extensão universitária de prática de caminhada e orientação nutricional para mulheres obesas. REMEFE [Internet]. 2015 [cited 2018 June 10];14(1):163-176. Available from: http://editorarevistas.mackenzie.br/index.php/remef/article/download/6161/5994

Oliveira DM, Merighi MAB, Kortchmar E, Braga VA, Silva MH, Jesus MCP. Experience of women in the postoperative period of bariatric surgery: a phenomenological study. OBJN [Internet]. 2016 [cited 2018 June 10];15(1):1-10. Available from: https://www.objnursing.uff.br/index.php/nursing/article/view/5167/html_1038

Pan American Health Organization. Pan American Health Organization Nutrient Profile Model. Washington DC; 2016.

Paula CC, Padoin SMM, Terra MG, Souza IEO, Cabral IV. Modos de condução da entrevista em pesquisa fenomenológica: relato de experiência. Rev Bras Enferm [Internet]. 2014 [cited 2018 June 10];67(3):468-72. Available from: http://www.scielo.br/pdf/reben/v67n3/00347167-reben-67-03-0468.pdf

Pbert L, Druker S, Barton B, et al. A School-Based Program for Overweight and Obese Adolescents: A Randomized Controlled Trial. The Journal of school health [Internet]. 2016 [cited 2018 June 10];86(10):699-708. Available from: https://www.ncbi.nlm.nih.gov/pmc/articles/PMC5033122/pdf/nihms805023.pdf

Pedraza DF, Menezes TN, Costa GMC. Food and nutrition actions in the family health strategy: structure and work process. Rev Enferm UERJ [Internet]. 2016 [cited 2018 June 10];24(4):e15848. Available from: http://www.epublicacoes.uerj.br/index.php/enfermagemuerj/article/view/15848/23420

Pereira S, Ferreira DM, Capelli JCS, Pereira AV, Anastácio A. Confrontations for the implantation and maintenance of educational groups for pregnant women in primary care. Demetra [Internet]. 2017 [cited 2018 June 10];12(4);1133-1146. Available from: http://www.epublicacoes.uerj.br/index.php/demetra/article/download/28804/22898

Peuker AC, Bizarro L. Características do processo de cessação do tabagismo na abstinência prolongada. Contextos Clínicos [Internet]. 2015 [cited 2018 June 10];8(1):87-98. Available from: http://revistas.unisinos.br/index.php/contextosclinicos/article/view/ctc.2015.81.09/4660

Phillips K, Wood F, Kinnersley P. Tackling obesity: the challenge of obesity management for practice nurses in primary care. Fam Pract [Internet]. 2014 [cited 2018 June 10];31(1):51-9. Available from: https://academic.oup.com/fampra/article/31/1/51/437261

Rech DC, Borfe L, Emmanouilidis A, Garcia EL, Krug SBF. As políticas públicas e o enfrentamento da obesidade no Brasil: uma revisão reflexiva. Rev de Epidemiologia e Controle de Infecção [Internet]. 2016 [cited 2018 June 10];1(1). Available from: https://online.unisc.br/seer/index.php/epidemiologia/article/download/7974/5165 
Riiser K, Londal K, Ommundsen Y, Smastuen MC, Misvaer N, Helseth S. The outcomes of a 12-week internet intervention aimed at improving fitness and health-related quality of life in overweight adolescents: the Young \& Active controlled trial. PLoS One [Internet]. 2014 [cited 2018 June 10];9(12):1-21. Available from: https://www.ncbi.nlm.nih.gov/pmc/articles/PMC4257715/pdf/pone.0114732.pdf

Ritten A, Waldrop J, Kitson J. Fit living in progress--fighting lifelong obesity patterns (FLIPFLOP): A nurse practitioner delivered intervention. Appl Nurs Res [Internet]. 2016 [cited 2018 June 10];30(1):119-24. Available from: https://www.ncbi.nlm.nih.gov/pubmed/27091265

Robinson A, Denney-Wilson E, Laws R, Harris M. Child obesity prevention in primary health care: investigating practice nurse roles, attitudes and current practices. J Paediatr Child Health [Internet]. 2013 [cited 2018 June 10];49(4):294-9. Available from: https://onlinelibrary.wiley.com/doi/pdf/10.1111/jpc.12164

Rosa VS, Sales CMM, Andrade MAC. Acompanhamento nutricional por meio da avaliação antropométrica de crianças e adolescentes em uma Unidade Básica de Saúde. Rev. Bras. Pesq. Saúde [Internet]. 2017 [cited 2018 June 10];19(1):28-33. Available from: http://periodicos.ufes.br/RBPS/article/download/17713/12139

Santos FDR, Vitola CB, Arrieira ICO, Chagas MCS, Gomes GC, Pereira FW. Ações de enfermeiros e professores na prevenção e combate à obesidade infantil. Rev Rene [Internet]. 2014 [cited 2018 June 10]; 15(3):463-70. Available from: http://www.periodicos.ufc.br/rene/article/download/3205/2464

Santos RCA, Miranda FAN. Importância do vínculo entre profissional-usuário na estratégia de saúde da Família. Rev Enferm UFSM [Internet]. 2016 [cited 2018 June 10];6(3):350-359. Available from: https://periodicos.ufsm.br/reufsm/article/download/17313/pdf

Sargent GM, Forrest LE, Parker RM. Nurse delivered lifestyle interventions in primary health care to treat chronic disease risk factors associated with obesity: a systematic review. Obes Rev [Internet]. 2012 [cited 2018 June 10];13(12):1148-71. Available from: https://www.ncbi.nlm.nih.gov/pmc/articles/PMC3533768/pdf/obr0013-1148.pdf

Schütz A, Luckmann T. Las estructuras del mundo de la vida. 2 reimp. Buenos Aires: Amorrortu; 2009.

Schütz A. Sobre fenomenologia e relações sociais. Org. Wagner HTR. Petrópolis: Vozes; 2012.

Silva CR, Carvalho BG, Cordoni Júnior L, Nunes EFPA. Difficulties in accessing services that are of medium complexity in small municipalities: a case study. Ciência \& Saúde Coletiva [Internet]. 2017 [cited 2018 June 10];22(4):1109-1120. Available from: http://www.scielo.br/pdf/csc/v22n4/en_1413-8123-csc-22-04-1109.pdf

Silva JAM, Peduzzi M, Orchard C, Leonello VM. Interprofessional education and collaborative practice in Primary Health Care. Rev Esc Enferm USP [Internet]. 2015 [cited 2018 June 
10];49(2):16-24. Available from: http://www.scielo.br/pdf/reeusp/v49nspe2/en_1980-220Xreeusp-49-spe2-0016.pdf

Smith S, Seeholzer EL, Gullett H, Jackson B, Antognoli E, Krejci SA, et al. Primary Care Residents' Knowledge, Attitudes, Self-Efficacy, and Perceived Professional Norms Regarding Obesity, Nutrition, and Physical Activity Counseling. J Grad Med Educ [Internet]. 2015 [cited 2018 June 10];7(3):388-94. Available from: https://www.ncbi.nlm.nih.gov/pmc/articles/PMC4597949/pdf/i1949-8357-7-3-388.pdf

Soares AH, Oliveira C, Rocha TR, Cordoba GMC, Nobre JAS. Porque obesos abandonam o planejamento nutricional em uma clínica-escola de nutrição? RBONE [Internet]. 2017 [cited 2018 June 10];11(65):368-375. Available from: http://www.rbone.com.br/index.php/rbone/article/download/551/454

Sousa LAPA, Ascari TA, Ferraz L, Zanatta EA. Obesidade infantil: o olhar dos enfermeiros inseridos na Atenção Básica. Cultura de los Cuidados [Internet]. 2015 [cited 2018 June 10];19(41):147-156. Available from: https://rua.ua.es/dspace/bitstream/10045/46622/1/Cultura-Cuidados_41_17.pdf

Stephen C, McInnes S, Halcomb E. The feasibility and acceptability of nurse-led chronic disease management interventions in primary care: an integrative review. J Adv Nurs [Internet]. 2018 [cited 2018 June 10];74(2):279-288. Available from: https://www.ncbi.nlm.nih.gov/pubmed/28880393

Teixeira F, Pais-Ribeiro JL, Maia A. Uns desistem, outros insistem: semelhanças e diferenças no discurso de profissionais de saúde face à obesidade. Rev Port Sau Pub [Internet]. 2015 [cited 2018 June 10];33(2):137-47. Available from: http://www.scielo.mec.pt/pdf/rpsp/v33n2/v33n2a03.pdf

Toledo MTT, Mendonça RD, Abreu MN, Lopes ACS. Aconselhamento sobre modos saudáveis de vida na Atenção Primária à Saúde. Mundo saúde [Internet]. 2017 [cited 2018 June 10];41(1):87-97. Available from: http://bvsms.saude.gov.br/bvs/periodicos/mundo_saude_artigos/aconselhamento_modos_saud aveis.pdf

Toloni MHA, Longo-Silva G, Konstantyner T, Taddei JAAC. Consumption of industrialized food by infants attending child day care centers. Rev Paul Pediatr [Internet]. 2014 [cited 2018 June 10];32(1):37-43. Available from: http://www.scielo.br/pdf/rpp/v32n1/0103-0582-rpp-3201-00037.pdf

Tucker SJ, Ytterber KL, Lenoch LM, Schmit TL, Mucha DI, Wooten JA, et al. Reducing pediatric overweight: nurse-delivered motivational interviewing in primary care. J Pediatr Nurs [Internet]. 2013 [cited 2018 June 10];28(6):536-47. Available from: https://www.pediatricnursing.org/article/S0882-5963(13)00094-8/pdf

Vannuchi RO, Carreira CM, Pegoraro LGO, Gvozd R. Impacto da intervenção multiprofissional em grupo no perfil nutricional e hábitos de vida de mulheres com sobrepeso e obesidade. Espaço 
para a Saúde [Internet]. 2016 [cited 2018 June 10];17(2);189-198. Available from: http://www.uel.br/revistas/uel/index.php/espacoparasaude/article/download/27052/pdf19

Vasconcelos ANCP, Magalhães R. Práticas educativas em Segurança Alimentar e Nutricional: reflexões a partir da experiência da Estratégia Saúde da Família em João Pessoa, PB, Brasil. Interface (Botucatu) [Internet]. 2016 [cited 2018 June 10];20(56):99-110. Available from: http://www.scielo.br/pdf/icse/v20n56/1807-5762-icse-1807-576220150156.pdf

Vieira AM, Gomes AS, Vieira RAL, Silva FC, Previato HDRA, Volp ACP. Association between anthropometric measurements and body composition with components of the metabolic syndrome and diet quality index in overweight adult individuals. Demetra [Internet]. 2016 [cited 2018 June 10];11(2):399-413. Available from: http://www.epublicacoes.uerj.br/index.php/demetra/article/download/15564/20261

Vincha KRR, Vieira VL, Guerra LDS, Botelho FC, Pava-Cádenas A, Cervato-Mancuso AM. "Então não tenho como dimensionar": um retrato de grupos educativos em saúde na cidade de São Paulo, Brasil. Cad. Saúde Pública [Internet]. 2017 [cited 2018 June 10];33(9):e00037116. Available from: http://www.scielo.br/pdf/csp/v33n9/1678-4464-csp-33-09-e00037116.pdf

Vitorino SAS, Cruz MM, Barros DC. Validação do modelo lógico teórico da vigilância alimentar e nutricional na Atenção Primária em Saúde. Cadernos de Saúde Pública [Internet]. 2017 [cited 2018 June 10];33(12):e00014217. Available from: http://www.scielo.br/pdf/csp/v33n12/1678-4464-csp-33-12-e00014217.pdf

Weykamp JM, Cecagno D, Vieira FP, Siqueira HCH. Educação permanente em saúde na atenção básica: percepção dos Profissionais de enfermagem. REUFSM [Internet]. 2016 [cited 2018 June 10];6(2):281-289. Available from: https://periodicos.ufsm.br/reufsm/article/download/16754/pdf

World Health Organization. Global action plan for the prevention and control of noncommunicable diseases 2013-2020. Geneva; 2013.

World Health Organization. WHO. Obesity and overweight: Key facts. Geneva;2017.

Zampier VSB, Silva MH, Ribeiro de Jesus R, Oliveira PP, Jesus MCP, Merighi MAB. Maintenance of tobacco withdrawal by former smokers: a phenomenological study. Rev Gaúcha Enferm [Internet]. 2017 [cited 2018 June 10];38(4):e2017-0027. Available from: http://www.scielo.br/pdf/rgenf/v38n4/en_1983-1447-rgenf-38-04-e2017-0027.pdf 
APÊNDICES 


\section{APÊNDICES}

\section{APÊNDICE A - TERMO DE CONSENTIMENTO LIVRE E ESCLARECIDO}

Convido o (a) Sr (a) para participar da pesquisa intitulada "Atuação dos enfermeiros na prevenção e no controle da obesidade na Atenção Primária à Saúde” desenvolvida pela Sra. Vanessa Augusta Souza Braga, sob a orientação da Professora Maria Cristina Pinto de Jesus, credenciada no Programa de Pós-Graduação em Enfermagem (PPGE) da Escola de Enfermagem da Universidade de São Paulo (EEUSP).

O estudo tem como objetivo compreender a atuação dos enfermeiros na prevenção e no controle da obesidade na Atenção Primária à Saúde. A atuação do enfermeiro diz respeito ao aconselhamento e suporte aos usuários do serviço de saúde, visando ao controle, à prevenção e ao tratamento da obesidade. Os resultados desta pesquisa poderão ajudar o enfermeiro a repensar sua atuação e rever as estratégias de intervenção voltadas às pessoas com obesidade no contexto das Unidades Básicas de Saúde.

Sua participação é voluntária e, caso concorde em participar do estudo, farei uma entrevista individual em local de sua escolha com duração de cerca de 40 minutos, a qual será gravada em áudio para posterior transcrição e análise dos dados. O material gravado será arquivado por mim e os depoimentos serão utilizados apenas para fins científicos. Sua entrevista ajudará as pesquisadoras a compreenderem a atuação do enfermeiro nas Unidades Básicas de Saúde, mas não será, necessariamente, para seu benefício direto. Entretanto, fazendo parte deste estudo, o(a) sr.(a) terá a oportunidade de refletir sobre a atuação do enfermeiro nesse nível de atenção e contribuir para promover discussões que possam subsidiar a prática de enfermagem voltada para prevenção e controle da obesidade.

Assumo o compromisso de manter sigilo quanto à sua identidade durante todas as etapas da pesquisa. As informações coletadas serão identificadas com um código fictício. Esta pesquisa não possui financiamento. Não haverá custo e nem remuneração por sua participação. Como a entrevista será realizada em seu local de trabalho ou na sua residência, não haverá despesa com transporte para o(a) sr. (a) ceder o depoimento. A qualquer momento, o(a) sr. (a) poderá pedir informações sobre o andamento da pesquisa, bem como interromper a sua participação no estudo, sem que isso lhe acarrete qualquer prejuízo.

$\mathrm{O}$ (a) sr. (a) pode achar que determinadas perguntas o(a) incomodam, porque as informações que coletamos são sobre suas experiências pessoais. Para minimizar essa situação, o(a) sr. (a) pode escolher não responder a quaisquer perguntas que o(a) façam sentir-se incomodado(a). No caso de apresentar algum constrangimento ou desconforto emocional durante a entrevista, o(a) sr. (a) poderá fazer uma pausa e, se desejar, poderá se recusar a continuar a ceder o depoimento. Haverá indenização para eventuais danos decorrentes da pesquisa comprovados legalmente.

$\mathrm{O}$ presente termo será rubricado e assinado pelo participante e pela pesquisadora principal em duas vias. Uma ficará com o(a) sr. (a) e a outra ficará arquivada comigo. Se precisar de outras informações e esclarecimentos, entre em contato comigo pelo telefone: (32)98858-7330, pelo e-mail vanessabraga@usp.br ou pelo endereço: Rua Professora Marta Waltemberg, 220/904 Bairro Granbery, Juiz de Fora - MG. CEP 36010-460. Caso você tenha alguma consideração ou dúvida sobre a ética da pesquisa, entre em contato com o Comitê de Ética em Pesquisa (CEP) - Endereço - Av. Dr. Enéas de Carvalho Aguiar, 419 - Cerqueira Cesar - São Paulo/SP CEP - 05403-000 Telefone- (11) 30618858 email-cepee@usp.br

Esta pesquisa atende a todas as especificações da Resolução n. 466, de 12 de dezembro de 2012, do Conselho Nacional de Saúde, que aprova as diretrizes e normas regulamentadoras de pesquisas envolvendo seres humanos.

Assinatura do pesquisador

Assinatura do participante/representante legal

Data.. ..$/ . .$. 


\section{APÊNDICE B - INSTRUMENTO DE COLETA DE DADOS}

1. Caracterização dos participantes

Sexo:

Idade:

Formação (graduação) Ano:

Formação (pós-graduação) Ano:

Possui algum curso voltado para a temática da obesidade? ( ) Sim ( ) Não Qual? Ano:

Tempo de atuação na Unidade Básica de Saúde:

Modelo de APS da Unidade em que atua:
( ) Tradicional
( ) ESF
( ) Misto

1. Questões da Entrevista:

- O que você tem feito em relação à prevenção e ao controle da obesidade na UBS?

- Quais suas expectativas em relação a sua atuação frente à obesidade? 
ANEXOS 


\section{ANEXOS}

\section{ANEXO 1 - AUTORIZAÇÃo DA SUBSECRETARIA DE ATENÇÃo PRIMÁRIA À SAÚDE}

\section{Declaração}

Eu Thiago Augusto Campos Horta, na qualidade de responsável pela Subsecretaria de Atenção Primária à Saúde da Subsecretaria de Atenção Primária à Saúde, autorizo a realização da pesquisa intitulada "Atuação do Enfermeiro junto aos Usuários com Obesidade nas Unidades Básicas de Saúde" a ser conduzida sob a responsabilidade do Pesquisador Responsável Professora Doutora Maria Cristina Pinto de Jesus e da Pesquisadora Vanessa Augusta Souza Braga no município de Juiz de Fora e DECLARO que esta instituição apresenta infraestrutura necessária à realização da referida pesquisa e que AUTORIZAMOS a divulgação do nome do município de Juiz de Fora no relatório de pesquisa e publicações científicas.

Esta declaração é válida apenas no caso de haver parecer favorável do Comitê de Ética pertinente para a referida pesquisa.

Solicita-se, assim que concluídos, o Relatório de Pesquisa e as Bases de Dados da referida pesquisa para apreciação e potencial utilização desta Secretaria de Saúde.

Subsecretário de Atenção Primária à Saúde

\begin{tabular}{|c|c|}
\hline \multicolumn{2}{|c|}{ Recebido em: 2010912017} \\
\hline Nome:lanursa Augusta Souza & CPF:099000406.60 \\
\hline \multicolumn{2}{|c|}{ Instituição: Universidade de Sas Paulo } \\
\hline E-mail:vanussabnaga@usp.er & Telefone: $98858-7330$ \\
\hline
\end{tabular}




\section{ANEXO 2 - PARECER DO COMITÊ DE ÉTICA EM PESQUISA}

\begin{tabular}{|c|c|c|c|} 
USP - ESCOLA DE \\
ENFERMAGEM DA \\
ENIVERSIDADE DE SÃO
\end{tabular}

\section{PARECER CONSUBSTANCIADO DO CEP}

\section{DADOS DO PROJETO DE PESQUISA}

Título da Pesquisa: ATUAÇÃO DO ENFERMEIRO JUNTO AOS USUÁRIOS COM OBESIDADE NAS UNIDASES BÁSICAS DE SAÚDE

Pesquisador: Vanessa Augusta Souza Braga

Área Temática:

Versão: 1

CAAE: 77967117.7 .0000 .5392

Instituição Proponente: Escola de Enfermagem da Universidade de São Paulo - EEUSP

Patrocinador Principal: Financiamento Próprio

\section{DADOS DO PARECER}

\section{Número do Parecer: 2.340 .033}

\section{Apresentação do Projeto:}

O projeto busca pesquisar a atuação do profissional enfermeiro junto aos usuários com obesidade nas unidades básicas de saúde. Contextualiza o problema da obesidade com ampla pesquisa bibliográfica nacional e internacional, evidenciando a necessidade de intervenções programática voltadas para alimentação saudável, estímulo às atividades físicas como políticas públicas entendendo a complexidade do cenário. O local da pesquisa será em Juiz de For, Minas Gerais onde coexistem Unidades de Saúde da Família como de modelo tradicional. Haverá seleção desses profissionais conforme critérios de inclusão e exclusão. A metodologia proposta é qualitativa de abordagem

fenomenológica baseado na teoria do Alfred Schütz. A coleta de dados será por meio da entrevista fenomenológica.

\section{Objetivo da Pesquisa:}

Tem como o objetivo primário compreender a atuação do enfermeiro junto às pessoas com obesidade nas Unidades Básicas de Saúde. E, os objetivos secundários são: identificar as atividades dsenvolvidas pelo enfermeiro nas Unidades Básicas de Saúde voltadas às pessoas com obesidade; identificar as expectativas do enfermeiro frente a sua situação junto às pessoas com obesidade.

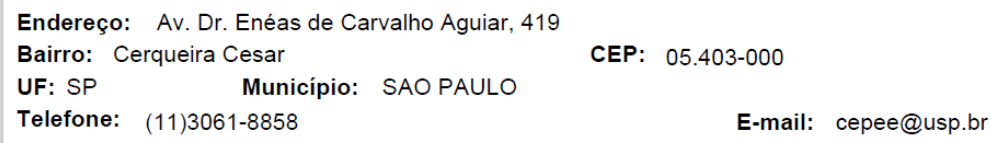




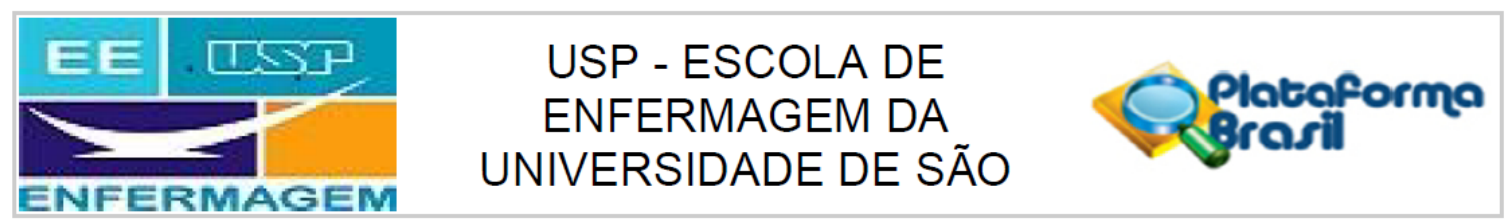

Continuação do Parecer: 2.340.033

Avaliação dos Riscos e Benefícios:

Será informado no TCLE que a participação na pesquisa envolve riscos, como passar por constrangimento ao responder às perguntas da entrevista e que esta será suspensa caso haja algum impedimento por parte do pesquisador ou se os participantes se recusarem a continuar a ceder o depoimento. Serão informados também que, a qualquer momento, poderão pedir informações sobre o andamento da pesquisa, bem como interromper a sua participação no estudo, sem que isso lhes acarrete qualquer prejuízo.

\section{Comentários e Considerações sobre a Pesquisa:}

Projeto apresenta consistência teórica, metodológica e coerência entre partes.

\section{Considerações sobre os Termos de apresentação obrigatória:}

O TCLE encontra-se elaborado com linguagem acessível, claro e objetivo. Atende os aspectos éticos em pesquisa preconizados pela Resolução 466/2012.

\section{Recomendações:}

----não há.

\section{Conclusões ou Pendências e Lista de Inadequações:}

Não há pendências.

\section{Considerações Finais a critério do CEP:}

- Este CEP informa a necessidade de registro dos resultados parciais e finais na Plataforma Brasil;

- Esta aprovação não substitui a autorização da instituição coparticipante, antes do início da coleta de dados.

Este parecer foi elaborado baseado nos documentos abaixo relacionados:

\begin{tabular}{|l|l|c|l|c|}
\hline \multicolumn{1}{|c|}{ Tipo Documento } & \multicolumn{1}{|c|}{ Arquivo } & Postagem & Autor & Situação \\
\hline Informações Básicas & PB_INFORMAÇÕES_BASICAS_DO_P & $01 / 10 / 2017$ & & Aceito \\
do Projeto & ROJETO 991914.pdf & $12: 05: 41$ & & Aceito \\
\hline Projeto Detalhado / & Projeto_Plataforma_brochura_pesquisad & $01 / 10 / 2017$ & Vanessa Augusta & \\
Brochura & or.docx & $12: 05: 13$ & Souza Braga & \\
Investiqador & & & & \\
\hline
\end{tabular}

Endereço: Av. Dr. Enéas de Carvalho Aguiar, 419

$\begin{array}{llll}\text { Bairro: } & \text { Cerqueira Cesar } & \text { CEP: } & 05.403-000 \\ \text { UF: SP } & \text { Município: SAO PAULO } & \end{array}$

Telefone: (11)3061-8858 E-mail: cepee@usp.br 


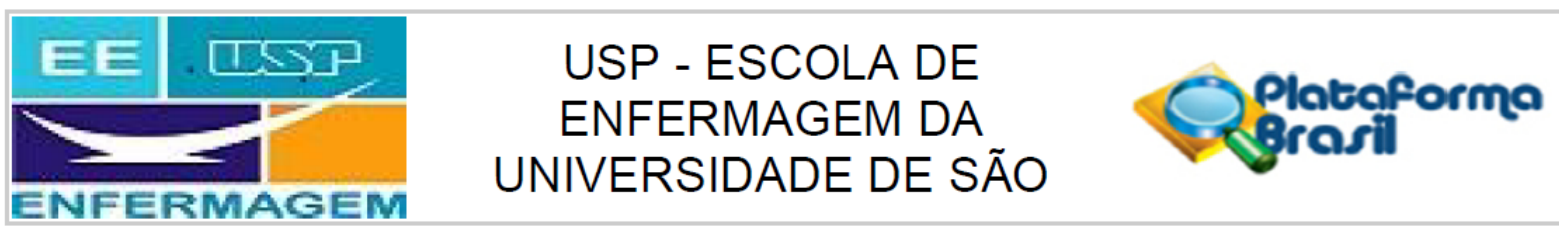

Continuação do Parecer: 2.340.033

\begin{tabular}{|c|c|c|c|c|}
\hline $\begin{array}{l}\text { TCLE / Termos de } \\
\text { Assentimento / } \\
\text { Justificativa de } \\
\text { Ausência }\end{array}$ & TCLE.pdf & $\begin{array}{c}\text { 26/09/2017 } \\
00: 07: 03\end{array}$ & $\begin{array}{l}\text { Vanessa Augusta } \\
\text { Souza Braga }\end{array}$ & Aceito \\
\hline $\begin{array}{l}\text { Declaração de } \\
\text { Instituição e } \\
\text { Infraestrutura }\end{array}$ & Declaracao_Infraestrutura.pdf & $\begin{array}{c}25 / 09 / 2017 \\
23: 59: 59\end{array}$ & $\begin{array}{l}\text { Vanessa Augusta } \\
\text { Souza Braga }\end{array}$ & Aceito \\
\hline Outros & Instrumento_Coleta_Dados.pdf & $\begin{array}{c}18 / 09 / 2017 \\
17: 33: 50 \\
\end{array}$ & $\begin{array}{l}\text { Vanessa Augusta } \\
\text { Souza Braga } \\
\end{array}$ & Aceito \\
\hline Orçamento & Orcamento.pdf & $\begin{array}{c}18 / 09 / 2017 \\
17: 31: 28 \\
\end{array}$ & $\begin{array}{l}\text { Vanessa Augusta } \\
\text { Souza Braga }\end{array}$ & Aceito \\
\hline Cronograma & Cronograma.pdf & $\begin{array}{c}18 / 09 / 2017 \\
17: 31: 07 \\
\end{array}$ & $\begin{array}{l}\text { Vanessa Augusta } \\
\text { Souza Braga }\end{array}$ & Aceito \\
\hline Folha de Rosto & Folha_de_Rosto_assinada.pdf & $\begin{array}{c}18 / 09 / 2017 \\
17: 18: 26\end{array}$ & $\begin{array}{l}\text { Vanessa Augusta } \\
\text { Souza Braga }\end{array}$ & Aceito \\
\hline
\end{tabular}

Situação do Parecer:

Aprovado

Necessita Apreciação da CONEP:

Não

SAO PAULO, 20 de Outubro de 2017

Assinado por:

Marcelo José dos Santos

(Coordenador)

Endereço: Av. Dr. Enéas de Carvalho Aguiar, 419

Bairro: Cerqueira Cesar

UF: SP Município: SAO PAULO

CEP: $05.403-000$

Telefone: (11)3061-8858

E-mail: cepee@usp.br 